\title{
Intercomparison of $\mathrm{NO}_{3}$ radical detection instruments in the atmosphere simulation chamber SAPHIR
}

\author{
H.-P. Dorn ${ }^{1}$, R. L. Apodaca ${ }^{2}$, S. M. Ball ${ }^{3}$, T. Brauers ${ }^{1}$, S. S. Brown ${ }^{4}$, J. N. Crowley ${ }^{5}$, W. P. Dubé ${ }^{4}$, H. Fuchs ${ }^{4,1}$, \\ R. Häseler ${ }^{1}$, U. Heitmann ${ }^{6}$, R. L. Jones ${ }^{7}$, A. Kiendler-Scharr ${ }^{1}$, I. Labazan ${ }^{5}$, J. M. Langridge ${ }^{7}{ }^{*}$, J. Meinen ${ }^{8}$, \\ T. F. Mentel ${ }^{1}$, U. Platt ${ }^{9}$, D. Pöhler ${ }^{9}$, F. Rohrer ${ }^{1}$, A. A. Ruth $^{6}$, E. Schlosser ${ }^{1, * *}$, G. Schuster ${ }^{5}$, A. J. L. Shillings ${ }^{7}$, \\ W. R. Simpson ${ }^{2}$, J. Thieser ${ }^{9, * *}$, R. Tillmann ${ }^{1}$, R. Varma $^{6, * * * *}$, D. S. Venables ${ }^{10}$, and A. Wahner ${ }^{1}$ \\ ${ }^{1}$ Institute of Energy and Climate Research, IEK-8: Troposphere, Forschungszentrum Jülich, Julich, Germany \\ ${ }^{2}$ Department of Chemistry and Biochemistry and Geophysical Institute, University of Alaska, Fairbanks, AK, USA \\ ${ }^{3}$ Department of Chemistry, University of Leicester, Leicester, UK \\ ${ }^{4}$ Earth System Research Laboratory, National Oceanic and Atmospheric Administration, Boulder, CO, USA \\ ${ }^{5}$ Max Planck Institute for Chemistry, Mainz, Germany \\ ${ }^{6}$ Physics Department \& Environmental Research Institute, University College Cork, Cork, Ireland \\ ${ }^{7}$ Department of Chemistry, University of Cambridge, Cambridge, UK \\ ${ }^{8}$ Institute for Meteorology and Climate Research - Atmospheric Aerosol Research, Karlsruhe Institute of Technology, \\ Karlsruhe, Germany \\ ${ }^{9}$ Institute of Environmental Physics, University of Heidelberg, Heidelberg, Germany \\ ${ }^{10}$ Chemistry Department and Environmental Research Institute, University College Cork, Cork, Ireland \\ *now at: Earth System Research Laboratory, NOAA, Boulder, CO, USA \\ ** now at: Institute for Meteorology and Climate Research, IMK-AAF, Karlsruhe Institute of Technology, Karlsruhe, Germany \\ **** now at: Max Planck Institute for Chemistry, Mainz, Germany \\ ${ }^{* * * * *}$ now at: Physics Department, National Institute of Technology Calicut, Calicut, India
}

Correspondence to: H.-P. Dorn (h.p.dorn@fz-juelich.de)

Received: 5 December 2012 - Published in Atmos. Meas. Tech. Discuss.: 9 January 2013

Revised: 3 April 2013 - Accepted: 6 April 2013 - Published: 2 May 2013

\begin{abstract}
The detection of atmospheric $\mathrm{NO}_{3}$ radicals is still challenging owing to its low mixing ratios $(\approx 1$ to $300 \mathrm{pptv})$ in the troposphere. While long-path differential optical absorption spectroscopy (DOAS) has been a well-established $\mathrm{NO}_{3}$ detection approach for over $25 \mathrm{yr}$, newly sensitive techniques have been developed in the past decade. This publication outlines the results of the first comprehensive intercomparison of seven instruments developed for the spectroscopic detection of tropospheric $\mathrm{NO}_{3}$. Four instruments were based on cavity ring-down spectroscopy (CRDS), two utilised open-path cavity-enhanced absorption spectroscopy (CEAS), and one applied "classical" long-path DOAS. The intercomparison campaign "NO3Comp" was held at the atmosphere simulation chamber SAPHIR in Jülich (Germany) in June 2007. Twelve experiments were performed in the well-mixed chamber for variable concentrations of $\mathrm{NO}_{3}$,
\end{abstract}

$\mathrm{N}_{2} \mathrm{O}_{5}, \mathrm{NO}_{2}$, hydrocarbons, and water vapour, in the absence and in the presence of inorganic or organic aerosol. The overall precision of the cavity instruments varied between 0.5 and 5 pptv for integration times of $1 \mathrm{~s}$ to $5 \mathrm{~min}$; that of the DOAS instrument was 9 pptv for an acquisition time of $1 \mathrm{~min}$. The $\mathrm{NO}_{3}$ data of all instruments correlated excellently with the NOAA-CRDS instrument, which was selected as the common reference because of its superb sensitivity, high time resolution, and most comprehensive data coverage. The median of the coefficient of determination $\left(r^{2}\right)$ over all experiments of the campaign (60 correlations) is $r^{2}=0.981$ (quartile 1 (Q1): 0.949; quartile 3 (Q3): 0.994; $\mathrm{min} / \max$ : 0.540/0.999). The linear regression analysis of the campaign data set yielded very small intercepts (median: 1.1 pptv; Q1/Q3: -1.1/2.6 pptv; min/max: -14.1/28.0 pptv), and the slopes of the regression lines were close to unity 
(median: 1.01; Q1/Q3: 0.92/1.10; $\min / \max$ : 0.72/1.36). The deviation of individual regression slopes from unity was always within the combined accuracies of each instrument pair. The very good correspondence between the $\mathrm{NO}_{3}$ measurements by all instruments for aerosol-free experiments indicates that the losses of $\mathrm{NO}_{3}$ in the inlet of the instruments were determined reliably by the participants for the corresponding conditions. In the presence of inorganic or organic aerosol, however, differences in the measured $\mathrm{NO}_{3}$ mixing ratios were detectable among the instruments. In individual experiments the discrepancies increased with time, pointing to additional $\mathrm{NO}_{3}$ radical losses by aerosol deposited onto the filters or on the inlet walls of the instruments. Instruments using DOAS analyses showed no significant effect of aerosol on the detection of $\mathrm{NO}_{3}$. No hint of a cross interference of $\mathrm{NO}_{2}$ was found. The effect of non-Lambert-Beer behaviour of water vapour absorption lines on the accuracy of the $\mathrm{NO}_{3}$ detection by broadband techniques was small and well controlled. The NO3Comp campaign demonstrated the high quality, reliability and robustness of performance of current state-of-the-art instrumentation for $\mathrm{NO}_{3}$ detection.

\section{Introduction}

Radical chemistry in the polluted nighttime troposphere is governed by the abundance of $\mathrm{NO}_{3}$ radicals. They are very reactive and effectively oxidise alkenes, aldehydes, and biogenic volatile organic compounds (VOCs). Although their role as atmospheric oxidant during the day is negligible due to their fast photolytic decomposition, their importance in atmospheric nighttime chemistry is comparable to that of $\mathrm{OH}$ radicals during daytime. Fundamental reviews on the physics and chemistry of $\mathrm{NO}_{3}$ radicals were published by Wayne et al. (1991) and recently by Brown and Stutz (2012).

The key reactions controlling the nighttime formation and destruction of oxidised nitrogen are summarised in the following. In the troposphere $\mathrm{NO}_{3}$ radicals are formed through the reaction of nitrogen dioxide with ozone:

$\mathrm{NO}_{2}+\mathrm{O}_{3} \rightarrow \mathrm{NO}_{3}+\mathrm{O}_{2}$.

During daytime $\mathrm{NO}_{3}$ radicals do not build up to relevant levels ( $<1$ pptv) because they efficiently absorb light in the visible region of the solar spectrum, leading to photolysis into a radical channel,

$\mathrm{NO}_{3}+h v \rightarrow \mathrm{NO}_{2}+\mathrm{O}$,

and a molecular channel,

$\mathrm{NO}_{3}+h v \rightarrow \mathrm{NO}+\mathrm{O}_{2}$.

Based on these photolysis reactions the lifetime of $\mathrm{NO}_{3}$ under typical daylight conditions is approximately $5 \mathrm{~s}$. In addition $\mathrm{NO}_{3}$ radicals react very rapidly with NO:

$\mathrm{NO}_{3}+\mathrm{NO} \rightarrow \mathrm{NO}_{2}+\mathrm{NO}_{2}$.
This reaction is important during the day, when its rate often exceeds that of photolysis, and in cases of fresh emissions of NO. At night the NO reaction often limits the lifetime of $\mathrm{NO}_{3}$ when no excess $\mathrm{O}_{3}$ is present to convert $\mathrm{NO}$ into $\mathrm{NO}_{2}$.

$\mathrm{NO}_{3}$ itself reacts with $\mathrm{NO}_{2}$ to form $\mathrm{N}_{2} \mathrm{O}_{5}$ (the anhydride of nitric acid, $\mathrm{HNO}_{3}$ ):

$\mathrm{NO}_{3}+\mathrm{NO}_{2}+\mathrm{M} \rightleftharpoons \mathrm{N}_{2} \mathrm{O}_{5}+\mathrm{M}$.

$\mathrm{N}_{2} \mathrm{O}_{5}$ is thermally unstable and can decompose into its precursors, thereby establishing an equilibrium between $\mathrm{NO}_{3}$ and $\mathrm{N}_{2} \mathrm{O}_{5}$. The back-reaction of (R5) is strongly temperature dependent, with $\mathrm{N}_{2} \mathrm{O}_{5}$ being dominant at low temperatures. Recently Osthoff et al. (2007) remeasured the equilibrium constant of Reaction (R5) to $K_{\text {eq }}(T)=(5.1 \pm 0.8) \times$ $10^{-27} \exp ((10871 \pm 46) / T) \mathrm{cm}^{3}$ molecule ${ }^{-1} \cdot \mathrm{N}_{2} \mathrm{O}_{5}$ can efficiently be hydrolysed to $\mathrm{HNO}_{3}$ on the surface of aerosol particles:

$\mathrm{N}_{2} \mathrm{O}_{5}+\mathrm{H}_{2} \mathrm{O}$ (het) $\rightarrow 2 \mathrm{HNO}_{3}$.

The wet and dry deposition of the $\mathrm{HNO}_{3}$ formed by hydrolysis of $\mathrm{N}_{2} \mathrm{O}_{5}$ is one of the most important loss reactions of oxidised nitrogen compounds in the atmosphere (Brown et al., 2006).

Owing to the high reactivity, the mixing ratio of $\mathrm{NO}_{3}$ radicals in the troposphere is typically in the lower pptv range, and their spatial and temporal variability can be high. This places high demands on the selectivity, sensitivity, and time resolution of measurement techniques used for $\mathrm{NO}_{3}$ detection. High-quality, accurate, and precise in situ measurements of $\mathrm{NO}_{3}$ and $\mathrm{N}_{2} \mathrm{O}_{5}$ are a prerequisite to understand the chemical processes controlling the chemistry of nocturnal nitrogen oxides and the significance of these species for the oxidising capacity of the nighttime troposphere. In the late 1970s the detection of $\mathrm{NO}_{3}$ radicals in the troposphere was pioneered by Platt and Perner (Platt and Perner, 1980; Platt et al., 1980). They used long-path differential optical absorption spectroscopy (DOAS), which has evolved into a standard technique for the detection of atmospheric $\mathrm{NO}_{3}$. DOAS has been widely used in different configurations in field experiments (e.g. Platt et al., 1981; Allan et al., 2000; Geyer et al., 2001, 2003; Stutz et al., 2004; McLaren et al., 2004; Sommariva et al., 2007; Vrekoussis et al., 2004, 2007) and chamber studies (e.g. Wängberg et al., 1997; Bossmeyer et al., 2006).

In the 1980s the matrix isolation electron spin resonance (MI-ESR) technique was developed, enabling absolute, calibration-free detection of $\mathrm{NO}_{3}$ radicals (Mihelcic et al., 1993). In a field intercomparison on $\mathrm{NO}_{3}$ detection between DOAS and MI-ESR (Geyer et al., 1999), the latter worked very successfully. It, however, suffered from its inferior time resolution (sampling time $\geq 30 \mathrm{~min}$ ) and substantial handling difficulties which only allowed a limited number of samples to be taken per day.

In the past $15 \mathrm{yr}$ new spectroscopic instruments for sensitive tropospheric $\mathrm{NO}_{3}$ detection have been developed. Their 
detection principle either makes use of the specific fluorescence properties of the $\mathrm{NO}_{3}$ molecule, as applied in laserinduced fluorescence (LIF) spectroscopy (Matsumoto et al., 2005; Wood et al., 2003), or takes advantage of its wellresolved strong visible absorption band arising from the $\tilde{B}^{2} E^{\prime} \leftarrow \tilde{X}^{2} A_{2}^{\prime}$ electronic transition on which the new cavity-enhanced absorption techniques are based (cf. Ball and Jones, 2003; Brown, 2003, and references therein). Since the first laboratory detection of $\mathrm{NO}_{3}$ radicals by cavity ringdown spectroscopy (CRDS) by King et al. (2000), many cavity-based approaches have been developed (see, for instance, Ayers et al., 2005; Bitter et al., 2005; Brown et al., 2001, 2002a,b; Dubé et al., 2006; Fiedler et al., 2003, 2007; Simpson, 2003; Venables et al., 2006). Some of these instruments are also capable of measuring $\mathrm{N}_{2} \mathrm{O}_{5}$ concentrations indirectly by quantitative thermal conversion into $\mathrm{NO}_{3}$ in a heated detection cell, and the $\mathrm{N}_{2} \mathrm{O}_{5}$ concentration is obtained after subtraction of the (generally much smaller) $\mathrm{NO}_{3}$ concentration. In this way, simultaneous measurements of $\mathrm{NO}_{3}$ and its equilibrium partner $\mathrm{N}_{2} \mathrm{O}_{5}$ in the troposphere became feasible for the first time (Chang et al., 2011).

This publication presents the results of an intercomparison of instruments for the detection of tropospheric $\mathrm{NO}_{3}$ radicals that are all based on various absorption spectroscopic principles. The large atmosphere simulation chamber SAPHIR on the campus of Forschungszentrum Jülich was chosen for the "NO3Comp" campaign where the instruments were able to be operated concurrently under controlled atmosphere-like conditions. Chamber experiments are more appropriate for intercomparison exercises than field trials in the open atmosphere because natural spatial and temporal fluctuations of the air mass introduce additional variability and hence uncertainty to the measurement conditions, which in turn causes the comparison data to be less reliable. The chamber, however, allows for controlled production of $\mathrm{NO}_{3}$ and $\mathrm{N}_{2} \mathrm{O}_{5}$ from Reactions (R1) and (R5), and provides the opportunity for multiple instruments to sample from the same well-mixed volume of gas.

Each of the participating instruments adhered to different calibration schemes of the radical transmission efficiency through filters and inlets and of the effective absorption path length in the cavity and was likely to exhibit different sensitivity to potential artefacts such as reactive trace gases or aerosol. Hence the instruments were exposed to various representative atmospheric scenarios during twelve measurement days in June 2007. This activity was the first comprehensive multi-instrument intercomparison of $\mathrm{NO}_{3}$ detection instruments. Five instruments participating in NO3Comp were also capable of detecting $\mathrm{N}_{2} \mathrm{O}_{5}$, and four instruments detected $\mathrm{NO}_{2}$ concurrently with $\mathrm{NO}_{3}$. The results of the $\mathrm{NO}_{2}$ and $\mathrm{N}_{2} \mathrm{O}_{5}$ measurements are reported in separate articles (Fuchs et al., 2010a, 2012). The ability of three broadband instruments to quantify the extinction coefficient of aerosols during the campaign is described by Varma et al. (2013). All experiments during NO3Comp were conducted as an open instrument intercomparison where discussions between the participants were generally allowed.

\section{Instrumental}

\subsection{Absorption cross section of $\mathrm{NO}_{3}$}

In the following sections the experimental setups of the seven $\mathrm{NO}_{3}$ detection instruments, as they were used at the SAPHIR chamber, are described in detail. A summary of their main properties is presented in the supplement to this publication.

Since all instruments made use of absorption spectroscopy the participants of NO3Comp agreed before the campaign to apply the absorption cross section published by Yokelson et al. (1994) for the retrieval of the $\mathrm{NO}_{3}$ mixing ratio. Yokelson et al. measured the temperature dependence of the $\mathrm{NO}_{3}$ absorption cross section between 440 and $720 \mathrm{~nm}$ within the temperature range $200-298 \mathrm{~K}$ in laboratory experiments. The $\mathrm{NO}_{3}$ peak absorption cross section at $662 \mathrm{~nm}$ was reported to be $(2.23 \pm 0.22) \times 10^{-17} \mathrm{~cm}^{2}$ at $298 \mathrm{~K}(2 \sigma$ error limits $)$. With decreasing temperature this value was found to increase by $36 \%$ at $200 \mathrm{~K}$. Orphal et al. (2003) re-measured the visible $\mathrm{NO}_{3}$ spectrum using high-resolution Fourier transform spectroscopy $(\Delta \lambda=0.026 \mathrm{~nm})$ and derived a parametrisation of the temperature dependence $(200-330 \mathrm{~K})$ of the peak cross section, which has been accepted into the current NASA/JPL recommendations (Sander et al., 2011). Excellent agreement exists between the Orphal model and the empirical relationships from Yokelson et al. (1994) and Osthoff et al. (2007). All groups participating in NO3Comp used this parameterisation to calculate the respective $\mathrm{NO}_{3}$ cross section valid for the specific temperature of their $\mathrm{NO}_{3}$ detection channel.

\subsubsection{Pulsed cavity ring-down spectrometer, NOAA-CRDS}

The most mature cavity-enhanced instrument employed in this campaign was the NOAA (Boulder, $\mathrm{CO}$, USA) pulsed cavity ring-down spectrometer measuring $\mathrm{NO}_{2}, \mathrm{NO}_{3}$, and $\mathrm{N}_{2} \mathrm{O}_{5}$ simultaneously in separate channels. At the time of the intercomparison, this instrument and its predecessors (Brown et al., 2001, 2002a,b) had already been deployed in a number of atmospheric field measurement campaigns on the ground (Brown et al., 2003, 2007), aboard an aircraft (Brown et al., 2005) and aboard ships (Brown et al., 2004, 2005; Aldener et al., 2006).

The setup and performance of this instrument has been described in detail in the publication by Dubé et al. (2006). Inlet transmission and conversion efficiencies have been thoroughly studied by Fuchs et al. (2008). The NOAA-CRDS instrument consisted of 4 optical cavities used for the detection of $\mathrm{NO}_{3}$ and $\mathrm{N}_{2} \mathrm{O}_{5}$ at $662 \mathrm{~nm}$, and two cavities (at $532 \mathrm{~nm}$ ) were taken for calibration purposes and measurement of $\mathrm{NO}_{2}$ (Fuchs et al., 2010a). The temperature in the $\mathrm{NO}_{3}$ detection channel was actively controlled to match the outside 
temperature. A pulsed Nd:YAG-pumped dye laser (repetition rate $50 \mathrm{~Hz})$ provided light at $662 \mathrm{~nm}(\mathrm{FWHM} \leq 1.5 \mathrm{pm})$ to detect $\mathrm{NO}_{3}$. In addition, about $5 \%$ of the light from the pump laser at $532 \mathrm{~nm}$ was used for the detection of $\mathrm{NO}_{2}$ (Fuchs et al., 2012). The $662 \mathrm{~nm}$ cavity mirrors were separated by $0.91 \mathrm{~m}$ and had a reflectivity of $99.999 \%$. The light transmitted through the end mirror of the cavities was detected by photomultiplier tubes. The mixing ratio of the $\mathrm{NO}_{3}$ radicals was calculated from the difference between the ring-down times with $(\tau)$ and without $\left(\tau_{0}\right) \mathrm{NO}_{3}$ in the cavity and the $\mathrm{NO}_{3}$ absorption cross section $\left(\sigma_{\mathrm{NO}_{3}}\right)$ :

$\left[\mathrm{NO}_{3}\right]=\frac{R_{\mathrm{L}}}{c \sigma_{\mathrm{NO}_{3}}}\left(\frac{1}{\tau}-\frac{1}{\tau_{0}}\right)$,

where $c$ is the speed of the light and $R_{\mathrm{L}}$ is the ratio of the physical cavity length to the length over which the absorber is present in the cavity. The latter was reduced because the volumes adjacent to the mirrors were purged with zero air in order to avoid contamination of the mirror surfaces. The value of $R_{\mathrm{L}}$ had been determined previously in laboratory experiments to be $1.15 \pm 0.03$ (Fuchs et al., 2008). The zero ring-down time $\left(\tau_{0}\right)$ of the $\mathrm{NO}_{3}$ cavity was measured every 3 to $5 \mathrm{~min}$ by adding $40 \mathrm{~mL}$ of a mixture of $100 \mathrm{ppmv} \mathrm{NO}$ in nitrogen to the cavity for $5 \mathrm{~s}$. This yielded an NO mixing ratio of $0.5 \mathrm{ppmv}$ in the sampled air, which was enough to quantitatively titrate $\mathrm{NO}_{3}$ via Reaction(R4) before the gas entered the detection cavity. This method of determining the baseline signal allows for the selective separation of the $\mathrm{NO}_{3}$ signal from the contributions of other atmospheric absorbers such as $\mathrm{NO}_{2}, \mathrm{O}_{3}$, and $\mathrm{H}_{2} \mathrm{O}$, and it is superior to, e.g., flushing the cavity with zero air because it leaves the $\mathrm{O}_{3}$ and water absorptions unchanged.

During NO3Comp air was sampled from the chamber at a flow rate of $8 \mathrm{slm}$ (standard litre per minute) through a Teflon FEP line (i.d. $4 \mathrm{~mm}$, total length about $0.4 \mathrm{~m}$ ) extending about $0.2 \mathrm{~m}$ into the chamber. In order to minimise wall losses in the system, the instrument operated at reduced pressure $(\sim 350 \mathrm{hPa})$. A Teflon filter $(25 \mu \mathrm{m}$ thickness, $47 \mathrm{~mm}$ diameter, $2 \mu \mathrm{m}$ pore size) was placed downstream of the inlet to remove aerosol particles which scatter light efficiently and would therefore constitute a large interference to a gas phase optical extinction measurement. Automated, regular filter changes $(0.5-3 \mathrm{~h})$ ensured constant $\mathrm{NO}_{3}$ loss on the filter, which was well characterised when clean (Dubé et al., 2006; Fuchs et al., 2008).

The dye laser (tuning uncertainty $\pm 0.02 \mathrm{~nm}$ ) was fine tuned to a point on the broad maximum of the $\mathrm{NO}_{3}$ absorption spectrum $(\approx 661.94 \mathrm{~nm})$ that is not resonant with any of the discrete water vapour absorption transitions in this region. The laser wavelength was not actively controlled but checked regularly by scanning across the water absorption lines around the $\mathrm{NO}_{3}$ absorption peak.

Ring-down times of all channels were determined every second from the sum of 50 ring-down transients. Mixing ratios were corrected for possible changes in the
$\mathrm{NO}_{2} / \mathrm{NO}_{3} / \mathrm{N}_{2} \mathrm{O}_{5}$ equilibrium (R5) due to temperature differences between the chamber and the ring-down detection cells. A model simulated the changes assuming a linear temperature profile between the measured SAPHIR temperature and the constant temperature in the cavity. The correction was typically $<0.5 \%$, with maximal differences during the campaign of ca. $5 \%$ at high $\mathrm{NO}_{2}$ mixing ratios. Extinction corrections (typically $<2 \%$ ) were made for varying Rayleigh scattering losses as well as for $\mathrm{NO}_{2}$ and $\mathrm{O}_{3}$ absorption (at $662 \mathrm{~nm}$ ).

The accuracy of cavity ring-down data was dominated by the uncertainty of the absorption cross section $( \pm 5 \%, 1 \sigma)$, the error of the effective cavity length $( \pm 3 \%)$, and the $\mathrm{NO}_{3}$ transmission efficiencies of the cavity and the inlet/filter assembly. Calibrations based on standard additions to the inlet were unreliable and were made infrequently during the campaign due to a contamination in the $\mathrm{N}_{2} \mathrm{O}_{5}$ source used to generate $\mathrm{NO}_{3}$. Therefore, laboratory measurements of the $\mathrm{NO}_{3}$ transmission reported by Fuchs et al. (2008) of $92 \pm 3 \%$ were used for evaluation of all data during the campaign. An additional $10 \%$ error was estimated in order to account for a possible systematic uncertainty of the $\mathrm{NO}_{3}$ transmission during the campaign. The overall accuracy for NO3Comp was therefore $+17 \% /-5 \%$. The precision was determined from repeated measurements of $\tau_{0}$ in zero air at $1 \mathrm{~s}$ data acquisition (Dubé et al., 2006). Under field measurement conditions values between $0.2 \mathrm{pptv}$ and $0.5 \mathrm{pptv}$ were obtained.

\subsubsection{Off-axis cavity ring-down spectrometer, UAF-CRDS}

A prototype diode-laser-pumped cavity ring-down instrument using off-axis excitation of the cavity (Paul et al., 2001; Kasyutich et al., 2002) was used by the group of the University of Alaska, Fairbanks (USA). The setup was mainly based on the same technical principles as described by Ayers et al. (2005). The emission intensity of a temperaturestabilised diode laser $(662 \mathrm{~nm})$ was square-wave modulated (100\% modulation depth) at a rate of $500 \mathrm{~Hz}$ and directed into an optical cavity consisting of two highly reflective mirrors $(>99.995 \%$ at $662 \mathrm{~nm})$ that were separated by $0.66 \mathrm{~m}$. A purge flow $(0.2 \mathrm{slm})$ of synthetic air protected the mirrors. Light transmitted through the second mirror was collected by an off-axis parabolic mirror and directed into a photomultiplier tube whose signal was digitised at a rate of $5 \mathrm{MS} \mathrm{s}^{-1}$ by a 12-bit ADC. Air was sampled from the chamber at $8 \mathrm{slm}$ through a Teflon inlet line (length $0.4 \mathrm{~m}$, i.d. $6.3 \mathrm{~mm}$ ). To remove particulate matter the sample gas flowed through a Teflon filter (Pall Teflo, $2 \mu \mathrm{m}$ pore size) which was changed daily at the beginning of each experiment. The residence time of the sample gas in the measurement cell was $2 \mathrm{~s}$. The cell consisted entirely of PFA teflon tubing (i.d. $16 \mathrm{~mm}$ ).

During NO3Comp it was noticed that the laser occasionally oscillated on two longitudinal modes, leading to multiexponential ring-down decay. These events were diagnosed 
and the corresponding data was excluded from the analysis. All data were corrected for the effective length of the cavity. The transmission efficiency of $\mathrm{NO}_{3}$ was determined for each filter several times a day from measurements at different sample flow rates (i.e. for different residence times). An initial transmission of $76 \%$ was found and a typical decay rate of $-0.4 \% \mathrm{~h}^{-1}$ was inferred from the plot of transmission versus filter use time. Both values were applied for all measurements during NO3Comp. Possible re-equilibration between $\mathrm{NO}_{3}$ and $\mathrm{N}_{2} \mathrm{O}_{5}$ due to different temperatures between the SAPHIR chamber air and gas sample inside the detection cell was analysed using a simple equilibrium model. At low $\mathrm{NO}_{2}$ mixing ratios $(<20 \mathrm{ppbv})$ the correction factor was small and reached maximal values around $13 \%$ per degree of temperature difference ( $\Delta T$ was always $<2 \mathrm{~K}$ ) at high $\mathrm{NO}_{2}$ mixing ratios. The zero ring-down time, $\tau_{0}$, was determined regularly by addition of nitric oxide to the sample air, resulting in an NO mixing ratio of $50 \mathrm{ppbv}$ in the measurement cell. The $\mathrm{NO}$ also reacts with $\mathrm{O}_{3}$-forming $\mathrm{NO}_{2}$. At $662 \mathrm{~nm}$ the $\mathrm{NO}_{2}$ absorption is 1.39 times stronger than that of $\mathrm{O}_{3}$, resulting in an offset of a few pptv $\mathrm{NO}_{3}$ equivalent at 100 ppbv $\mathrm{O}_{3}$. Moreover it was noted that the NO titrant cylinder used for the UAF instrument was contaminated with traces of $\mathrm{NO}_{2}$, so adding $\mathrm{NO}$ also resulted in addition of some $\mathrm{NO}_{2}(<1 \mathrm{pptv}$ $\mathrm{NO}_{3}$ equivalent). The $\mathrm{NO}_{3}$ mixing ratios were corrected for both interfering processes.

The instrument as operated during NO3Comp had a noiseequivalent $1 \sigma$ detection limit of $0.5 \mathrm{pptv}$ in $1 \mathrm{~s}$. The total accuracy of the UAF-CRDS instrument was $20 \%(1 \sigma)$ taking into account an uncertainty of $17 \%$ in the transmission efficiency of the inlet and measurement cell, $5 \%$ uncertainty in the peak cross section for $\mathrm{NO}_{3}$, and $10 \%$ uncertainty of the effective cavity length.

\subsubsection{Cavity ring-down spectrometer, MPI-CRDS}

During the intercomparison campaign the cavity ring-down instrument from the Max Planck Institute for Chemistry (Mainz, Germany) was employed for the first time outside the laboratory. The instrument could be operated either in cavity ring-down (CRDS) or in cavity-enhanced absorption mode (CEAS) (Schuster et al., 2009). Although the CEAS mode had lower noise levels $(\sim 0.2 \mathrm{pptv}$ in $1 \mathrm{~s})$, baseline drifts limited the accuracy of this device, and all data reported here were measured exclusively based on the CRDS principle. The emission of a pulsed laser diode close to $662 \mathrm{~nm}(100 \%$ square-wave power modulated at $200 \mathrm{~Hz}$ ) entered the cavity off-axis (mirror reflectivity $\approx 99.998 \%$ ). The light exiting the cavity was detected by a photomultiplier (PMT) through a $590 \mathrm{~nm}$ cut-off filter and a $662 \mathrm{~nm}$ interference filter. The photomultiplier signal was digitised with a $100 \mathrm{MHz}$, 9-bit oscilloscope and averaged resulting in a time resolution of $5 \mathrm{~s}$. The mirror distance was $0.7 \mathrm{~m}$; sheath flows of filtered zero air $(0.15 \mathrm{slm})$ protected the mirrors. The cavity enclo- sure was made from Pyrex glass (i.d. $15 \mathrm{~mm}$ ), coated with a film of Teflon (DuPont FEP 121a).

Typical ring-down times were measured to be $86-100 \mu$ s. $\tau_{0}$ was recorded by adding NO upstream of the Teflon filter, and complete titration of $\mathrm{NO}_{3}$ was established within $0.1 \mathrm{~s}$. Usually one minute of $\mathrm{NO}_{3}$ measurement was followed by one minute of background measurement. The effect of adding $\mathrm{NO}$ to air samples containing $\mathrm{O}_{3}$ on the total absorption at $662 \mathrm{~nm}$ was taken into account in the final analysis. Air was sampled from the SAPHIR chamber at a flow rate of $8 \mathrm{slm}$ through a $0.68 \mathrm{~m}$-long PFA tubing $(9.5 \mathrm{~mm}$ i.d.), protruding $0.39 \mathrm{~m}$ into the chamber. A $22 \mathrm{~mm}$-diameter Teflon membrane filter (pore size $2 \mu \mathrm{m}$ ) eliminated particles from the air stream. The average residence time within the optical cavity was $\approx 1 \mathrm{~s}$.

Random fluctuations in the ring-down times resulted in an $\mathrm{NO}_{3}$ precision ( $1 \sigma$ detection limit) of $3 \mathrm{pptv}$ for a $10 \mathrm{~s}$ acquisition time. The accuracy of the measurement was governed by systematic errors in the absorption cross section of $\mathrm{NO}_{3}$, errors in the inlet gas transmission, correction for filter loss, and effective absorption path length. The $\mathrm{NO}_{3}$ inlet losses were measured during four experiments at times of constant $\mathrm{NO}_{3}$ in the chamber by variation of the flow rate through the instrument. An averaged correction factor of $1.13 \pm 0.1$ was determined. Filter losses were measured later in the lab, resulting in a correction factor of $1.18 \pm 0.1$. Both factors were taken constant for the campaign and were applied to correct the measured mixing ratios. The overall $1 \sigma$ accuracy of the $\mathrm{NO}_{3}$ measurement by MPI-CRDS of $14 \%$ is given by the uncertainties of the determination of filter loss $(8.5 \%)$, inlet/cavity loss $(8.9 \%)$, cavity length (2.9\%), and absorption cross section $(5 \%)$.

\subsubsection{Broadband cavity ring-down spectrometer, ULEIC-BBCRDS}

The operating principles of the broadband cavity ring-down spectrometer of the University of Leicester (UK) have been discussed in Ball and Jones (2003, 2009), and an example of applying this instrument to measure ambient $\mathrm{NO}_{3}$ during the NAMBLEX field campaign has been described by Bitter et al. (2005). The instrument's dye laser and CCD camera detector were upgraded following the NAMBLEX campaign; further details of the new hardware deployed for the SAPHIR intercomparison are given by Shillings et al. (2011).

A free-running dye laser, pumped by a Q-switched $\mathrm{Nd}$ :YAG laser at $20 \mathrm{~Hz}$ repetition rate, was employed as the broadband light source. A mixture of DCM and LDS698 dyes dissolved in methanol/DMSO was used to obtain laser emission with an approximately Gaussian spectrum $(16 \mathrm{~nm}$ FWHM centred at $662 \mathrm{~nm}$ ). The ring-down cavity was mounted $0.3 \mathrm{~m}$ below the SAPHIR chamber, supported from the same optical table as the laser. The cavity mirrors (diameter $20 \mathrm{~mm}$, separation $1.83 \mathrm{~m}$, peak reflectivity $99.996 \%$ at $680 \mathrm{~nm}$ ) were held in adjustable bellows mounts attached to 
a thermally insulated Teflon tube (i.d. $19 \mathrm{~mm}$ ) that formed the main body of the cavity. To reduce contamination of the mirror surfaces, the mirrors were purged with $0.5 \mathrm{slm}$ of dry synthetic air. Hence the absorption measured over the full cavity length was multiplied by an experimentally determined length factor of $R_{\mathrm{L}}=1.05$ to correct for the gas sample being excluded from regions immediately in front of the mirrors. Air was drawn from the SAPHIR chamber through four parallel Teflon tubes (i.d. $3 \mathrm{~mm}$, length $0.4 \mathrm{~m}$, tubes protected from sunlight outside the chamber); the tubes projected $15 \mathrm{~cm}$ above the chamber's floor to sample gas uncompromised by wall effects. The sample flow rate of $10.1 \mathrm{slm}$ corresponded to a mean residence time of $2.7 \mathrm{~s}$ inside the cavity. Light exiting the ring-down cavity was collected by a lens and focused into a $200 \mu \mathrm{m}$-diameter optical fibre attached to an imaging Czerny-Turner type spectrograph $(f=250 \mathrm{~mm}$, $f / 4$ optics, spectral resolution $0.36 \mathrm{~nm}$ FWHM). Time resolved spectra of light exiting the cavity were measured using a clocked CCD camera with an image sector of 512 pixels along the frame transfer axis (i.e. time) and 512 pixels along the wavelength dispersed axis (spectral coverage 645$683 \mathrm{~nm}$, although in practice only the central $652-673 \mathrm{~nm}$ contributed usefully to the BBCRDS spectra recorded here). A slit mask bonded to the CCD chip resulted in the cavity output illuminating only 5 pixel rows on the frame transfer axis. Thus the CCD's clocking rate of $0.65 \mu$ s per pixel produced a minimum time resolution of $3.3 \mu$ s.

Owing to its broadband detection approach, BBCRDS is sensitive to all molecules that contribute structured features to the measured absorption spectrum (Ball and Jones, 2003, 2009). The absolute concentrations of the relevant absorbers, $n_{i},\left(\mathrm{NO}_{3}, \mathrm{NO}_{2}\right.$, and $\left.\mathrm{H}_{2} \mathrm{O}\right)$ were obtained by fitting the measured absorption spectrum, $\alpha(\lambda)$, with a linear combination of reference cross sections of the trace gases, $\alpha_{i}(\lambda)$, convoluted with the spectral response function of the BBCRDS instrument. The sample's absorption spectrum was calculated from wavelength-resolved ring-down times measured when the cavity contained the sample, $\tau(\lambda)$, and when the cavity was purged with dry synthetic air, $\tau_{0}(\lambda)$ :

$\alpha(\lambda)=\alpha_{\mathrm{bb}}(\lambda)+\sum_{i} \sigma_{i}(\lambda) \cdot n_{i}=\frac{R_{\mathrm{L}}}{c} \cdot\left[\frac{1}{\tau(\lambda)}-\frac{1}{\tau_{0}(\lambda)}\right]$.

Because air drawn from the chamber was not filtered for aerosol, the broadband absorption background due to aerosol scattering, $\alpha_{\mathrm{bb}}(\lambda)$, was accounted for by a polynomial function of second or third degree. Ozone has a weak, but detectable, broadly structured absorption at the wavelengths employed here; ozone was not included in the spectral fitting routine; instead its absorption was subtracted from the fitted $\alpha_{\mathrm{bb}}(\lambda)$ background using ozone concentrations measured by SAPHIR's core instruments.

Water vapour is the largest contributor to the differential structure in atmospheric spectra around $662 \mathrm{~nm}$, with line widths substantially narrower than the spectral resolution of the BBCRDS instrument, leading to non-Lambert-Beer absorption behaviour. Slight errors in fitting the water absorption features have been shown to mask the $\mathrm{NO}_{3}$ absorption features and lead to spurious $\mathrm{NO}_{3}$ retrievals. The approach to quantitatively evaluate the water vapour concentrations from the measured multi-exponential decay of the cavity output has been described by Ball and Jones (2003, 2009), Bitter et al. (2005), Langridge et al. (2008), and Shillings et al. (2011), and these methods were again applied to the present data set.

BBCRDS spectra were analysed assuming that the gas temperature inside the thermally insulated cavity was the same as inside SAPHIR. Consequently no corrections were made to the submitted data for $\mathrm{NO}_{3} / \mathrm{N}_{2} \mathrm{O}_{5}$ re-equilibration (R5). In fact, temperature measurements taken infrequently during the campaign showed the gas inside the cavity to be marginally cooler than inside SAPHIR. Box modelling performed post-campaign indicated that the mean $\mathrm{NO}_{3}$ mixing ratio inside the cavity was $95.8 \%$ of that in the SAPHIR chamber itself, assuming a representative $1.5 \mathrm{~K}$ temperature drop on entering the cavity and a $2.7 \mathrm{~s}$ residence time. Thus the BBCRDS data are subject to a small, systematic undermeasurement of the $\mathrm{NO}_{3}$ mixing ratio by typically around $4 \%$ due to $\mathrm{NO}_{3}$ re-partitioning to $\mathrm{N}_{2} \mathrm{O}_{5}$. The model showed the worst under-measurement to be $9 \%$ when gas inside SAPHIR was at its warmest.

A small amount of ambient air ( $<6 \%$ of the total flow) was found to be leaking into the BBCRDS cavity during the campaign. The leak rate into the cavity was quantified for each experiment by comparing the measured water vapour mixing ratio in the cavity with data from a dew point hygrometer in the SAPHIR chamber. $\mathrm{NO}_{3}$ mixing ratios reported were corrected for the dilution caused by this leak, and an overall uncertainty of $5 \%$ for this effect was estimated. The leak was assumed not to contribute any additional chemical loss of $\mathrm{NO}_{3}$. The $\mathrm{NO}_{3}$ loss rate on the walls and inlet of the instrument was measured during the campaign by varying the flow rate (i.e. residence time) of the sample through the BBCRDS system. For the standard flow conditions $(10.1 \mathrm{slm})$, the loss rate was $k_{\mathrm{w}}=0.045 \mathrm{~s}^{-1}$ corresponding to $\mathrm{NO}_{3}$ transmission efficiency of 0.75 , and this value was applied to correct the whole BBCRDS $\mathrm{NO}_{3}$ data set. Whilst the uncertainty on this one measurement of $k_{\mathrm{w}}$ was relatively small $( \pm 3 \%)$, it is likely that the $\mathrm{NO}_{3}$ transmission losses varied somewhat throughout the campaign. In line with other instruments, conservatively, a $\pm 10 \%$ error was assigned on the 0.75 efficiency used to correct for the instrument's inlet/wall losses.

The overall accuracy of the BBCRDS $\mathrm{NO}_{3}$ measurements is $+15 \% /-12 \%$, inferred from adding the individual sources of measurement error (length factor $\pm 5 \% ; \mathrm{NO}_{3} / \mathrm{N}_{2} \mathrm{O}_{5}$ reequilibration 0 to $-9 \%$; air leak $\pm 5 \%$; $\mathrm{NO}_{3}$ wall loss $\pm 10 \%)$. The BBCRDS accuracy becomes $+16 \% /-13 \%$, including the $5 \%$ uncertainty in the $\mathrm{NO}_{3}$ absorption cross section. The precision of the retrieval of the $\mathrm{NO}_{3}$ mixing ratio 
(and other absorbers) was determined from the error of a linear fit to the absorber's absorption coefficients as a function of the corresponding absorption cross section. This method has been shown to produce robust estimates of the measurement precision and detection limits in other broadband cavity systems, e.g. Langridge et al. (2008). The precision for the present $\mathrm{NO}_{3}$ data set was typically 2 pptv $(1 \sigma)$ for the $61 \mathrm{~s}$ averaging time.

\subsubsection{Incoherent-broadband cavity-enhanced absorption spectrometer, UCC-IBBCEAS}

The IBB-CEAS instrument of University College Cork (Cork, Ireland) is a broadband multi-component absorption technique using an optical cavity to measure the total extinction of an air sample (Fiedler et al., 2003). Instead of observing the temporal decay of the light intensity inside the cavity as in CRDS, the steady state intensity, $I$, of light leaking out of the cavity is measured and spectrally resolved. Setup and characteristics of the UCC-IBBCEAS instrument used during the campaign and details of the data evaluation procedure have been published by Varma et al. (2009). The underlying theory of cavity-enhanced absorption spectroscopy has been described in Fiedler et al. (2003, 2005, 2007); Venables et al. (2006); Gherman et al. (2008); and Triki et al. (2008).

The instrument consisted of a transmitter unit and a receiver unit, each housing one of the cavity mirrors (radius of curvature $21 \mathrm{~m}$, diameter $4 \mathrm{~cm}$, nominal reflectivity $99.87 \%$ at $660 \mathrm{~nm}$ ). The units were installed at the north and south ends of the SAPHIR chamber, resulting in a geometrical mirror distance of the open-path CEAS cavity of $20.13 \pm 0.05 \mathrm{~m}$. Considering the length of the cavity the setup was very stable. The cavity mirrors needed only marginal realignment during the campaign. The transmitter unit housed a $300 \mathrm{~W}$ "hot-spot" Xe lamp. The light was imaged onto an iris using two off-axis parabolic mirrors. Between the mirrors the wavelength range was selected with a dielectric band-pass filter $(610-720 \mathrm{~nm})$. Because the light spot tended to wander on the cathode, a fraction of the light was focused onto a quadrant detector which triggered a feedback loop to correct for changes in spot position. A telescope imaged the iris aperture approximately into the centre of the open-path cavity. Light transmitted by the cavity was further filtered in the receiver unit with a long-pass cut-off filter $(630 \mathrm{~nm}$, Schott RG630) and a $700 \mathrm{~nm}$ short-pass interference filter to ensure that light outside the mirror reflectivity range was eliminated. The light was focused into a fibre bundle ( $1 \mathrm{~mm}$ diameter) and connected to the $100 \mu \mathrm{m}$ entrance slit of a spectrometer $(f=0.33 \mathrm{~m}$, spectral resolution $0.6 \mathrm{~nm})$. A spectral interval from 620 to $720 \mathrm{~nm}$ was detected by a CCD detector, and an acquisition time of $5 \mathrm{~s}$ was used for all $\mathrm{NO}_{3}$ measurements.

The transmitter and receiver units were each equipped with a $1 \mathrm{~m}$ stainless steel pipe (diameter $57 \mathrm{~mm}$ ) pointing from the cavity mirrors along the optical axis of the cavity. A seal was made between the pipes and the adjustable mirror mounts of the cavity mirrors using flexible Teflon foil in each unit. The pipes served three purposes: firstly, they allowed the mirrors to be purged with pure nitrogen with a flow rate of $10 \mathrm{slm}$ which caused the effective cavity length to be $L_{\text {eff }}=18.27 \pm 0.20 \mathrm{~m}$. Secondly, on the receiver side of the setup the pipe reduced stray light entering the detection system. Thirdly, the pipes were necessary to install the instrument to the outside of the SAPHIR chamber and to make a seal with its teflon wall.

The total extinction, $\alpha(\lambda)$, of the air sample is calculated by

$\alpha(\lambda)=\frac{1-R(\lambda)}{L_{\mathrm{eff}}}\left(\frac{I_{0}(\lambda)}{I(\lambda)}-1\right)$,

where $I_{0}(\lambda)$ and $I(\lambda)$ are the intensities transmitted by the cavity in zero air and with a sample gas, respectively, $R(\lambda)$ is the average mirror reflectivity, and $L_{\text {eff }}$ is the effective cavity length (Fiedler et al., 2003). The UCC-IBBCEAS instrument used an open cavity; hence, the background intensity, $I_{0}(\lambda)$, in zero air could only be determined once a day in the morning after the chamber was flushed over night and before trace gases were introduced into the chamber.

To provide absolute absorption measurements using the IBB-CEAS principle, the reflectivity of the cavity mirrors, $R(\lambda)$, has to be known across the bandwidth of the measurement. During NO3Comp, $R(\lambda)$ was measured daily by moving an antireflection-coated window of well-known loss into the cavity in zero air (Varma et al., 2009). The total loss (reflection plus transmission) of the window was determined in the lab with a pulsed cavity ring-down instrument as a function of wavelength, ranging from $0.55 \%$ around $630 \mathrm{~nm}$ to $0.3 \%$ at $690 \mathrm{~nm}$. An average reflectivity function, $R_{\mathrm{avg}}(\lambda)$, peaking at $R_{\text {avg }}(620 \mathrm{~nm})=0.9987 \pm 1.5 \times 10^{-4}$ was calculated from all individual measurements during NO3Comp and applied for the retrieval of the $\mathrm{NO}_{3}$ mixing ratios.

A singular value decomposition algorithm was used for the retrieval of the absorber mixing ratios from a linear combination of the reference spectra (convoluted for $0.6 \mathrm{~nm}$ spectral resolution), and a second-order polynomial represented broadband spectral structures, $\alpha_{\mathrm{bb}}(\lambda)=n_{0}+n_{1} \lambda+n_{2} \lambda^{2}$, resulting mainly from aerosol extinction:

$$
\begin{aligned}
\alpha(\lambda) & =\alpha_{\mathrm{bb}}(\lambda)+\sum_{i} \sigma_{i}(\lambda) \cdot \int_{0}^{L_{\text {eff }}} n_{i}(x) \mathrm{d} x \\
& =\frac{1}{L_{\text {eff }}}\left[\frac{I_{0}(\lambda)}{I(\lambda)}-1\right](1-R(\lambda)) .
\end{aligned}
$$

The fitting algorithm did not include $\mathrm{O}_{3}$ because its absorption spectrum in the region of interest $(655-670 \mathrm{~nm})$ is weak and free of spectral fine structures; hence the broadband $\mathrm{O}_{3}$ absorption was accounted for by the polynomial. To properly describe the complex absorption spectrum of water vapour, a concentration-corrected absorption cross section, $\sigma_{\mathrm{H}_{2} \mathrm{O}}^{\prime}(\lambda)$, 
was calculated for each water concentration that occurred in experiments as described by Varma et al. (2009).

The overall accuracy of UCC-IBBCEAS was estimated to be $\pm 16 \%$. This estimate took into account the standard deviation of the reflectivity measurements, the uncertainty of the $\mathrm{NO}_{3}$ cross section and the effective cavity length, the fluctuations of $I_{0}$ and a $10 \%$ uncertainty of various analysis approaches (choice of fit range and weighting). The measurement precision was given as percentage error of the $\mathrm{NO}_{3}$ mixing ratio determined from the $1 \sigma$ standard deviation of the fit residuals. The $1 \sigma$ detection limit is estimated to be 1 pptv for a $5 \mathrm{~s}$ averaging time.

\subsubsection{Cavity-enhanced DOAS, UHD-CEDOAS}

The University of Heidelberg (Germany) CEAS-based DOAS instrument used a short open-path setup and was installed inside the SAPHIR chamber mounted on a steel frame $60 \mathrm{~cm}$ above the floor in front of the fan. Except for the cavity mirrors all parts of the instrument were enclosed with Teflon foil to avoid surface reactions or out-gasing close to the optical absorption path. The optical setup and the specifics of the data evaluation of CEDOAS measurements are described in the publications by Meinen et al. (2010) and Platt et al. (2009), respectively.

The cavity consisted of two highly reflective mirrors ( $25.4 \mathrm{~mm}$ diameter and $1 \mathrm{~m}$ radius of curvature) with a nominal peak reflectivity of $99.9985 \%$ at $655 \mathrm{~nm}$. The separation of the mirrors was $0.62 \mathrm{~m}$, and the effective optical path length was reduced to $0.5 \pm 0.01 \mathrm{~m}$ by a purge flow of $5 \mathrm{slm}$ of synthetic air. An LED (peak wavelength $665 \mathrm{~nm}$, FWHM $23 \mathrm{~nm})$, housed in a temperature-stabilised box $(300 \pm 2 \mathrm{~K})$, was mounted to one of the mirrors, and the light was guided into the cavity by a $40 \mathrm{~mm}$ plano convex lens and a $610 \mathrm{~nm}$ long-pass filter (Schott RG610). Light leaking through the exit mirror was focused into a $400 \mu \mathrm{m}$ quartz fibre (NA $=0.22,5 \mathrm{~m}$ length). The fibre was attached alternatively to a photomultiplier tube (PMT) or to a temperaturestabilised mini-spectrograph $(273 \pm 0.1 \mathrm{~K}, f=42 \mathrm{~mm}$, spectral resolution $1.06 \mathrm{~nm}$ ), both placed outside the chamber, for time-resolved (CRD) or wavelength-dispersed measurements (CEAS), respectively. Typical signal averaging times were $300 \mathrm{~s}$.

Data evaluation was based on the classical DOAS approach (Platt and Stutz, 2008). In DOAS applications the length of the absorption light path is well known and constant. In combination with an optical cavity (CEDOAS), however, the effective path length that photons travel in the optical cavity, $X_{\text {eff }}$, can be highly variable because $X_{\text {eff }}$ depends not only on the wavelength-dependent reflectivity finesse of the cavity, $F=\pi \sqrt{R(\lambda)} /(1-R(\lambda)$ ) (Triki et al., 2008 ), but also on broadband losses by Mie and Rayleigh scattering, as well as on the mixing ratios of all absorbing constituents contributing to the total extinction in the cavity (cf. Platt et al., 2009).
The effective mirror reflectivity, $R_{\text {eff }}(\lambda)$, was determined daily from measurements of the cavity ring-down decay in pure synthetic air, using the LED in pulsed mode. The multi-exponential time-dependent decay of the cavity intensity was modelled after Meinen et al. (2010, Eq. 4b) using the cavity transmission spectrum measured in CEAS mode (which reflects the LED emission spectrum folded by the unknown "true" mirror reflectivity function) and the wavelength-dependent mirror reflectivity, $R_{\mathrm{M}}(\lambda)$, provided by the mirror manufacturer. A single scaling factor, $a$, and an offset, $b$, were fitted to the modelled decay function in order to reproduce the measured time decay. The effective ("true") mirror reflectivity, $R_{\text {eff }}$, was obtained by $R_{\text {eff }}(\lambda)=$ $a \times R_{\mathrm{M}}(\lambda)+b$ assuming the shape of the mirror reflectivity $R_{\mathrm{M}}(\lambda)$ to be invariant. The effective path length in the cavity at the $\mathrm{NO}_{3}$ absorption maximum in zero air, required for the DOAS evaluation process, was calculated according to ( $L=$ mirror separation)

$X_{0}(662 \mathrm{~nm})=\frac{L}{1-R_{\mathrm{eff}}(662 \mathrm{~nm})}$.

Typical values during NO3Comp were $8400 \mathrm{~m} \pm 100 \mathrm{~m}$ (9...18 June) and $8700 \mathrm{~m} \pm 300 \mathrm{~m}$ (on 20 and 21 June).

The CEDOAS $\mathrm{NO}_{3}$ data retrieval required several steps. (1) Zero air spectra, $I_{0}(\lambda)$, were recorded in the morning of each day of the campaign in the clean, flushed SAPHIR chamber containing only dry synthetic air (dew point $<220 \mathrm{~K}$ ). (2) During the running experiment, the time series of measurement spectra, $I_{\mathrm{m}}(\lambda, t)$, with absorbers (and aerosol extinction, in case of their presence) were recorded and the resulting optical density, $D_{\mathrm{CE}}(t)$, was determined:

$D_{\mathrm{CE}}(t)=\ln \left(\frac{I_{0}(\lambda)}{I_{\mathrm{m}}(\lambda, t)}\right)$

Literature reference spectra of the present trace gases convoluted to the spectral resolution of the instrument and a second-order polynomial accounting for all broadband absorption effects were fitted to the differential structures of the spectra according to the classical "DOAS procedure" (Platt and Stutz, 2008). The trace gas concentrations, $C_{0}$, were obtained from the retrieved column densities using the actual path length, $X_{0}(662 \mathrm{~nm})$, of the respective day. In the case of small trace gas absorption and aerosol-free conditions the mixing ratios are properly accounted for. (3) If, however, light losses due to broadband and/or narrowband extinction processes were larger, i.e. during the aerosol experiments, then the effective path length in the cavity was reduced and consequently the mixing ratios $C_{0}$ had to be corrected according to the procedure described by Platt et al. (2009, Eq. 41):

$C_{\text {true }}=C_{0} \frac{e^{D_{\mathrm{CE}}}-1}{D_{\mathrm{CE}}}$.

As this correction relays on the absolute optical density, the long-term stability of the light source becomes of 
importance. A scatter plot of the intensities of all zero air spectra $I_{0}(\lambda)$ acquired during the intercomparison, normalised to $1 \mathrm{~ms}$ integration time, showed a linear decrease with time (correlation coefficient $r=-0.991$ ). The corresponding zero intensity $I_{0}(\lambda, t)$ for each $\mathrm{NO}_{3}$ measurement at time $t$ during the campaign (to be used in Eq. 6) was calculated using the linear regression line through these data.

The typical precision of the CEDOAS technique varied between 3 and $6 \mathrm{pptv}(1 \sigma)$ for a data acquisition time of $5 \mathrm{~min}$ with the larger value for experiments with high water vapour concentrations or in the presence of high aerosol load. The total measurement accuracy was $8 \%$ and takes into account a $3 \%$ error of the light path length, $X_{0}$, calculation, $5 \%$ uncertainty of the cross section, $5 \%$ error of the effective cavity length, and the correction of the reduced path length of $3 \%$.

\subsubsection{Differential Optical Absorption Spectroscopy, FZJ-DOAS}

Forschungszentrum Jülich used broadband DOAS for in situ $\mathrm{NO}_{3}$ measurements in SAPHIR. DOAS allowed for the separation of overlapping narrowband spectral structures of different atmospheric constituents with high selectivity (fingerprint detection). DOAS is "immune" against continuous (broadband) extinction processes caused by mirror coatings and Rayleigh and aerosol scattering (Platt and Stutz, 2008). The setup of the FZJ-DOAS instrument at SAPHIR has been described in Bossmeyer et al. (2006) and Brauers et al. (2007).

A Xenon short arc lamp (OSRAM, XBO75W/2, arc size $0.3 \times 0.5 \mathrm{~mm}^{2}$ ) housed outside the chamber served as a light source. The light was collected in a fibre $(400 \mu \mathrm{m}, 2 \mathrm{~m}$ length $)$ and transferred to the chamber via a telescope. The light entered and left the chamber through a quartz window. Inside the chamber the light travelled 48 times within a modified version of a White type multiple reflection system of $20 \mathrm{~m}$ base length (Doussin et al., 1999) equipped with enhanced aluminium-coated mirrors (average reflectivity $\approx 94 \%$ between 600 and $700 \mathrm{~nm}$ ). The optical components of the White cell were setup at the north and south sides of the chamber. After leaving the White cell, the light passed through a longpass colour filter (Schott, OG530) to block excess light from entering the spectrograph. The light was guided via an optical fibre assembly into a temperature-stabilised $( \pm 0.25 \mathrm{~K})$ Czerny-Turner type spectrograph $(f=0.46 \mathrm{~m}$, spectral resolution $0.4 \mathrm{~nm}$ ) equipped with a linear photo diode array (1024 pixels, $25 \mu \mathrm{m}$ width, $2.5 \mathrm{~mm}$ length) detecting a spectral range from 601 to $690 \mathrm{~nm}$. The spectra recording, handling and fitting was controlled by the DOASIS software package (Kraus, 2006).

The $1 \sigma$ precision of the measurements was approximately 10 pptv for $1 \mathrm{~min}$ data acquisition time. The accuracy depended mainly on the uncertainty of the $\mathrm{NO}_{3}$ cross section $(5 \%, 1 \sigma)$. During the campaign an additional systematic variability by \pm 20 pptv was observed in the retrieved $\mathrm{NO}_{3}$ mixing ratios which was taken additionally into the accuracy. We explain this effect by intermittent shifts of the arc emission point on the surface of the electrodes of the Xe lamps used during NO3Comp. As a result of the geometrical displacement of the arc, the light transmission of the White cell was different and also the spectral emission of the lamp changed slightly, which led to a different spectral baseline compared with the zero-intensity spectrum measured at the beginning of the experiment. A systematic bias of the retrieved NO3 mixing ratios was the consequence.

\subsection{Atmosphere simulation chamber SAPHIR}

The SAPHIR chamber has been primarily designed for the controlled investigation of atmospheric chemical reaction systems under conditions similar to those in the ambient atmosphere, by using typical mixing ratios of trace gas constituents. SAPHIR is also optimally suited for the comparison of sensitive instruments for atmospheric trace gas and radical measurements. Unknown interferences do not affect the measurements as the composition of the air is known and the well-mixed air in the chamber allows for comparable measurements of all participating instruments (e.g. Schlosser et al., 2007, 2009; Fuchs et al., 2010b,a; Rohrer et al., 2005; Bossmeyer et al., 2006; Brauers et al., 2007; Wegener et al., 2007).

The SAPHIR chamber consists of a double-walled Teflon FEP (DuPont) bag of cylindrical shape (length $18 \mathrm{~m}$, diameter $5 \mathrm{~m}$, effective volume $270 \mathrm{~m}^{3}$, surface/volume $\approx 1 \mathrm{~m}^{-1}$ ) that is held by a steel frame. The space between the inner and the outer tube $(15 \mathrm{~cm})$ is permanently flushed with ultraclean nitrogen (purity $>99.9999 \%$ ) to prevent diffusion of gases from outside. The inner volume is always held $40 \mathrm{~Pa}$ over ambient pressure in order to avoid contamination with outside air and to keep the FEP film under tension. Losses by gas extraction by the instruments and small leaks are compensated for by a replenishment flow rate of 10 to $15 \mathrm{~m}^{3} \mathrm{~h}^{-1}$ which dilutes all constituents in the chamber at a rate of 3.5 to $5.5 \% \mathrm{~h}^{-1}$. The actual dilution is monitored by a flow controller and additionally by a gas-chromatographic measurement of an inert tracer (ethane) added to the chamber air. The chamber is housed within completely retractible metal blinds that keep the chamber in darkness as required for the detection of $\mathrm{NO}_{3}$ radicals. The blinds can be opened if daylight exposure is needed (i.e. in $\mathrm{NO}_{3}$ photolysis experiments). In order to minimise potential photolysis of $\mathrm{NO}_{3}$ during daylight measurements, all flanges and other light leaks were carefully covered by black foil, resulting in a reduction of the $\mathrm{NO}_{3}$ photolysis frequency in the chamber to $\ll 10^{-4}$ of the outside value.

The SAPHIR chamber is equipped with a comprehensive set of sensitive instruments comprising measurements of temperature, pressure, and humidity. $\mathrm{NO}$ and $\mathrm{NO}_{2}$ are measured by chemiluminescence; $\mathrm{O}_{3}$ is measured by UV absorption (Ansyco) and by chemiluminescence (modified 


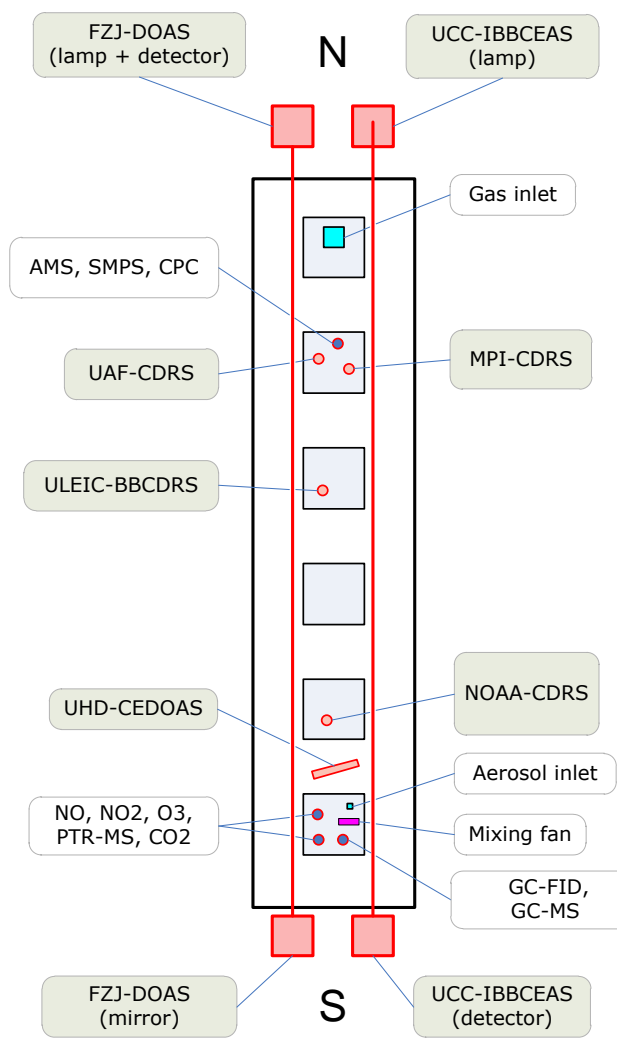

Fig. 1. Schematic top view onto the floor of SAPHIR with the positions of the individual instruments and inlet lines. The red lines indicate the open light paths of the FZJ-DOAS and UCC-IBBCEAS instruments, respectively. The UHD-CEDOAS open-path instrument was assembled on the floor of the chamber. All other $\mathrm{NO}_{3}$ instruments drew air from flanges in the chamber floor at the designated positions.

ECO Physics CLD AL 700). Volatile organic compounds (VOC) are measured by gas chromatography using a flame ionisation detector (Chrompack) (Wegener et al., 2007) and by proton transfer reaction mass spectrometry (PTR-MS, IONICON, Austria) (Lindinger et al., 1998). An ultrasonic anemometer (USA) measures the gas temperature inside the chamber with an accuracy of $\pm 0.2 \mathrm{~K}$.

Aerosol number densities and size distributions were measured with a water condensation particle counter (TSI WCPC model 3785 ) and a scanning mobility particle sizer (TSI SMPS 3936, consisting of a differential mobility analyser (DMA 3081) and a WCPC 3785). The time resolution was $20 \mathrm{~s}$ for the CPC measurements and $7 \mathrm{~min}$ for the SMPS. A time-of-flight aerosol mass spectrometer (Aerodyne TOFAMS) was operated to measure the aerosol chemical composition (Canagaratna et al., 2007). The AMS was connected to the SAPHIR chamber via a stainless steel tube designed to minimise losses in the sampling line (Fry et al., 2009).

Before each experiment, the chamber was purged with dry synthetic air overnight (from liquid $\mathrm{N}_{2}$ and $\mathrm{O}_{2}$, purity
$>99.9999 \%$, flow rate up to $500 \mathrm{~m}^{3} \mathrm{~h}^{-1}$ ) to parts per trillion (pptv) levels of nitrogen oxides, ozone, and hydrocarbons. If required, high-purity water (Milli-Q Gradient A10, Millipore Corp.) was evaporated in a steam generator and added to the purge flow at the end of the flushing of the chamber until the required humidity was reached. The trace gases $\left(\mathrm{O}_{3}, \mathrm{NO}_{2}\right.$, and hydrocarbons) were added to the replenishment flow. The inlet port was located at the northern end of SAPHIR at the main inlet which is also used to flush the chamber (Fig. 1). Ozone was produced by silent discharge in pure oxygen. Ammonium sulphate, $\left(\mathrm{NH}_{4}\right)_{2} \mathrm{SO}_{4}$, aerosol was added directly by spraying an aqueous solution into the chamber using a nebuliser. The resulting size distribution had a count mean diameter of $70 \mathrm{~nm}$, and the geometrical standard deviation was 1.56 . For some experiments $500 \mathrm{ppmv}$ of $\mathrm{CO}$ was added to the chamber before the reaction started in order to scavenge any $\mathrm{OH}$ radicals formed.

The homogeneity of the trace gas distribution in the chamber was established by a powerful fan which was mounted near the southern end of the chamber $1 \mathrm{~m}$ above the chamber floor. It was operated during all experiments. Measurements with the fan switched off showed noticeable mixing ratio differences between instruments which disappeared when the fan was running. Test measurements demonstrated that the inlet lines inside the chamber (lengths varied between 12 and $40 \mathrm{~cm}$ ) sampled air from the well-mixed volume so that potential surface gradients were negligible when the fan was running. The absence of concentration gradients under wellmixed conditions was already demonstrated during the intercomparison of $\mathrm{OH} / \mathrm{HO}_{2}$ detection instruments (Schlosser et al., 2009) where different $\mathrm{OH}$ instruments sampled air from 2 to $170 \mathrm{~cm}$ above the chamber floor.

Figure 1 shows the positions of the $\mathrm{NO}_{3}$ instruments at SAPHIR. FZJ-DOAS, UCC-IBBCEAS, and UHD-CEDOAS detected $\mathrm{NO}_{3}$ in situ inside the chamber. While the UHDCEDOAS open-path instrument was set up $60 \mathrm{~cm}$ above ground, the absorption light paths of FZJ-DOAS and UCCIBBCEAS extended along the central axis, about $1.7 \mathrm{~m}$ above the floor of SAPHIR. All other instruments were located beneath the chamber and sampled the chamber air through individual ports in the floor.

\subsection{Intercomparison experiments}

Chamber measurements were carried out in simple reaction mixtures to assess accuracy, precision, detection limits, and time response of the participating instruments. The experiments were performed in order of increasing chemical complexity. They were also designed to study the influence of species that potentially affect the measurement principles or retrieval approaches of the various instruments. Starting with water vapour and $\mathrm{NO}_{2}$ (9 to 13 June), followed by organic molecules and their oxidation products (14 to 21 June), the influence of inorganic aerosol (15 and 18 June), and secondary organic aerosol (SOA) formed during in situ 
Table 1. List of experiments performed during NO3Comp. The mixing ratios of key constituents are maximum values measured during the experiments. Ambient and dew point temperature ranges are given as well as the experiments' scopes.

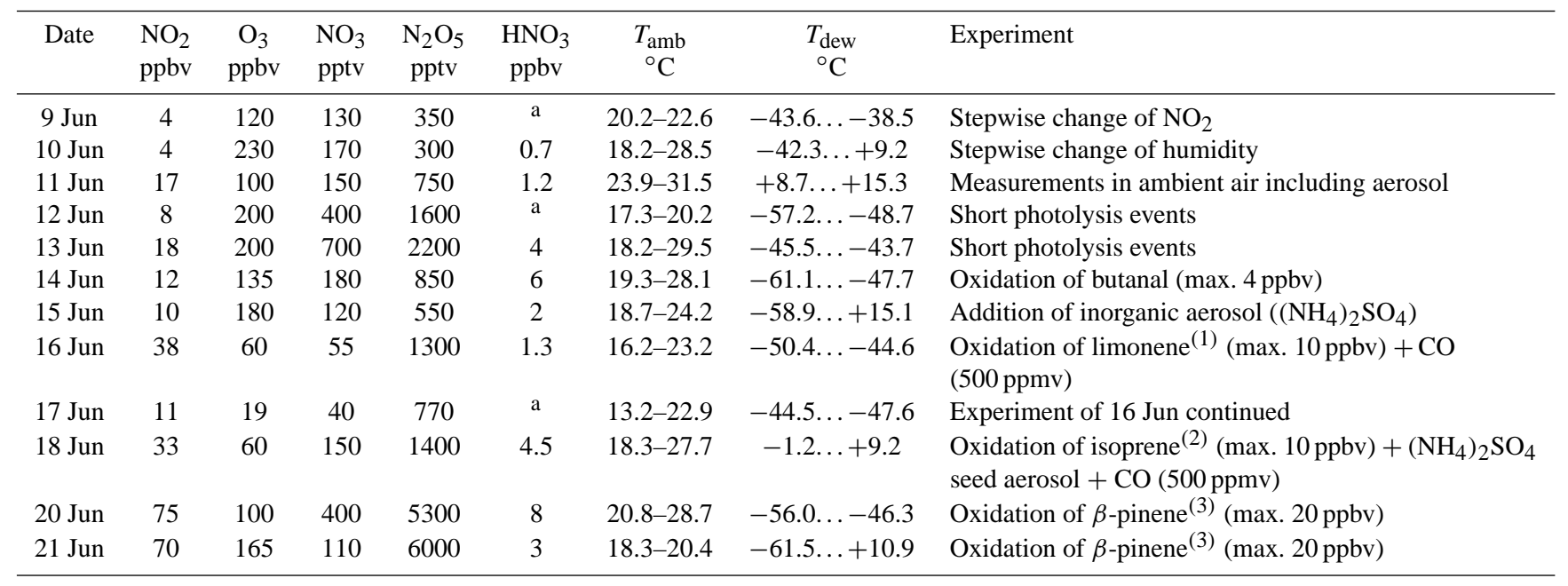

a no valid measurements; (1) Fry et al. (2011); (2) Rollins et al. (2009); (3) Fry et al. (2009).

experiments (16, 20, 21 June) was investigated (see Table 1). In order to allow for a full investigation of possible interferences with other unknown atmospheric components, ambient air was pumped into the chamber on 11 June. All simulation studies were performed under virtually ambient pressure and temperature so that the performance of the instruments was investigated under realistic, near-atmosphere conditions.

Experiments usually started by adding $\mathrm{NO}_{2}$ and $\mathrm{O}_{3}$ into the either dry or humidified synthetic air of the chamber. Maximum $\mathrm{NO}_{3}$ mixing ratios established typically after an hour. In many experiments the chemical system was "refuelled" after some time by a second addition of $\mathrm{NO}_{2}, \mathrm{O}_{3}$ or both. Fast modulations of the $\mathrm{NO}_{3}$ mixing ratio were initiated by the injection of reactive hydrocarbons $(16,18,20$ and 21 June) or by photolysis with ambient sunlight after opening the shutters of the SAPHIR chamber (12 and 13 June and at the end of most experiments in the afternoon).

\section{Observations and results}

\subsection{Precision of the instruments}

The instrumental precision was a key parameter required for a statistically sound regression analysis. The precision of the instruments was investigated under conditions of vanishingly small $\mathrm{NO}_{3}$ mixing ratios. All measurements in the clean chamber after flushing with synthetic air over night ("zero air" data) were included, but also $\mathrm{NO}_{3}$ data during the preparation phase of the experiments were selected, i.e. times were chosen when the chamber air already contained hydrocarbons, ozone or $\mathrm{NO}_{2}$ (aerosol excluded), but, in any case, before the formation of $\mathrm{NO}_{3}$ was initiated.
In Fig. 2 the frequency distributions of zero- $\mathrm{NO}_{3}$ measurements are shown. The optimal bin size to be used for the histograms depends on the sample size and the spread of the data range and was selected after Freedman and Diaconis (1981). A Gaussian distribution of the same area as the measured data was fitted to the histograms to visualise the mean of the zero measurements and their standard deviation, which is a measure of the actual instrumental precision. The histogram of the MPI-CRDS instrument is not included because the number of available zero air data $(n=7)$ was too small for a meaningful statistic. The calculated values of Skewness and Kurtosis for the histograms of UCC-IBBCEAS and UAF-CRDS (1.36/3.43 and 0.92/3.46, respectively) show significant differences from zero which indicate that these two data sets are most likely not normally distributed.

NOAA-CRDS (time resolution $\Delta t=1 \mathrm{~s}$ ), UAF-CRDS $(\Delta t=1 \mathrm{~s})$, ULEIC-BBCRDS $(\Delta t=1 \mathrm{~min})$, and UCCIBBCEAS $(\Delta t=5 \mathrm{~s})$ show excellent precision in the range of 0.5 to $2 \mathrm{pptv}$, and the calculated mean $\mathrm{NO}_{3}$ mixing ratios deviate no more than \pm 0.2 pptv from zero. The precision of UHD-CEDOAS $(\Delta t=5 \mathrm{~min})$ and FZJ-DOAS $(\Delta t=1 \mathrm{~min})$ is in the range 5 to $10 \mathrm{pptv}$, and the mean of the frequency distributions is biased to marginally higher values $(\approx 2$ and 4 pptv, respectively). The precision of the MPI-CRDS instrument $(\Delta t=10 \mathrm{~s})$, as estimated from visual comparison of measurements at $\mathrm{NO}_{3}$ mixing ratios $<35 \mathrm{pptv}$ on 16 June (Fig. 4), is comparable to the other CRDS instruments.

In part (a) of Table 2 the mean $\mathrm{NO}_{3}$ mixing ratio is compared with the corresponding confidence interval $2 \sigma / \sqrt{n}$. Given the high precision of the measurements and the large number of data points $n$, the observed deviation from zero is extremely small but statistically significant for all instruments except ULEIC-BBCRDS whose observed 
Table 2. (a) Mean $\mathrm{NO}_{3}$ mixing ratio (centre of the frequency distribution, Fig. 2) and the corresponding confidence interval, $\frac{2 \sigma}{\sqrt{n}}$. (b) Comparison of the mean of the errors of zero- $\mathrm{NO}_{3}$ measurements $(\langle\sigma\rangle)$ with the precision calculated from the frequency distribution of zero data ( $1 \sigma$ width of the Gaussian distribution). All values are in pptv.

\begin{tabular}{|c|c|c|c|c|c|c|c|}
\hline & & $\begin{array}{c}\text { FZJ } \\
\text { DOAS }\end{array}$ & $\begin{array}{l}\text { NOAA } \\
\text { CRDS }\end{array}$ & $\begin{array}{c}\text { UAF } \\
\text { CRDS }\end{array}$ & $\begin{array}{c}\text { ULEIC } \\
\text { BBCRDS }\end{array}$ & $\begin{array}{c}\text { UCC } \\
\text { IBBCEAS }\end{array}$ & $\begin{array}{c}\text { UHD } \\
\text { CEDOAS }\end{array}$ \\
\hline \multirow[t]{2}{*}{ (a) } & Mean $\mathrm{NO}_{3}$ & 2.1 & 0.2 & -0.2 & 0.1 & 0.2 & 3.4 \\
\hline & $\frac{2 \sigma}{\sqrt{n}}$ & 0.70 & 0.01 & 0.05 & 0.38 & 0.03 & 1.38 \\
\hline \multirow[t]{2}{*}{ (b) } & $\langle\sigma\rangle$ & $9.4 \pm 7.4$ & $0.4 \pm 0.2$ & $1.3 \pm 1.0$ & $0.9 \pm 0.7$ & $0.9 \pm 0.6$ & $3.7 \pm 1.9$ \\
\hline & $1 \sigma$ & 8.5 & 0.5 & 1.9 & 1.7 & 0.9 & 5.6 \\
\hline
\end{tabular}
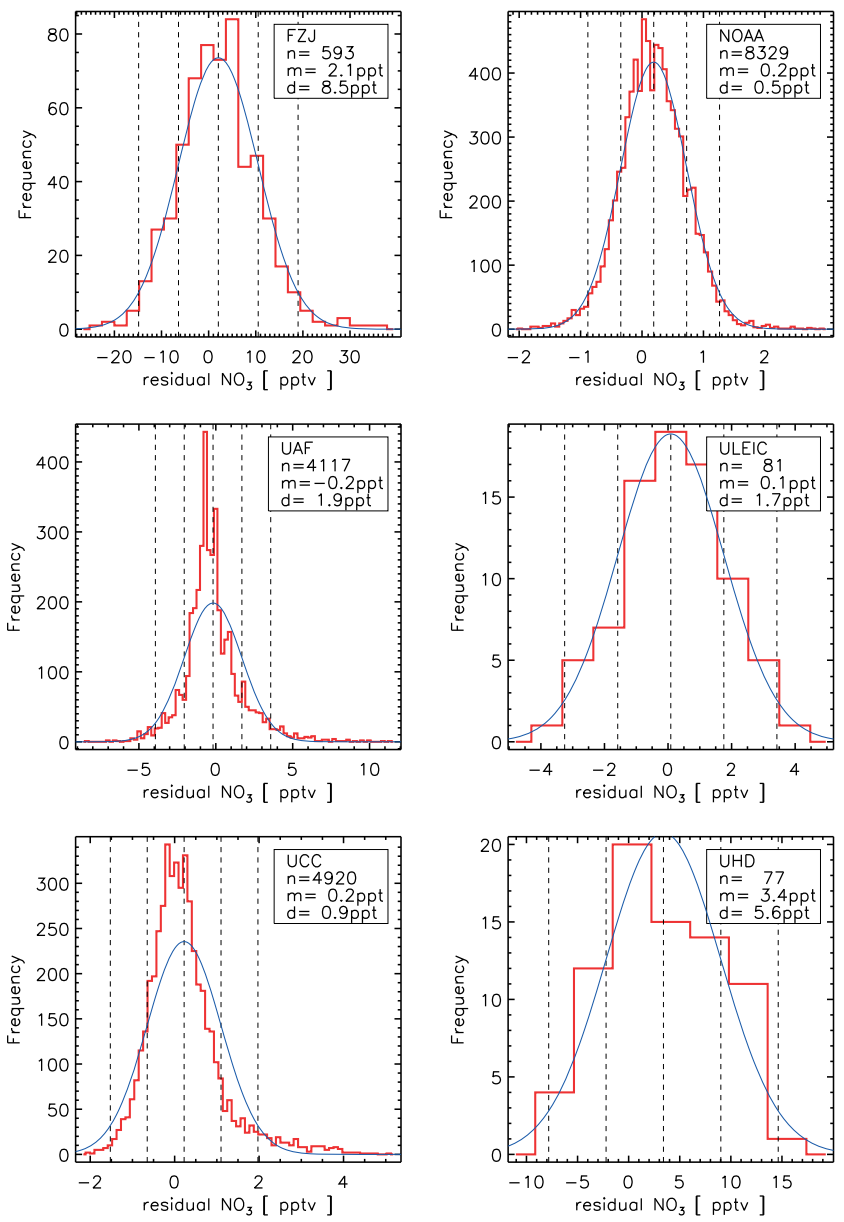

Fig. 2. Frequency distribution of zero- $\mathrm{NO}_{3}$ mixing ratio measurements. A normal distribution (blue line) was fitted to the histograms. The histogram of the MPI-CRDS instrument is not shown because the number of available data points $(n)$ was too small to be statistically meaningful. The $1 \sigma$ standard deviation, $d$, is a measure for the instrumental precision during NO3Comp; $m$ denotes the mean $\mathrm{NO}_{3}$ mixing ratio. deviation at zero is within the uncertainty interval. The lower part (b) of the table compares the mean of the errors of zero$\mathrm{NO}_{3}$ measurements $(\langle\sigma\rangle)$ with the precision calculated from the frequency distribution of zero data ( $1 \sigma$ width of the Gaussian distribution in Fig. 2). Within the calculated uncertainty no significant difference can be found, meaning that the a priori estimation of the measurement errors by the operators of each instrument correctly describes the statistical variation of the instruments.

\subsection{Time series of $\mathrm{NO}_{3}$ measurements}

Time series of $\mathrm{NO}_{3}$ mixing ratios and key constituents $\left(\mathrm{NO}_{2}\right.$, $\mathrm{O}_{3}$, and hydrocarbons), as well as water vapour partial pressure, and the total aerosol surface concentration for each day are presented in Figs. 3 and 4. The $\mathrm{NO}_{3}$ data are plotted with the original time resolution that each instrument's data reported, without any further averaging or filtering. Error bars are omitted for clarity.

$\mathrm{NO}_{3}$ mixing ratios throughout the campaign were below 250 pptv with three exceptions on the "photolysis days" (12 and 13 June, 350 and $700 \mathrm{pptv}$ ) and on the "SOA day" (20 June, 400 pptv). Exceptionally low $\mathrm{NO}_{3}$ mixing ratios occurred on 16 June $(\leq 40$ pptv) and especially on 18 June when $\mathrm{NO}_{3}$ mixing ratios remained between 2 pptv after the first isoprene injection and 12 pptv after a second addition (see Fig. 4). Prior to the discussion of the individual $\mathrm{NO}_{3}$ time series of each experiment of the campaign, some discernible features in the figures merit discussion.

1. $\mathrm{NO}_{3}$ mixing ratios measured by UCC-IBBCEAS on 10 , $11,13,15$, and 20 June significantly differed from the values of all other instruments (Figs. 3 and 4). A similar observation for the UCC instrument was described by Fuchs et al. (2010a) for the comparison of $\mathrm{NO}_{2}$ measurements performed during NO3Comp. The systematic difference of the $\mathrm{NO}_{3}$ mixing ratios can be explained by the fact that on those days no measurements of zero air background spectra $\left(I_{0}(\lambda)\right.$, Eq. 3) could be taken in the morning before the experiments for the following reasons. On 10, 15, and 20 June, $\mathrm{NO}_{3}$ was already produced in the chamber before the 

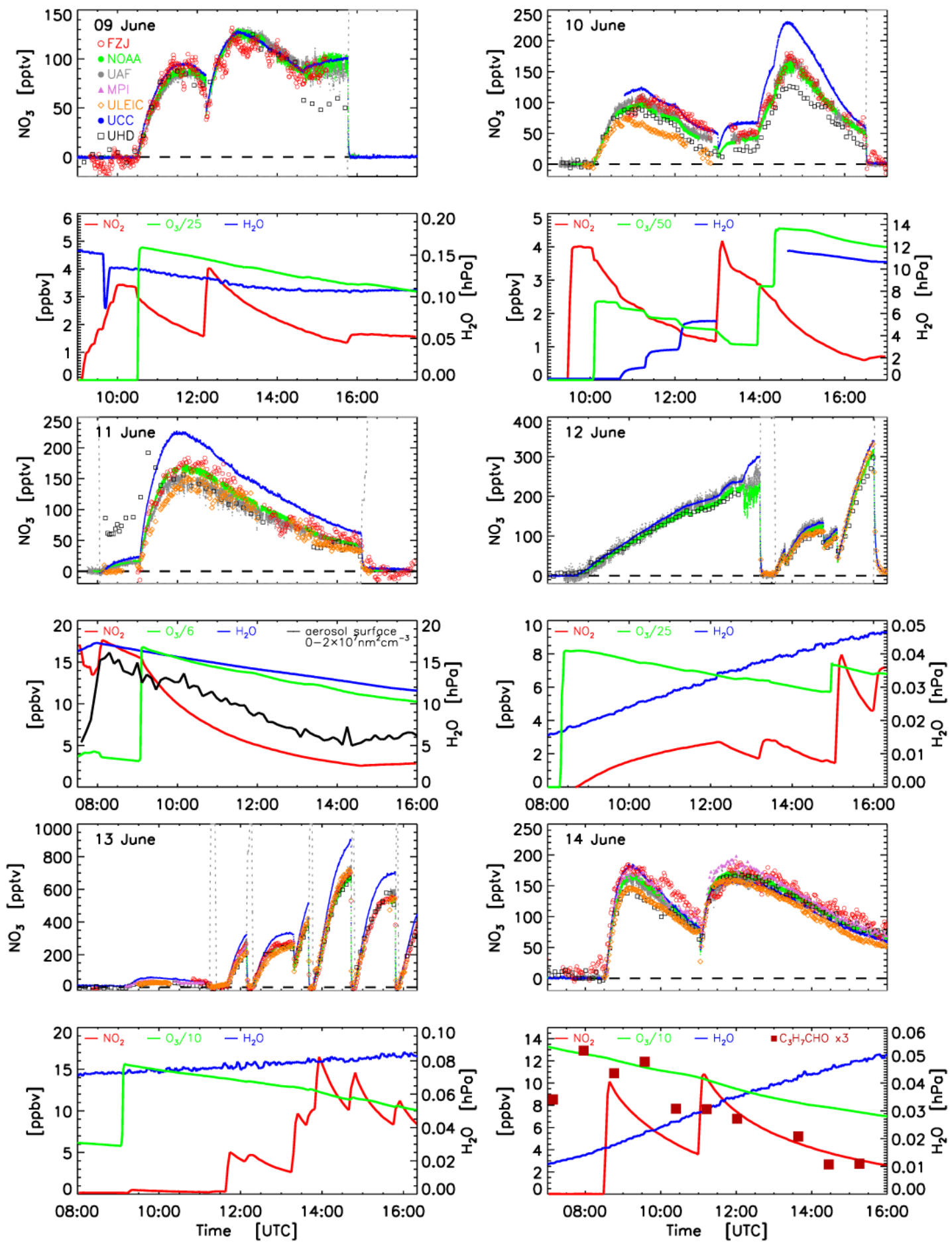

Fig. 3. Comparison of temporal profiles of $\mathrm{NO}_{3}$ mixing ratios and supporting measurements of other relevant species (as indicated in the panels) for all days of the intercomparison campaign. The respective upper panels show $\mathrm{NO}_{3}$ data measured with the original time resolution of the instruments (NOAA-CRDS $1 \mathrm{~s}$, UAF-CRDS $1 \mathrm{~s}$, UCC-IBBCEAS $5 \mathrm{~s}$, MPI-CRDS $10 \mathrm{~s}$, FZJ-DOAS $60 \mathrm{~s}$, ULEIC-BBCRDS $61 \mathrm{~s}$, and UHD-CEDOAS $300 \mathrm{~s}$ ). Vertical, dashed grey lines indicate times when the roof of the chamber was opened or closed to initiate photolysis or enable the build-up of $\mathrm{NO}_{3}$, respectively. The associated lower panels present the mixing ratios of $\mathrm{NO}_{2}, \mathrm{O}_{3}$, hydrocarbons (ppbv, left axis), and the water vapour partial pressure (hPa, right axis). For experiments containing aerosol, the aerosol surface area concentration is indicated by a black line (in units of $\mathrm{nm}^{2} \mathrm{~cm}^{-3}$, no separate axis associated, full data span specified in the legend). 

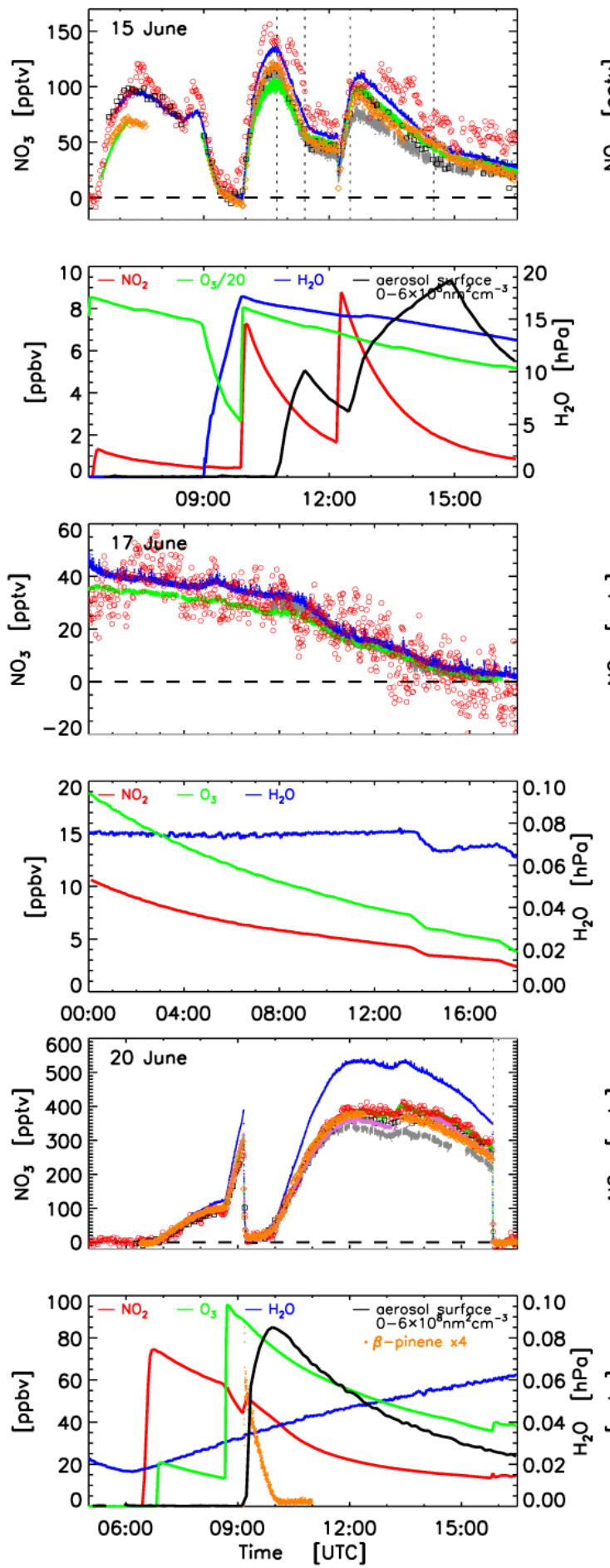
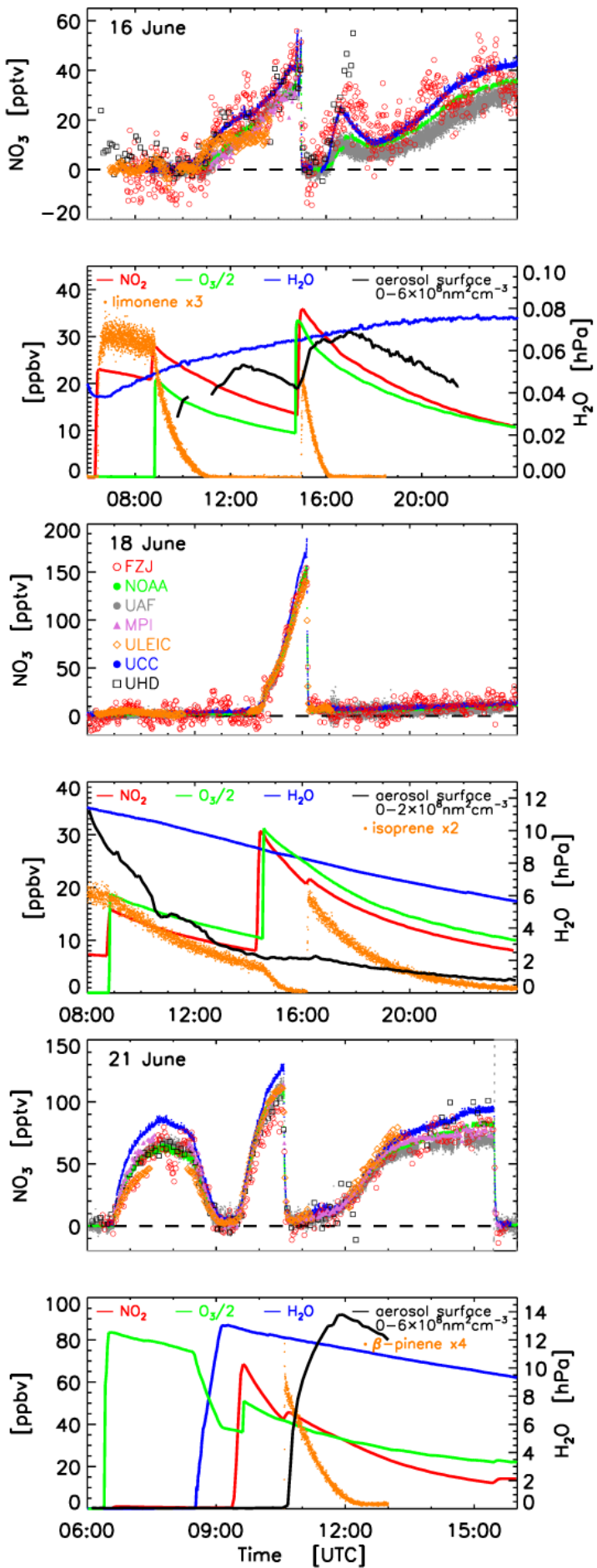

Fig. 4. Continued from Fig. 3. This figure comprises the chemically more complex experiments of the second part of the campaign. Dotted black lines on 15 June denote two time intervals during which inorganic aerosol was added to the chamber.

UCC-IBBCEAS instrument was operational, on 11 June ambient air was pumped into the chamber, and on 13 June the previous experiment was continued over night without flushing in the morning. Zero air spectra from the day after or before were used for the re- trieval of the $\mathrm{NO}_{3}$ mixing ratios in these cases. Notably, differences in the $\mathrm{NO}_{3}$ mixing ratio measured by UCC-IBBCEAS and other instruments are expected to be largest on days when the background spectrum could not be measured. This indicates that the long-term 
intensity variation of the lamp was a limiting factor for the UCC-IBBCEAS instrument during some experiments of NO3Comp.

2. Mixing ratios taken with the ULEIC-BBCRDS instrument on 10 June were exceptionally low (orange diamonds in Fig. 3). At the end of the experiment it was noticed that the sampling line had collapsed. Therefore it had to be assumed that during the experiment the flow rate was potentially already much smaller than expected, resulting in enhanced losses of $\mathrm{NO}_{3}$ in the instrument.

3. On 11 June the ULEIC-BBCRDS data exhibited the strongest fluctuations during NO3Comp. The amount of ambient air that was found to be leaking into the BBCRDS cavity (see Sect. 2.1.4) was highly variable, ranging between 0 and $30 \%$. Quantitative correction of the dilution effect was difficult to achieve under these conditions, resulting in less-precise measurements on that day.

4. Also the performance of the UHD-CEDOAS instrument was degraded on 11 June in the morning. The chamber was flushed with open roof, leading to an overheating of the LED light source by solar radiation. The induced drift of the LED output made the spectral retrieval unreliable as demonstrated by the large positive offset of the $\mathrm{NO}_{3}$ data before 09:45 UTC (Fig. 3).

5. On 9 June (14:38 UTC) and on 12 June (12:46 UTC) the fan inside the chamber was switched off some time before the roof was opened. In stagnant air, the mixing time in the dark chamber is on the order of an hour. This is considerably longer than the $\mathrm{NO}_{3}$ lifetime of $30 \mathrm{~min}$ (Fry et al., 2009) in the dry chamber, making wall reactions of $\mathrm{NO}_{3}$ a significant loss process and enabling measurable concentration gradients to build up. Consequently, these episodes of inhomogeneous sampling conditions were excluded from further data analysis.

In order to get a representative picture of the instrument performance throughout the campaign, the data on these occasions where specific instrument issues have been identified are still included in calculating the full-campaign correlations (except 5). The following paragraphs describe the time series of the $\mathrm{NO}_{3}$ mixing ratios recorded during NO3Comp. A brief summary of the typical mixing ratios of key constituents observed during the experiments is given in Table 1 .

9 June, 10 June: during the first part of the campaign (9-14 June) the majority of measurements were carried out in simple reaction mixtures. On 9 and 10 June a potential cross interference of $\mathrm{NO}_{2}$ and water vapour was investigated, respectively. With the exception of the scenarios discussed above the $\mathrm{NO}_{3}$ mixing ratios of all instruments agree well and mostly overlap within their errors. On 10 June the data of the UHD-CEDOAS instrument tend to lower values at higher water vapour mixing ratios.

11 June: an experiment with ambient aerosol was performed on 11 June. The chamber was flushed with ambient air while the roof was open in order to avoid $\mathrm{NO}_{3}$ formation during the flushing period. A filter (cut-off size unknown) removed coarse-mode particles. The resulting aerosol surface concentration was very low and did not vary much $\left((1.3 \ldots 0.5) \times 10^{7} \mathrm{~nm}^{2} \mathrm{~cm}^{-3}\right)$ during the experiment (Fig. 3). The aerosol mass spectrometer could not measure due to the low particle concentration; therefore chemical properties of the aerosol are unknown. Peak mixing ratios of $\mathrm{NO}_{2}, \mathrm{O}_{3}$, and water after closing the roof at 08:01 UTC were $23 \mathrm{ppbv}$, $25 \mathrm{ppbv}$, and $1.7 \%$, respectively. At 09:04 UTC formation of $\mathrm{NO}_{3}$ was stimulated by addition of $70 \mathrm{ppbv} \mathrm{O}_{3}$ into the dark chamber. Technical problems affected UHD-CEDOAS, ULEIC-BBCRDS, and UCC-IBBCEAS (see above), but NOAA-CRDS, FZJ-DOAS, and UAF-CRDS data were very similar throughout the day.

12 and 13 June: on these "photolysis days" the $\mathrm{NO}_{3}$ production rate was high and the chemical losses were low, leading to the largest $\mathrm{NO}_{3}$ mixing ratios of the campaign (700 pptv on 13 June). $\mathrm{NO}_{3}$ was frequently photolysed on both days by opening and closing the roof system of the SAPHIR chamber. The photolytic lifetime of $\mathrm{NO}_{3}$ was approximately $5 \mathrm{~s}$ when the roof was open; however the observed $\mathrm{NO}_{3}$ lifetime was approximately $1 \mathrm{~min}$ because the fast thermal dissociation of $\mathrm{N}_{2} \mathrm{O}_{5}$ (present at $\approx 2$ ppbv; Fuchs et al. (2012)) acted to partially buffer the $\mathrm{NO}_{3}$ lost to photolysis. Figure 3 clearly demonstrates the very good time resolution of the "faster" instruments, NOAA-CRDS, UAF-CRDS, UCC-IBBCEAS, and MPI-CRDS, which were able to detect the quick changes of $\mathrm{NO}_{3}$ very accurately.

14 June: in this experiment the oxidation of butanal by $\mathrm{NO}_{3}$ was studied. The measurements revealed very good agreement between the instruments. However, the sensitivity of the UHD-CEDOAS instrument seemed to have changed after 10:00 UTC probably due to a temperature change of the LED.

15 June: during this experiment ammonium sulphate aerosol was generated and added twice during 10:45-11:25 and 12:30-14:55 UTC (black dotted lines in Fig. 4) by spraying an aqueous solution into the clean humidified $(60 \%$ $\mathrm{RH})$ chamber using a nebuliser. Peak aerosol surface concentrations of $3 \times 10^{8}$ and $5.8 \times 10^{8} \mathrm{~nm}^{2} \mathrm{~cm}^{-3}$, corresponding to 5 and $12 \mu \mathrm{g} \mathrm{m}^{-3}$, respectively, were reached at the end of the injection periods. During the humidification of the aerosol-free chamber air (starting at 09:00 UTC) the mixing ratio of $\mathrm{NO}_{3}$ dropped to zero. The addition of $\mathrm{O}_{3}$ and $\mathrm{NO}_{2}$ at 09:56 UTC brought the $\mathrm{NO}_{3}$ mixing ratio back up to about 110 pptv (Fig. 4). The first aerosol generation began at the maximum of the $\mathrm{NO}_{3}$ mixing ratio which then decreased to about $50 \mathrm{pptv}$ due to the enhanced dilution of the chamber air by the high air flow through the aerosol generator. At the start of the aerosol addition the 
readings of UHD-CEDOAS, ULEIC-BBCRDS, and UAFCRDS corresponded well (115 pptv at 10:45 UTC), while UCC-IBBCEAS and FZJ-DOAS measured $135 \mathrm{pptv}$ and NOAA-CRDS was lowest at 100 pptv. After the first aerosol addition was finished (11:25 UTC), the $\mathrm{NO}_{3}$ mixing ratios reported by ULEIC-BBCRDS, UHD-CEDOAS, and particularly by UAF-CRDS had dropped significantly below the NOAA-CRDS readings. During the subsequent second particle injection, the aerosol surface concentration nearly doubled, but no further significant change of the relation between NOAA-CRDS and the other instruments was observed except for the ULEIC-BBCRDS instrument. $\mathrm{NO}_{3}$ data measured after 13:45 UTC until the end of the experiment agreed well with the NOAA reference instrument but were lower by about $16 \mathrm{pptv}$ prior to this. Most likely the pronounced underestimation of the $\mathrm{NO}_{3}$ mixing ratio before 13:45 UTC was caused by an intermittent problem with a leak as a comparison of the ULEIC water vapour data with a dew point hygrometer inside SAPHIR suggested. The FZJ-DOAS instrument showed excessive fluctuations caused by the unsteady arc of the Xe high-pressure lamp, making the $\mathrm{NO}_{3}$ measurements unreliable on 15 June.

16 and 17 June: during this two-day experiment the limonene- $\mathrm{NO}_{3}$ reaction and the formation of products, both in the gas and in the particulate phase, were studied (Fry et al., 2011). Limonene (10 ppbv) was already injected before $\mathrm{NO}_{3}$ was generated, so that the $\mathrm{NO}_{3}$ mixing ratio remained suppressed below the detection limit of all instruments. After limonene was fully consumed, the ongoing reaction between $\mathrm{NO}_{2}$ and $\mathrm{O}_{3}$ caused $\mathrm{NO}_{3}$ mixing ratios to rise to about $35 \mathrm{pptv}$. About $10 \mu \mathrm{g} \mathrm{m}^{-3}$ of aerosol was formed, resulting in an aerosol surface concentration of $3 \times 10^{8} \mathrm{~nm}^{2} \mathrm{~cm}^{-3}$. Data from all instruments compare well under these conditions except for FZJ-DOAS and UCC-IBBCEAS, which showed a trend to slightly higher $\mathrm{NO}_{3}$ mixing ratios (difference remained $<5 \mathrm{pptv}$ ). The FZJ-DOAS instrument was close to the detection limit $(S / N \approx 1$ to 3 ) on that day. The second limonene injection at 15:00 UTC on 16 June occurred almost simultaneously with the addition of $\mathrm{NO}_{2}$ and $\mathrm{O}_{3}$. During the second oxidation step further aerosol was formed, peaking at $24 \mu \mathrm{g} \mathrm{m}^{-3}\left(4 \times 10^{8} \mathrm{~nm}^{2} \mathrm{~cm}^{-3}\right)$. As expected, $\mathrm{NO}_{3}$ started to rise again quickly after limonene was consumed. The observed unexpected decrease of the $\mathrm{NO}_{3}$ mixing ratio reaching a minimum at 18:00 UTC (Fig. 4) was due to complex coupling of the chemistry in the gas phase with that of the organic particle phase and has not been fully understood yet (Fry et al., 2011). ULEIC, MPI, and UHD finished measurements at 13:30, 15:50, and 16:40 UTC, respectively, before the $\mathrm{NO}_{3}$ mixing ratios again began to rise up until midnight. During the last six hours of the 16 June data the differences between the readings of the remaining instruments increased.

NOAA-CRDS, UCC-IBBCEAS and FZJ-DOAS continued their measurements until 17 June, 19:00 UTC. No aerosol measurements were available for that day. UAFCRDS commenced measurements again at 08:00 UTC after the replacement of an aerosol filter. With a new filter in the inlet, the instrument detected slightly larger $\mathrm{NO}_{3}$ mixing ratios than NOAA-CRDS, while the opposite was the case on 16 June, indicating a potential loss of $\mathrm{NO}_{3}$ by aerosol particles deposited on the UAF-CRDS instrument's filter surface.

18 June: the oxidation of isoprene by $\mathrm{NO}_{3}$ in the presence of ammonium sulphate seed aerosol was studied on 18 June (Rollins et al., 2009). The first isoprene injection (10 ppbv at 07:40 UTC) was made before any $\mathrm{NO}_{3}$ was generated (the $\mathrm{NO}_{3}$ production started after ozone injection at 08:48 UTC), and the second isoprene injection (10 ppbv at 16:11 UTC) occurred two hours after the system was refuelled by $\mathrm{NO}_{2}$ and $\mathrm{O}_{3}$ addition. In the first part of the experiment the $\mathrm{NO}_{3}$ mixing ratio reached peak values of only 2 pptv; at the end of the experiment at midnight $\mathrm{NO}_{3}$ was less than 12 pptv, still close to the detection limit of FZJ-DOAS and UHD-CEDOAS. The aerosol surface concentration in the morning reached $1.3 \times 10^{8} \mathrm{~nm}^{2} \mathrm{~cm}^{-3}$, about $20 \%$ of the maximum value on 15 June, and gradually decreased to $0.2 \times 10^{8} \mathrm{~nm}^{2} \mathrm{~cm}^{-3}$. The fast increase of $\mathrm{NO}_{3}$ after mid-afternoon refuelling additions of $\mathrm{NO}_{2}$ and $\mathrm{O}_{3}$ was very well captured by all instruments. $\mathrm{NO}_{3}$ mixing ratios detected by UCC-IBBCEAS appear to be 5-10\% higher before isoprene was injected.

20 and 21 June: on the last two days of the campaign the oxidation of $\beta$-pinene in dry air and at $60 \% \mathrm{RH}$, respectively, was investigated. After the injection of $\beta$-pinene the $\mathrm{NO}_{3}$ mixing ratio dropped to $20 \mathrm{pptv}$ and $5 \mathrm{pptv}$, respectively, and remained suppressed until the hydrocarbon had reacted completely. Prompt SOA formation was observed reaching a maximum concentration of $40 \mu \mathrm{g} \mathrm{m}^{-3}$, corresponding to an aerosol surface concentration of $5.6 \times 10^{8} \mathrm{~nm}^{2} \mathrm{~cm}^{-3}$, about $45 \mathrm{~min}$ and $90 \mathrm{~min}$, respectively, after injection of the hydrocarbon (Fry et al., 2009). After the consumption of $\beta$-pinene, the $\mathrm{NO}_{3}$ mixing ratio increased again to a maximum of 400 and $80 \mathrm{pptv}$, respectively. During this period the high precision of the instruments allowed the investigators to visualise an increasing difference in the $\mathrm{NO}_{3}$ mixing ratios as measured by the instruments over time. A detailed discussion will follow in Sects. 3.3.3 and 4.4.2.

\subsection{Correlation and regression analysis}

\subsubsection{Correlation procedure}

In order to assess the performance of the individual instruments, all $\mathrm{NO}_{3}$ data sets were compared to one selected instrument. We chose the NOAA-CRDS $\mathrm{NO}_{3}$ measurements as the reference for the correlation analysis for three reasons. (1) The NOAA-CRDS instrument was the technically most advanced one (see Sect. 2.1.1). Its properties were comprehensively studied and characterised in detail before and after the campaign (Dubé et al., 2006; Osthoff et al., 2006; Fuchs et al., 2008). (2) The NOAA instrument measured on all days of the campaign and produced the most complete data set. (3) The instrumental precision and consequently the 
detection sensitivity and time resolution are excellent, so potential features in the correlation plots can be clearly identified. Especially the latter property favoured NOAA-CRDS over FZJ-DOAS, which would normally have been our preferred choice, because the DOAS instrument has no inlet one of the major uncertainties of the other instruments. In addition, DOAS is known to be "immune" against broadband light losses caused by Mie scattering of particles, Rayleigh scattering, or by other broadband absorbers in the atmosphere (Platt and Stutz, 2008). Unfortunately, the FZJ-DOAS measurements turned out to be unusually noisy and showed sudden systematic variations during many days. The latter were most likely due to instabilities of the Xe arc lamps used during NO3Comp. If DOAS had been chosen as reference, then excessive noise would have been added to all regressions. A comparison of the results of a regression analysis with FZJ-DOAS or NOAA-CRDS as reference instrument showed that the major conclusions drawn from the correlations did not depend on the choice of the reference. We would like to emphasise that our selection shall not imply that the NOAA-CRDS data are inherently correct.

The correlation and regression analysis presented in the following sections are based on data sets averaged to a $3 \mathrm{~min}$ time grid which allows for the comparison of fast and slower instruments within common time intervals. It was verified that the choice of the averaging interval does not significantly affect the results. In order to minimise potential errors by imperfect mixing in the chamber, all $\mathrm{NO}_{3}$ mixing ratios measured within a time interval of $5 \mathrm{~min}$ after injection of reactive trace gases $\left(\mathrm{NO}_{2}, \mathrm{O}_{3}\right.$, and hydrocarbons) were removed from the analysis.

In the case of multiple $\mathrm{NO}_{3}$ data points within one averaging interval, the mean value was calculated and assigned to the centre of the time interval. Data of "slower" instruments were assigned to the centre of the interval where they appeared. Whenever the observed variability of the $\mathrm{NO}_{3}$ mixing ratios within the averaging interval was comparable with the individual measurement errors, the standard deviation of the error bars was taken as $1 \sigma$ error of the mean. If the data variability was larger, the standard deviation of the mixing ratios was taken as the error bar of the mean value (Schlosser et al., 2009; Fuchs et al., 2010a).

A weighted linear regression line was calculated using the procedure "fitexy" by Press et al. (1992). This regression is invariant with respect to a permutation of independent and dependent variable and takes into account the errors of both coordinates. Thus, the statistical weight of each data point is calculated from the a priori precision of the data of both the respective instrument and NOAA-CRDS. In order to assess the statistical relevance of the linear regression parameters and their errors, the chi-square $\left(\chi^{2}\right)$ value of the linear fit to the measurements was calculated. A rule of thumb is that a "typical" value of $\chi^{2}$ for a "good" fit is $\chi^{2} \approx(n-2)$ ( $n$...number of data pairs correlated) (cf. Press et al., 1992, Chapter 15). Furthermore a "goodness-of-fit" parameter $q$ was calculated from the chi-square distribution for $(n-2)$ degrees of freedom. It denotes the statistical probability that the deviation of the $\chi^{2}$ value (obtained for some particular data set) from the "expected" $\chi^{2}=n-2$ value can be explained within the individual $1 \sigma$ measurement errors of the data pairs correlated. If $q$ is a very small probability, then the inherent variance of the data set is larger than the "confidence interval" defined by the individual error bars. Possible causes are that (1) the assumption of a linear model is wrong, (2) the errors are non-normally distributed, or (3) the measurement errors are really larger than stated. As an order of magnitude estimate the assumption of a linear dependency between the instruments within the range of their given measurement errors is believable if $q \geq 0.1$. For $q \geq 0.001$, the fit may be acceptable if the errors are non-normally distributed or have been moderately underestimated. If $q<0.001$, a linear relationship within the specified errors can be called into question. However, $q$ is a very sensitive quantity for underestimated measurement errors. Often truly wrong models will be rejected with vastly smaller values of $q\left(10^{-18}\right)$. The opposite extreme, $q \approx 1$, is almost always caused by overestimation of the measurement errors by the experimenter (Press et al., 1992).

\subsubsection{Correlations of combined data sets}

It was already indicated in Sect. 3.2 that the performance of some $\mathrm{NO}_{3}$ instruments could be affected by the presence of aerosol. A similar observation has been described by Fuchs et al. (2012) for the intercomparison of $\mathrm{N}_{2} \mathrm{O}_{5}$ measurements during NO3Comp. Therefore the scatter plots and the correlation and regression analysis of the $\mathrm{NO}_{3}$ data will be presented in separate figures for aerosol-free (Fig. 5) and aerosol-containing experiments (Fig. 6). Each panel in Figs. 5 and 6 shows the entire campaign data set for the nominated instruments plotted as a scatter plot against the NOAA-CRDS reference instrument. The figures visualise the total variability of the instrumental performance relative to the NOAA instrument, and the regression results allow for a comparison of the "average response" of the instruments during NO3Comp. The individual days of the campaign are distinguished by colour-coded symbols, and the error bars denote the $1 \sigma$ precision. The data range is limited to $420 \mathrm{pptv}$ to avoid any bias by the high $\mathrm{NO}_{3}$ mixing ratios on 13 June.

On average all instruments performed very well over the course of the intercomparison. The $\mathrm{NO}_{3}$ mixing ratios of all instruments are exceptionally well linearly correlated with NOAA-CRDS. The coefficients of determination, $r^{2}$, are $>0.955$ in all cases (Table 3), i.e. more than $95 \%$ of the variance observed in the instruments' responses is explained by the variance of the reference instrument. Due to the large number of data points, $n$, all correlations are highly significant. However, the regression analysis resulted in $\chi^{2}$ values which are significantly larger than the number of degrees of freedom $(n-2)$ (last column in Table 3$)$. Accordingly $q$ 

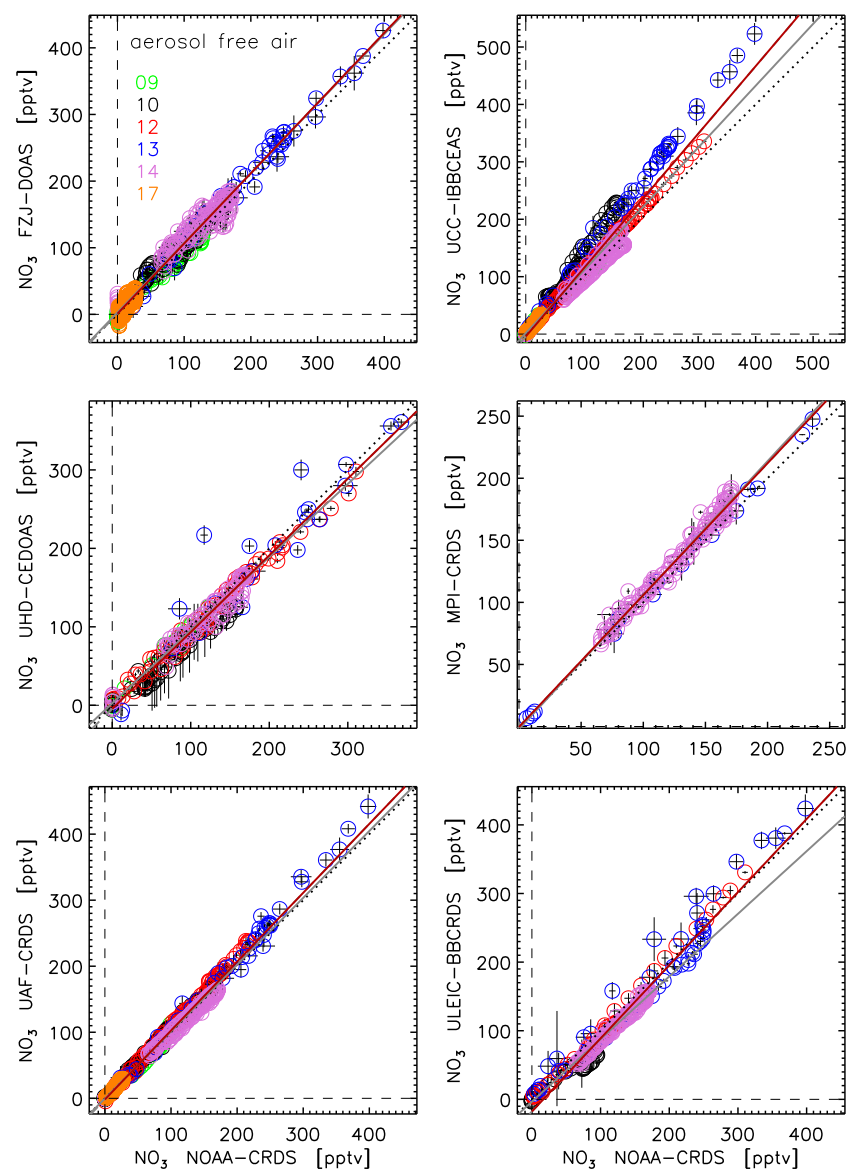

Fig. 5. Correlation of $\mathrm{NO}_{3}$ measurements versus the reference instrument NOAA-CRDS for aerosol-free conditions. The data sets were averaged onto a common 3 min time grid, and the data range was limited to $420 \mathrm{pptv}$ to exclude any bias by the high mixing ratios of 13 June. The colour code denotes the experiment days and error bars are $1 \sigma$. The "best-fit" line (dark-red solid line), calculated by a "least-normal-squares" regression method, represents the average instrumental response for the entire intercomparison and the dotted black line shows the ideal $1: 1$ line. The solid grey lines are the linear regression lines calculated by the "fitexy" algorithm. When the scatter of the data is significantly larger than expected from the measurement errors, the "fitexy" algorithm fails to determine the correct relation between the data pairs (cf. Sect. 3.3.2 and Table 3).

was $<10^{-10}$ in all cases and is therefore not listed in Table 3. This finding shows that the variance in the $\mathrm{NO}_{3}$ data set of each instrument, considered over the entire course of the campaign, was significantly larger than would be expected from the high precision of the measurements. Obviously the daily variability of the instrumental response was larger than the data variability during the single days. Consequently, the use of the data precision as weighting factor is not a suitable measure for the investigation of the "average" (linear) relationship between the instruments during NO3Comp. While the individual measurement errors during a specific chamber experiment can be assumed to be normally distributed with
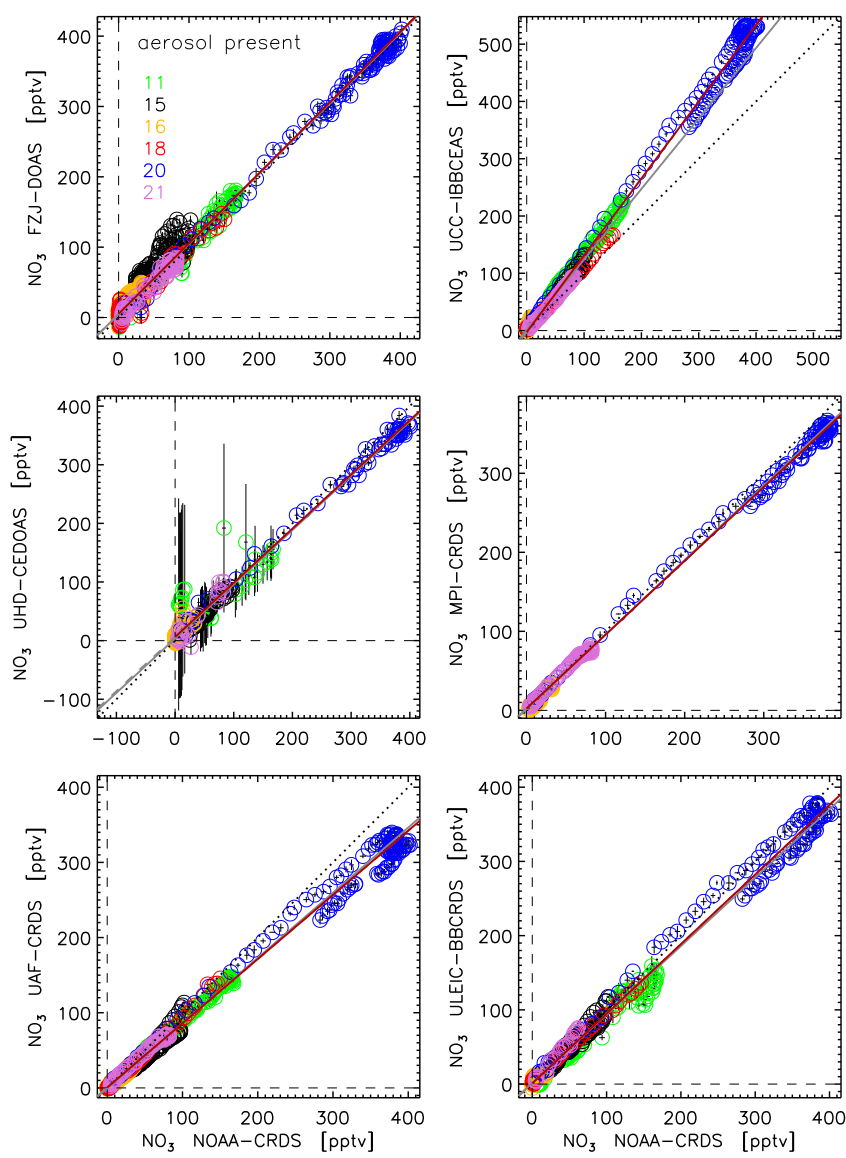

Fig. 6. Correlation of $\mathrm{NO}_{3}$ measurements versus the reference instrument NOAA-CRDS in presence of aerosol. See Fig. 5 for details on the regression lines.

a mean zero and constant variance, the statistical distribution of the day-to-day variability of the "calibration factors" is not known. As a consequence, for the days where $\chi^{2} /(n-2) \gg 1$ (i.e. when $q$ is not acceptable), the "fitexy" routine is not well suited to calculate correct values and errors of intercept $a$ and slope $b$ (Press et al., 1992). A more appropriate nonparametric line-fitting technique is to be used which makes no assumptions on the distribution function of the data and their errors. We applied the "least-normal-squares" (LNS) technique (Troutman and Williams, 1987), which minimises the sum of squared perpendicular distances between the data points and the regression line. LNS is invertible and a unique relation (slope and intercept) is obtained regardless which variable is chosen to be dependent. In order to determine the goodness of the procedure for fitting the straight line, i.e. the errors $\sigma_{a}$ and $\sigma_{b}$, a bootstrap technique was used. Bootstrapping is a non-parametric approach to determine statistical properties of data sets that does not require distributional assumptions such as normally distributed errors (Efron and Tibshirani, 1993). An application of this method for the determination of measurement errors in high-resolution DOAS 
spectroscopy was described by Hausmann et al. (1999). The total bootstrap procedure comprises three steps: (1) a large number, $m$, (typically $m \approx 1000$ ) of independent replicas from the data set under investigation (selected $\mathrm{NO}_{3}$ instrument vs reference instrument) are created by drawing with replacement a random sample of data pairs of the original data set. (2) The linear regression parameters intercept, $a^{\prime}$, and slope, $b^{\prime}$, for each replica are calculated. (3) The standard deviations of the $m$ values of $a^{\prime}$ and $b^{\prime}, \sigma_{a^{\prime}}$ and $\sigma_{b^{\prime}}$, finally represent the errors of the intercept, $a$, and the slope, $b$, of the LNS correlation line. The LNS line fit parameters (the "best-fit" linear regression) are highlighted in Table 3 and shown as dark-red solid lines in Figs. 5 and 6. Significant deviations of slope and intercept between fitexy (solid grey lines in the figures) and LNS mainly result for large chi-squared test values ( $\gtrsim 15)$. The "best-fit" linear regression line represents the average instrumental response for the entire intercomparison.

The LNS regression analysis reveals small intercepts close to the specified precision of the instruments. The slopes of the linear regression lines vary less than $15 \%$ around unity for the whole-campaign correlations with the known exception of UCC-IBBCEAS (problem of recording zero air background spectra). Between the experiments with and without aerosol a tendency to underestimate the $\mathrm{NO}_{3}$ mixing ratios in the presence of aerosol can be found for all instruments except FZJ-DOAS, which correlates very well with NOAACRDS, again demonstrating its insensitivity to broadband light extinction by aerosol. Overall we can state that the slopes of the regression lines are all within the combined $1 \sigma$-accuracies of the nominated test instruments and NOAACRDS. This demonstrates that the instrumental accuracy was very well determined by the experimentalists.

\subsubsection{Day-to-day correlations}

Day-to-day variations of the detection sensitivity or different responsivity of the instruments towards interferences become more apparent in scatter plots that compare data separated into individual days' experiments. Figures 7 and 8 show the correlations of $\mathrm{NO}_{3}$ data of all instruments versus NOAACRDS for each experiment of the NO3Comp campaign (cf. Table 1). Error bars are omitted for clarity. In order to assess the effect of aerosol on the quality of the measurements on 11 and 15-21 June, only $\mathrm{NO}_{3}$ data are compared which were recorded in the presence of aerosol.

The regression parameters are summarised in Table 4. Slopes and intercepts of the regression lines were calculated by the routine "fitexy" because the majority of the data sets showed reduced chi-square values $<15$ (cf. Sect. 3.3.2). For every day the slopes of the linear regression lines fitted to the data were within the limits of the combined accuracies of the instrument pairs (as based on the a priori uncertainty estimates provided for each instrument by its operators). Only on four days $(10,11,13$, and 20 June) did the slopes
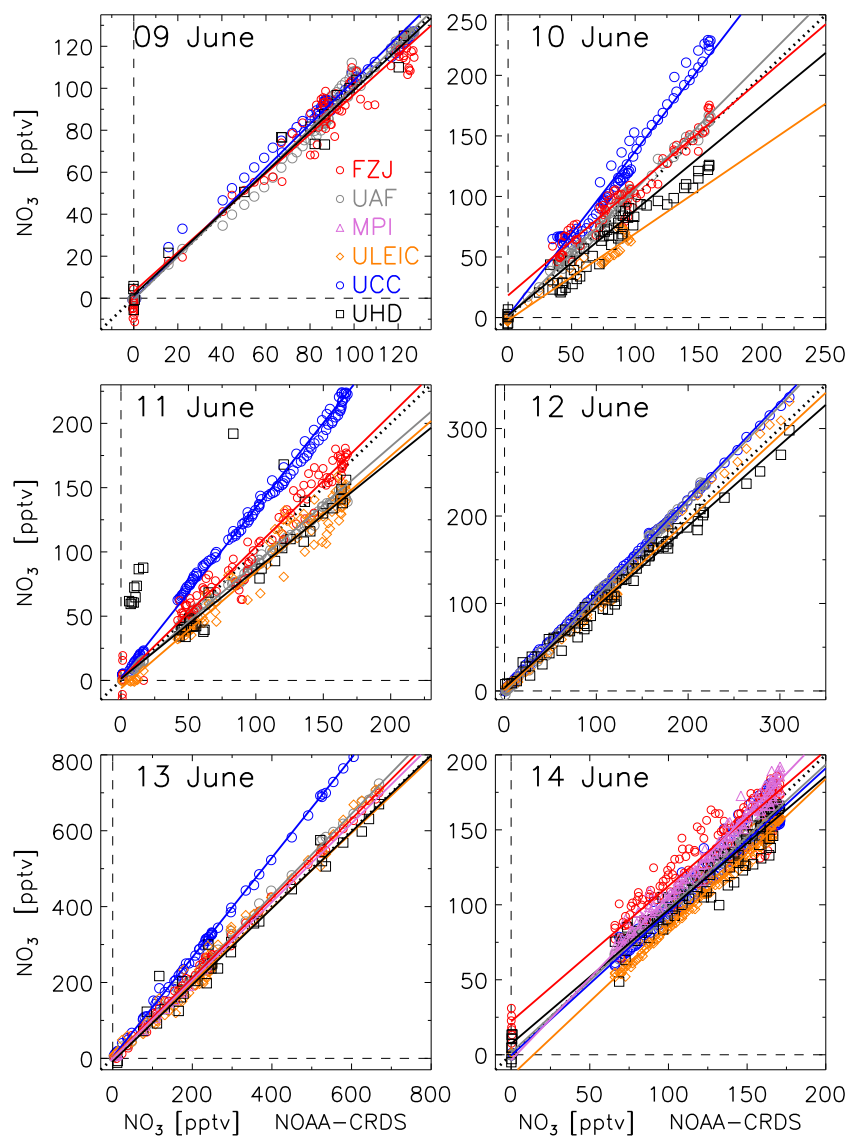

Fig. 7. Correlation and linear regression analysis for individual days of the intercomparison. The data sets were averaged to a common 3 min time grid. Linear regression lines calculated with the "fitexy" algorithm are shown colour coded for the particular instruments. The dotted black line is the ideal $1: 1$ line. Error bars were omitted for clarity.

of UCC-IBBCEAS slightly exceed these limits for reasons already stated.

9, 10 and 11 June: the experiments on 9 and 10 June will be discussed in detail in Sects. 4.2 and 4.3. On 11 June data correlated very well during the measurements in ambient air $\left(r^{2}>0.963\right)$. The UAF-CRDS data are very well linearly correlated with NOAA-CRDS $(q=0.85)$. The apparent linear correlation of UHD-CEDOAS was caused by the very large errors of the instrument on 11 June (see Sect. 3.2 and green symbols in Fig. 6).

12 and 13 June: $\mathrm{NO}_{3}$ was completely photolysed several times during the clean air/photolysis days (12 and 13 June). The large dynamic range of $\approx 700$ pptv allowed for tests of the linearity of the instruments. The measurements correlated extremely well; $r^{2}$ varied between 0.975 and 0.999 . The linear regression analysis revealed very good linearity over the full dynamic range of $\mathrm{NO}_{3}$ mixing ratios on 13 June and insignificant intercepts. 
Table 3. Results of the correlation and linear regression analysis of $\mathrm{NO}_{3}$ measurements from all instruments versus NOAA-CRDS as reference on the basis of 3 min averages. (a) Measurements in the absence of aerosol (cf. Fig. 5), (b) in the presence of aerosol (cf. Fig. 6). $n \ldots$ number of data pairs, $r^{2} \ldots$ Pearson linear correlation coefficient, $\chi^{2} /(n-2) \ldots$ reduced chi-squared. A value of $\approx 1$ indicates that the scatter of the data around the regression line is well covered by the individual $1 \sigma$ measurement errors (precision) of both instruments. When the scatter of the data is larger, "fitexy" fails to calculate the correct regression parameters and their errors. The italic numbers indicate the slope and intercept for an appropriate regression model ("least normal squares", LNS). For details see text in Sect. 3.3.2.

\begin{tabular}{|c|c|c|c|c|c|c|}
\hline & Instrument & $n$ & $r^{2}$ & Intercept/pptv & Slope & $\frac{\chi^{2}}{(n-2)}$ \\
\hline \multirow[t]{12}{*}{ (a) } & \multirow[t]{2}{*}{ FZJ } & \multirow[t]{2}{*}{542} & \multirow[t]{2}{*}{0.978} & $2.9 \pm 0.5$ & $1.05 \pm 0.005$ & \multirow[t]{2}{*}{2.7} \\
\hline & & & & $1.0 \pm 0.5$ & $1.05 \pm 0.006$ & \\
\hline & \multirow[t]{2}{*}{ UAF } & \multirow[t]{2}{*}{654} & \multirow[t]{2}{*}{0.992} & $-0.4 \pm 0.3$ & $1.01 \pm 0.002$ & \multirow[t]{2}{*}{2.2} \\
\hline & & & & $-1.8 \pm 0.4$ & $1.04 \pm 0.006$ & \\
\hline & \multirow[t]{2}{*}{ MPI } & \multirow[t]{2}{*}{154} & \multirow[t]{2}{*}{0.984} & $-2.1 \pm 0.6$ & $1.08 \pm 0.004$ & \multirow[t]{2}{*}{4.1} \\
\hline & & & & $-0.3 \pm, 1.3$ & $1.06 \pm 0.011$ & \\
\hline & \multirow[t]{2}{*}{ ULEIC } & \multirow[t]{2}{*}{250} & \multirow[t]{2}{*}{0.964} & $-3.3 \pm 0.4$ & $0.91 \pm 0.002$ & \multirow[t]{2}{*}{12.6} \\
\hline & & & & $-17.7 \pm 2.5$ & $1.07 \pm 0.021$ & \\
\hline & \multirow[t]{2}{*}{ UCC } & \multirow[t]{2}{*}{698} & \multirow[t]{2}{*}{0.956} & $1.6 \pm 0.3$ & $1.08 \pm 0.002$ & \multirow[t]{2}{*}{53.7} \\
\hline & & & & $-4.2 \pm 0.9$ & $1.18 \pm 0.015$ & \\
\hline & \multirow[t]{2}{*}{ UHD } & \multirow[t]{2}{*}{246} & \multirow[t]{2}{*}{0.955} & $2.5 \pm 0.5$ & $0.93 \pm 0.004$ & \multirow[t]{2}{*}{4.6} \\
\hline & & & & $-4.5 \pm 1.6$ & $0.98 \pm 0.016$ & \\
\hline \multirow[t]{12}{*}{ (b) } & \multirow[t]{2}{*}{ FZJ } & \multirow[t]{2}{*}{855} & \multirow[t]{2}{*}{0.989} & $4.8 \pm 0.3$ & $1.00 \pm 0.002$ & \multirow[t]{2}{*}{3.3} \\
\hline & & & & $5.2 \pm 0.4$ & $1.00 \pm 0.003$ & \\
\hline & \multirow[t]{2}{*}{ UAF } & \multirow[t]{2}{*}{856} & \multirow[t]{2}{*}{0.994} & $-0.5 \pm 0.1$ & $0.87 \pm 0.001$ & 3.7 \\
\hline & & & & $0.6 \pm 0.2$ & $0.85 \pm 0.005$ & \\
\hline & MPI & 242 & 0.991 & $1.1 \pm 0.4$ & $0.94 \pm 0.001$ & 7.5 \\
\hline & & & & $2.3 \pm 0.3$ & $0.93 \pm 0.002$ & \\
\hline & ULEIC & 465 & 0.991 & $1.2 \pm 0.2$ & $0.92 \pm 0.001$ & 46. \\
\hline & & & & $1.0 \pm 0.4$ & $0.94 \pm 0.005$ & \\
\hline & UCC & 879 & 0.996 & $0.9 \pm 0.1$ & $1.23 \pm 0.001$ & 115.5 \\
\hline & & & & $-2.8 \pm 0.3$ & $1.34 \pm 0.005$ & \\
\hline & UHD & 246 & 0.981 & $3.5 \pm 0.5$ & $0.93 \pm 0.003$ & 3.1 \\
\hline & & & & $6.1 \pm 1.3$ & $0.92 \pm 0.005$ & \\
\hline
\end{tabular}

14 June: the correlation and regression results on 14 June are very similar to 13 June. The $\mathrm{NO}_{3}$ data of the butanal oxidation experiment are well correlated $\left(r^{2}\right.$ was between 0.908 and 0.993). Although FZJ-DOAS and ULEIC-BBCRDS data were significantly offset by +22 and -14 pptv, respectively, the slopes of the regression lines (which ranged from 0.89 to 1.09 ) were still within the combined errors of the instrument pairs. For unknown reasons, the UHD-CEDOAS measurements revealed a change in sensitivity at 10:00 UTC (see Fig. 3, open black squares).

15 June: addition of inorganic aerosol (ammonium sulphate) to the chamber air generally caused a larger variability in the $\mathrm{NO}_{3}$ data. On 15 June the scatter plots of UAF-CRDS, UCC-IBBCEAS, and ULEIC-BBCRDS showed a common pattern (see, for example, blue and grey circles in Fig. 8). The first addition of aerosol began at the maximum of the $\mathrm{NO}_{3}$ mixing ratio (10:45 UTC) which then decreased to about $50 \mathrm{pptv}$ when the first particle injection ended (11:25 UTC, cf. Fig. 4). During the injection period the $\mathrm{NO}_{3}$ values of all instruments correlated well with the NOAA-CRDS mixing ratios. The course of the $\mathrm{NO}_{3}$ data pairs can be de- scribed by "trend lines" with a slope specific for each instrument. After the end of the aerosol injection, however, the pattern changed. The mixing ratios measured during the following 10 to $15 \mathrm{~min}$ decreased stronger than expected from the trend observed before. After this "transition period" all following $\mathrm{NO}_{3}$ mixing ratios measured after 11:40 UTC and during the second aerosol injection (12:30-14:55 UTC) are grouped around different "trend lines" with significantly smaller slopes than in the beginning. Obviously the increasing concentration of aerosol led to the recording of larger inlet losses of $\mathrm{NO}_{3}$ for some instruments. The UAF-CRDS instrument measured the lowest $\mathrm{NO}_{3}$ mixing ratios of all instruments on this day. The slope of the linear regression line (comprising the full data set of this day) was 0.86, while the slopes of ULEIC-BBCRDS, UHD-CEDOAS, and FZJ-DOAS showed no large deviation from unity. The FZJDOAS instrument was affected by excessive fluctuations of the light source leading to a moderate correlation $\left(r^{2}=\right.$ 0.707), an offset of $+28 \mathrm{pptv}$, and a slope of 0.92 (Table 4).

16 and 17 June: the experiment on 16 June was the first to include the in situ production of aerosol inside the 
Table 4. Results of the correlation and linear regression analysis of all instruments versus NOAA-CRDS for each experiment. Data are 3 min averages.

\begin{tabular}{|c|c|c|c|c|c|c|c|c|c|c|c|c|c|c|c|}
\hline Date & Inst. & $n$ & $r^{2}$ & Intercept/pptv & Slope & $\frac{\chi^{2}}{(n-2)}$ & $q$ & Date & Inst. & $n$ & $r^{2}$ & Intercept/pptv & Slope & $\frac{\chi^{2}}{(n-2)}$ & $q$ \\
\hline 9 Jun & UCC & 89 & 0.994 & $-0.4 \pm 0.3$ & $1.04 \pm 0.003$ & 3.3 & $\mathrm{a}$ & 15 Jun & UCC & 113 & 0.981 & $-1.1 \pm 0.4$ & $1.17 \pm 0.007$ & 2.1 & $\mathrm{a}$ \\
\hline 9 Jun & UAF & 87 & 0.993 & $-0.5 \pm 0.4$ & $1.01 \pm 0.004$ & 2.4 & a & 15 Jun & UAF & 108 & 0.900 & $-3.0 \pm 0.7$ & $0.86 \pm 0.011$ & 3.9 & a \\
\hline 9 Jun & FZJ & 79 & 0.967 & $3.1 \pm 2.8$ & $0.94 \pm 0.034$ & 0.7 & 0.9809 & 15 Jun & FZJ & 111 & 0.707 & $28.0 \pm 1.7$ & $0.92 \pm 0.028$ & 3.7 & a \\
\hline 9 Jun & UHD & 17 & 0.977 & $1.5 \pm 1.5$ & $0.98 \pm 0.020$ & 3.1 & 0.0001 & 15 Jun & ULEIC & 100 & 0.932 & $-4.2 \pm 0.5$ & $1.05 \pm 0.009$ & 7.7 & a \\
\hline 10 Jun & UCC & 78 & 0.974 & $1.5 \pm 0.7$ & $1.36 \pm 0.007$ & 12.7 & $\mathrm{a}$ & 15 Jun & UHD & 55 & 0.934 & $-7.4 \pm 1.5$ & $1.06 \pm 0.025$ & 2.4 & a \\
\hline $10 \mathrm{Jun}$ & UAF & 92 & 0.994 & $0.4 \pm 0.8$ & $1.05 \pm 0.009$ & 0.8 & 0.9044 & $16 \mathrm{Jun}$ & UCC & 275 & 0.959 & $1.4 \pm 0.0$ & $1.17 \pm 0.002$ & 253.8 & a \\
\hline $10 \mathrm{Jun}$ & FZJ & 73 & 0.930 & $18.2 \pm 1.5$ & $0.90 \pm 0.016$ & 4.1 & a & 16 Jun & UAF & 265 & 0.965 & $-1.1 \pm 0.1$ & $0.91 \pm 0.007$ & 2.1 & a \\
\hline 10 Jun & ULEIC & 29 & 0.937 & $-2.3 \pm 0.6$ & $0.72 \pm 0.008$ & 9.5 & a & 16 Jun & FZJ & 280 & 0.750 & $3.6 \pm 0.5$ & $1.02 \pm 0.029$ & 1.4 & a \\
\hline 10 Jun & UHD & 57 & 0.953 & $1.9 \pm 1.4$ & $0.87 \pm 0.014$ & 1.7 & 0.0009 & 16 Jun & ULEIC & 76 & 0.660 & $0.4 \pm 0.1$ & $0.73 \pm 0.006$ & 72.1 & a \\
\hline 11 Jun & UCC & 124 & 0.996 & $2.3 \pm 0.5$ & $1.32 \pm 0.004$ & 7.9 & $\mathrm{a}$ & 16 Jun & UHD & 69 & 0.590 & $5.0 \pm 0.4$ & $1.02 \pm 0.036$ & 5.2 & a \\
\hline 11 Jun & UAF & 121 & 0.997 & $0.3 \pm 0.6$ & $0.91 \pm 0.005$ & 0.9 & 0.8531 & 16 Jun & MPI & 51 & 0.945 & $-2.8 \pm 0.3$ & $1.03 \pm 0.015$ & 5.2 & a \\
\hline 11 Jun & FZJ & 98 & 0.966 & $1.2 \pm 1.1$ & $1.03 \pm 0.010$ & 3.9 & a & 17 Jun & $\mathrm{UCC}$ & 329 & 0.993 & $1.2 \pm 0.0$ & $1.12 \pm 0.001$ & 15.7 & a \\
\hline 11 Jun & ULEIC & 81 & 0.963 & $-6.2 \pm 0.6$ & $0.90 \pm 0.005$ & 8.9 & a & 17 Jun & UAF & 172 & 0.995 & $-1.2 \pm 0.1$ & $1.12 \pm 0.008$ & 0.5 & 1.0000 \\
\hline 11 Jun & UHD & 38 & 0.540 & $1.3 \pm 14.8$ & $0.85 \pm 0.158$ & 0.1 & 1.0000 & 17 Jun & FZJ & 326 & 0.796 & $-0.7 \pm 0.7$ & $1.14 \pm 0.028$ & 1.5 & $\mathrm{a}$ \\
\hline 12 Jun & UCC & 131 & 0.999 & $-0.8 \pm 0.5$ & $1.10 \pm 0.002$ & 1.1 & 0.1566 & 18 Jun & UCC & 284 & 0.999 & $1.8 \pm 0.1$ & $1.06 \pm 0.003$ & 9.3 & $\mathrm{a}$ \\
\hline 12 Jun & UAF & 107 & 0.998 & $-2.3 \pm 1.1$ & $1.09 \pm 0.009$ & 0.3 & 1.0000 & 18 Jun & UAF & 275 & 0.998 & $-0.9 \pm 0.1$ & $0.95 \pm 0.006$ & 0.3 & 1.0000 \\
\hline 12 Jun & ULEIC & 44 & 0.994 & $0.7 \pm 0.8$ & $0.97 \pm 0.006$ & 5.5 & $\mathrm{a}$ & 18 Jun & FZJ & 284 & 0.925 & $1.9 \pm 0.5$ & $0.98 \pm 0.015$ & 1.1 & 0.0571 \\
\hline 12 Jun & UHD & 65 & 0.986 & $3.8 \pm 0.9$ & $0.92 \pm 0.006$ & 4.8 & a & 18 Jun & ULEIC & 88 & 0.997 & $1.8 \pm 0.2$ & $1.02 \pm 0.006$ & 39.4 & $\mathrm{a}$ \\
\hline 13 Jun & UCC & 65 & 0.999 & $3.6 \pm 1.5$ & $1.31 \pm 0.004$ & 0.2 & 1.0000 & 20 Jun & UCC & 127 & 0.991 & $1.7 \pm 0.7$ & $1.32 \pm 0.002$ & 26.5 & a \\
\hline 13 Jun & UAF & 63 & 0.998 & $-1.2 \pm 2.0$ & $1.08 \pm 0.006$ & 0.6 & 0.9979 & 20 Jun & UAF & 120 & 0.983 & $5.4 \pm 0.9$ & $0.84 \pm 0.003$ & 9.9 & a \\
\hline 13 Jun & FZJ & 65 & 0.997 & $2.5 \pm 1.8$ & $1.05 \pm 0.006$ & 1.4 & 0.0178 & 20 Jun & FZJ & 127 & 0.994 & $1.0 \pm 1.3$ & $1.01 \pm 0.004$ & 1.8 & a \\
\hline 13 Jun & ULEIC & 62 & 0.987 & $2.7 \pm 1.7$ & $0.99 \pm 0.005$ & 7.4 & a & 20 Jun & ULEIC & 107 & 0.982 & $6.1 \pm 0.5$ & $0.91 \pm 0.001$ & 24.9 & $\mathrm{a}$ \\
\hline 13 Jun & UHD & 30 & 0.975 & $-7.7 \pm 3.6$ & $1.01 \pm 0.011$ & 6.2 & a & 20 Jun & UHD & 66 & 0.994 & $4.6 \pm 1.8$ & $0.93 \pm 0.006$ & 1.6 & 0.0009 \\
\hline 13 Jun & MPI & 16 & 0.998 & $-0.8 \pm 1.6$ & $1.03 \pm 0.011$ & 0.2 & 0.9995 & 20 Jun & MPI & 107 & 0.974 & $3.0 \pm 0.6$ & $0.93 \pm 0.001$ & 3.3 & $\mathrm{a}$ \\
\hline 14 Jun & UCC & 157 & 0.967 & $-0.5 \pm 0.2$ & $0.96 \pm 0.001$ & 17.3 & $\mathrm{a}$ & 21 Jun & UCC & 92 & 0.998 & $0.1 \pm 0.1$ & $1.13 \pm 0.002$ & 7.6 & $\mathrm{a}$ \\
\hline 14 Jun & UAF & 145 & 0.993 & $1.4 \pm 0.7$ & $0.96 \pm 0.005$ & 1.0 & 0.6123 & $21 \mathrm{Jun}$ & UAF & 87 & 0.991 & $2.7 \pm 0.5$ & $0.86 \pm 0.010$ & 0.8 & 0.8849 \\
\hline 14 Jun & FZJ & 150 & 0.908 & $22.2 \pm 1.5$ & $0.90 \pm 0.012$ & 2.9 & $\mathrm{a}$ & 21 Jun & FZJ & 91 & 0.966 & $-1.1 \pm 1.0$ & $1.00 \pm 0.018$ & 1.2 & 0.1528 \\
\hline 14 Jun & ULEIC & 128 & 0.987 & $-14.1 \pm 0.7$ & $0.99 \pm 0.005$ & 2.1 & a & 21 Jun & ULEIC & 30 & 0.988 & $-0.8 \pm 0.5$ & $1.19 \pm 0.013$ & 4.2 & $\mathrm{a}$ \\
\hline 14 Jun & UHD & 85 & 0.954 & $7.3 \pm 1.1$ & $0.89 \pm 0.009$ & 5.1 & a & 21 Jun & UHD & 30 & 0.914 & $-2.8 \pm 1.7$ & $1.15 \pm 0.035$ & 1.7 & 0.0131 \\
\hline 14 Jun & MPI & 138 & 0.979 & $-3.5 \pm 0.8$ & $1.09 \pm 0.006$ & 4.4 & a & 21 Jun & MPI & 91 & 0.991 & $1.6 \pm 0.2$ & $0.97 \pm 0.003$ & 5.0 & $a$ \\
\hline
\end{tabular}

$q$ : quality parameter - see text. ${ }^{\mathrm{a}} q<10^{-4}$

SAPHIR chamber, in this case secondary organic aerosol (SOA) formed by $\mathrm{NO}_{3}$ oxidation of limonene (Fry et al., 2011). This experiment resulted in similar observations as made in the inorganic aerosol study on 15 June. During the first oxidation step, at low aerosol concentrations, the data could be described by a line with a different slope than the $\mathrm{NO}_{3}$ mixing ratios measured after the second injection of limonene (see UCC-IBBCEAS (blue circles) and UAF-CRDS (grey circles) in Fig. 8). The data are still highly correlated $\left(r^{2}=0.959\right.$ and 0.965 , respectively) and the slopes of the regression lines (1.17 and 0.91 , respectively) are within the combined uncertainties of the instruments. FZJ-DOAS and UHD-CEDOAS correlate moderately $\left(r^{2}=0.75\right.$ and 0.59 , slopes $=1.02$ and 1.02 , respectively $)$ due to the low signal-to-noise ratio (relatively small $\mathrm{NO}_{3}$ mixing ratios were produced by this experiment). ULEICBBCRDS and MPI-CRDS stopped measurements already shortly before and after the second limonene injection. Owing to the lack of data from these instruments for high aerosol load the comparison is not particularly meaningful. NOAA-CRDS, UCC-IBBCEAS and FZJ-DOAS continued to record data overnight until 17 June, 19:00 UTC. UAFCRDS commenced measurements again at 08:00 UTC with a new aerosol filter. For the instruments that were recording on 17 June, the $\mathrm{NO}_{3}$ mixing ratios correlated very well with
NOAA-CRDS, slopes were all $\geq 1.1$ and intercepts were negligible $(<1.2 \mathrm{pptv})$.

18 June: this experiment divides into two phases. As shown in Fig. 4, the $\mathrm{NO}_{3}$ mixing ratio was smaller than 3 pptv in the morning and less than 12 pptv in the afternoon due reaction with isoprene. Only during a two-hour period, after the addition of extra $\mathrm{NO}_{2}$ and $\mathrm{O}_{3}$ at 14:25 UTC, the $\mathrm{NO}_{3}$ mixing ratio increased to $150 \mathrm{pptv}$. The comparison of the UAF-CRDS, UCC-IBBCEAS, and ULEICBBCRDS instruments with NOAA-CRDS showed coefficients of correlation close to unity during the interval of high $\mathrm{NO}_{3}$. A slope of $0.95\left(r^{2}=0.998\right), 1.06\left(r^{2}=0.999\right)$, and $1.02\left(r^{2}=0.997\right)$ were determined, respectively. The scatter plot of the time intervals of very low $\mathrm{NO}_{3}$ mixing ratios (08:00-14:00 UTC and 16:30-23:50 UTC) is shown in the inset in Fig. 8. A regression analysis was successfully performed for UCC-IBBCEAS and UAF-CRDS and revealed $r^{2}=0.948$, slope $=1.007$, offset $=2.1 \mathrm{pptv}$ and $r^{2}=0.934$, slope $=0.974$, offset $=-1.0 \mathrm{pptv}$, respectively. FZJ-DOAS and ULEIC-BBCRDS allowed no meaningful analysis for this time period because the $\mathrm{NO}_{3}$ mixing ratios were below or close to the detection limit. ULEIC-BBCRDS measured only in the morning when $\mathrm{NO}_{3}$ merely varied within $\pm 2 \mathrm{pptv}$, so the regression line is not well defined.

20 and 21 June: the first oxidation experiment of $\beta$-pinene with $\mathrm{NO}_{3}$ was performed in dry air on 20 June. After the 

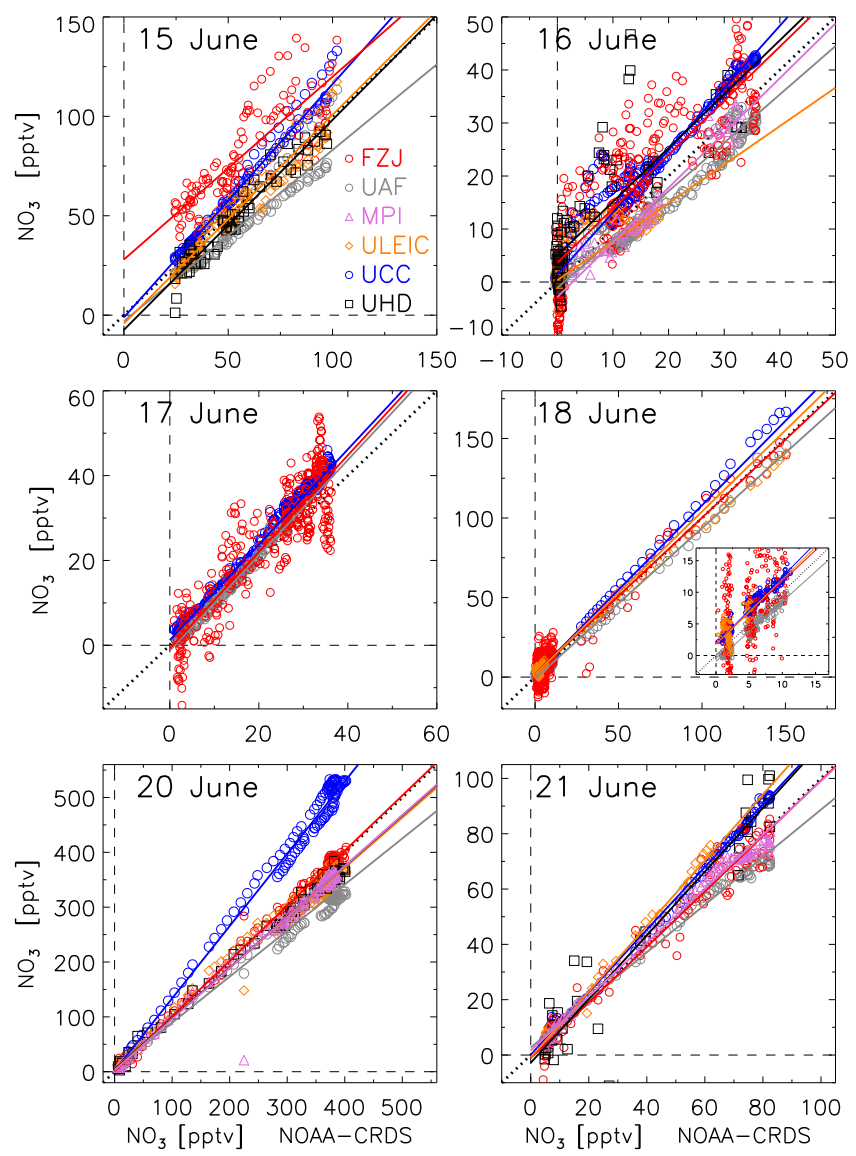

Fig. 8. Continued from Fig. 7. Inset on 18 June: $\mathrm{NO}_{3}$ mixing ratios in the presence of isoprene (08:00-14:00 UTC $\left(\mathrm{NO}_{3}<3\right.$ pptv) and 16:10-24:00 UTC $\left.\left(\mathrm{NO}_{3}<12 \mathrm{pptv}\right)\right)$.

$\beta$-pinene injection (09:10 UTC) very rapid formation of SOA was observed (cf. Fig. 4). The excellent precision of the CRDS and CEAS instruments allowed us to visualise an increasing systematic difference in the $\mathrm{NO}_{3}$ mixing ratios relative to the reference technique. The resulting "u-shaped" scatter plots are presented individually for each instrument by the blue circles in Fig. 6 and compared to each other in the corresponding panel of Fig. 8. This observation is very similar to the experiments on 15 and 16 June described above. The data sets were nevertheless very well $\left(r^{2}=0.974 \ldots 0.994\right)$ correlated with the reference instrument and the slopes of regression close to unity (FZJ-DOAS) or slightly lower $(1.01 \ldots 0.84)$ except for UCC-IBBCEAS (see Sect. 3.2). Details are analysed in Sect. 4.4.2.

On 21 June, the previous experiment was repeated at high relative humidity. The correlation and regression results were fairly similar to 20 June. Coefficients of determination $\left(r^{2}\right)$ were close to unity, the intercepts were negligible, and the slopes of FZJ-DOAS, MPI-CRDS, and UAF-CRDS were nearly identical for both days. The UHD-CEDOAS and ULEIC-BBCRDS instruments both slightly overestimated the $\mathrm{NO}_{3}$ mixing ratio (slopes 1.15 and 1.19 , respectively). Again data of FZJ-DOAS correlated linearly with the NOAA reference instrument $\left(r^{2}=0.966\right.$, slope $\left.=1.0, q=0.15\right)$ as well as the data of UAF-CRDS $\left(r^{2}=0.991, q=0.86\right)$. However, the $\mathrm{NO}_{3}$ mixing ratios measured by UAF-CRDS were the lowest ones of all instruments on both SOA days (slopes were 0.84 on 20 June, and 0.86 on 21 June).

Unfortunately the measurements stopped before the maximum $\mathrm{NO}_{3}$ mixing ratio was reached. However, the comparison of the $\mathrm{NO}_{3}$ mixing ratios above $70 \mathrm{pptv}$ with the linear regression lines of the MPI-CRDS and UAF-CRDS instruments (violet diamonds and grey circles in the last panel of Fig. 8) clearly showed significantly smaller mixing ratios as would be expected from the regression (see also Sect. 4.4.2). This observation resembled the findings of the previous day. The UHD-CEDOAS instruments measured only few $\mathrm{NO}_{3}$ data points on 21 June because of instrumental tests. ULEICBBCRDS stopped measurements on 13:30 UTC, resulting in an also limited data set during the time when the chamber was loaded with aerosol.

\section{Discussion}

\subsection{Uncertainty of the inlet transmission efficiency of the NOAA-CRDS instrument}

The transmission efficiency of NOAA-CRDS determined during NO3Comp was $10 \%$ lower than measured in a postcampaign lab study. However, only few calibrations were made during the campaign due to technical difficulties with the calibration source used at the chamber (see Sect. 2.1.1); thus an additional $10 \%$ uncertainty was added by the authors to account for the calibration problems during NO3Comp, resulting in a final accuracy of $+0.17 /-0.05$.

The large data set of the day-to-day correlations of the instruments relative to NOAA-CRDS allows us to apply a statistical test to determine the most likely calibration accuracy of the instrument. The slopes of the linear regressions for clean air and aerosol-containing air are close to unity. A chi-square statistic to the $95 \%$ confidence level (NIST/SEMATECH, 20 May 2012) was used to test the null hypothesis that the true standard deviation of the slopes is less than the specified value of 0.17 . From the table of the critical values of the chi-square distribution, the value of $\chi_{0.95}^{2}=36.42$ had to be compared to the observed value of $\chi_{\exp }^{2}=14.25$, and consequently the hypothesis has to be accepted. Equality of both $\chi^{2}$ values was obtained for a "true" standard deviation of 0.11 . Hence, the analysis indicates that the conservatively estimated upper limit of the accuracy of the NOAA-CRDS instrument (0.17) is very likely overestimated by $35 \%$. 

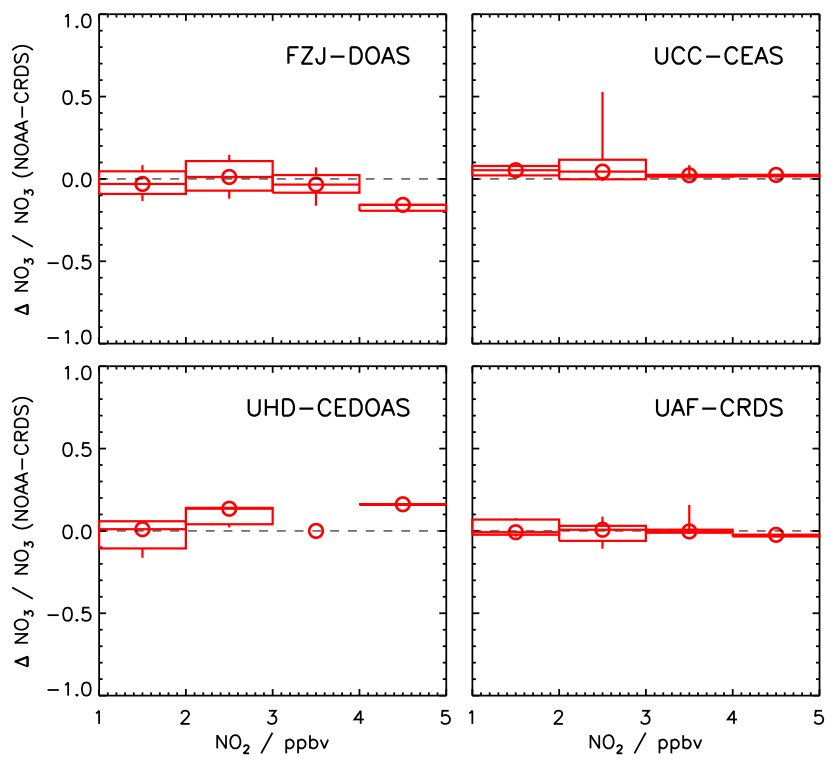

Fig. 9. Box-and-whisker plot of the relative difference of $\mathrm{NO}_{3}$ measurements between various instruments and the reference NOAACRDS as function of the $\mathrm{NO}_{2}$ mixing ratio during the chamber experiment on 9 June. Dots are medians, boxes give the first and third quartile and whiskers denote the 10th and 90th percentiles.

\subsection{Cross sensitivity to $\mathrm{NO}_{2}$ - experiment on 9 June}

Generally, the potential interference of $\mathrm{NO}_{2}$ on the detection of $\mathrm{NO}_{3}$ is expected to be minor. The optical absorption coefficient of $\mathrm{NO}_{2}$ in the spectral range of the $\mathrm{NO}_{3}$ absorption band is small $\left(1.27 \times 10^{-4} \times \sigma\left(\mathrm{NO}_{3}\right)\right)$. Hence, the resulting interference signal from $\mathrm{NO}_{2}$ ought to be of minor relevance, unless the $\mathrm{NO}_{2}$ mixing ratio greatly exceeds that of $\mathrm{NO}_{3}$. Figure 9 compares the observed differences in $\mathrm{NO}_{3}$ measurements relative to NOAA-CRDS as a function of $\mathrm{NO}_{2}$ mixing ratios. $\mathrm{NO}_{3}$ values below 5 pptv were excluded from this and all following investigations. Circles denote the median, boxes stand for 25 and $75 \%$ percentiles, and vertical lines are the 10th and 90th percentiles of the distribution in the particular interval. A trend could not be identified for any of the data sets. Regression slopes listed in Table 4 are close to unity $(0.94 \ldots 1.04)$ and intercepts are negligible. MPI-CRDS and ULEIC-BBCRDS did not measure on 9 June.

\subsection{Cross sensitivity to $\mathrm{H}_{2} \mathrm{O}$ - experiment on 10 June}

All instruments made use of the strong $\mathrm{NO}_{3} B \leftarrow X$ absorption transition centred at $662 \mathrm{~nm}$, which partly overlaps with the spectrally much sharper overtone bands of $\mathrm{H}_{2} \mathrm{O}$ within the $4 v+\delta$ polyad centred at $652 \mathrm{~nm}$. The impact of the water absorption on the retrieval of $\mathrm{NO}_{3}$ mixing ratios was therefore investigated in a clean-air experiment on 10 June. $\mathrm{NO}_{3}$ was formed in the flushed dry chamber (water mixing ratio $<100 \mathrm{ppmv}$ ) and the water mixing ratio was increased in several steps to $1.1 \%$ (Fig. 3). For instruments using the cav-
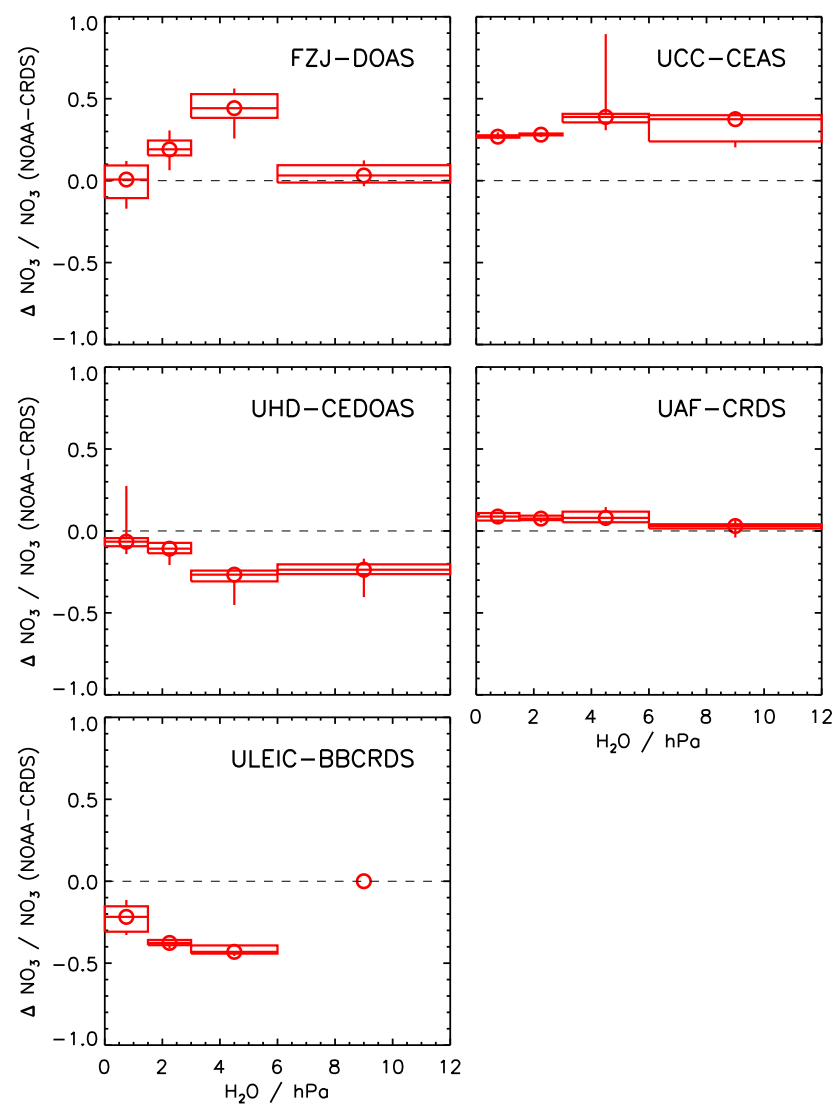

Fig. 10. Box-and-whisker plot of the relative difference of $\mathrm{NO}_{3}$ measurements between various instruments and the reference NOAA-CRDS as function of the $\mathrm{H}_{2} \mathrm{O}$ partial pressure during the chamber experiment on 10 June. Dots are medians, boxes give the first and third quartile and whiskers denote the 10th and 90th percentiles.

ity ring-down principle the effect of water vapour absorption on the detection of $\mathrm{NO}_{3}$ radicals is small, because the contribution of the water vapour absorption is subtracted from the signal by the selective removal of $\mathrm{NO}_{3}$ in the sample by titration with NO (cf. Eq. 1). The precondition is, however, that the time interval between zero ring-down measurements is smaller than the time it takes for significant changes of water vapour concentration to occur in the sample, which was the case for NO3Comp. Broadband CEAS and CRDS instruments as well as DOAS are potentially more severely affected by water vapour absorption (Aliwell and Jones, 1996; Platt and Stutz, 2008). Usually the spectral resolution of the instruments used for the measurement of atmospheric $\mathrm{NO}_{3}$ is not sufficiently high to fully resolve the narrow atmospheric absorption lines of water vapour. This can give rise to apparent non-linearity between the optical density measured and the real atmospheric water concentration if not corrected for by appropriate means (see, for instance, Ball and Jones, 2003; Bitter et al., 2005). 
In Fig. 10 the relative differences between the instruments and NOAA-CRDS are plotted in intervals of the water vapour partial pressure in the chamber. Only the UHD-CEDOAS instrument was affected by higher water vapour mixing ratios. As can be seen in Fig. 3 (black squares) UHD-CEDOAS and NOAA-CRDS data agreed as long as the chamber air was dry. With the addition of water vapour an increasing difference between the UHD-CEDOAS data and NOAA-CRDS is observed which levels off at higher partial pressures of water. Simultaneously the size of the error bars (not shown) increased from 10 pptv in dry air to some 30 pptv at the final partial pressure of water, which indicates a notable influence of water vapour, at least for this experiment. The deviation of the UHD-CEDOAS instrument can be explained partly by non-linear saturation effects of some water vapour absorption lines which were not treated properly in the retrieval process and partly by insufficient temperature stabilisation of the LED on this day.

FZJ-DOAS, UCC-IBBCEAS, and UAF-CRDS showed no dependency on water vapour. The observed scatter of the FZJ-DOAS ratio in Fig. 10 is attributable to instabilities of the Xe arc lamps causing "jumps" of the DOAS data relative to the very precise NOAA-CRDS instrument. The offset in the UCC-IBBCEAS data resulted from the missing update of the zero air reference spectrum as discussed in Sect. 3.2. The apparent increase of the relative difference of the ULEICBBCRDS instrument shown in Fig. 10 is not due to a cross interference by water vapour, but to inhomogeneities in the sample flow (see Sect. 3.2). We want to point out that the $\mathrm{NO}_{2}$ and water vapour tests were done early in the campaign, so not all the instruments were yet performing optimally.

\subsection{Cross sensitivity to aerosol}

The comparison of $\mathrm{N}_{2} \mathrm{O}_{5}$ measurements during NO3Comp by Fuchs et al. (2012) showed that the inlet transmission efficiency for $\mathrm{N}_{2} \mathrm{O}_{5}$ of some instruments can degrade in the presence of aerosol on which $\mathrm{N}_{2} \mathrm{O}_{5}$ is taken up. The same observations were described above for $\mathrm{NO}_{3}$. The aerosol experiments during NO3Comp were divided into three groups: ambient aerosol on 11 June, inorganic (ammonium sulphate, $\left.\left(\mathrm{NH}_{4}\right)_{2} \mathrm{SO}_{4}\right)$ aerosol on 15 and 18 June, and secondary organic aerosol (SOA) on 16, 20, and 21 June. The potential cross sensitivity to aerosol particles was assessed by investigating the changes of the differences of $\mathrm{NO}_{3}$ mixing ratios measured by the instruments relative to NOAA-CRDS as a function of the aerosol surface concentration. We expected the NOAA-CRDS instrument to be the least affected by wall/inlet losses because of the frequent automatic changing of the inlet filter (versus filter change only once per day for other instruments), and because of the low operating pressure and fast flow rate and therefore minimum residence time of the air inside the instrument. For three experiments the analysis did not lead to statistically significant results.
11 June: on this day ambient air was pumped into the chamber using a filter on the chamber's inlet that removed only coarse-mode particles. The peak aerosol surface concentration, $S$, in the chamber was very low $\left(S_{\max }=1.3 \times 10^{7} \mathrm{~nm}^{2} \mathrm{~cm}^{-3}\right)$ and the dynamic range was fairly small $\left(S_{\min }=0.3 \times 10^{7} \mathrm{~nm}^{2} \mathrm{~cm}^{-3}\right)$. For comparison, during the inorganic aerosol experiment on 15 June $S$ was a factor of 30 larger. An analysis of the relative differences of $\mathrm{NO}_{3}$ mixing ratios as a function of the aerosol surface concentration showed no discernible dependency of the $\mathrm{NO}_{3}$ measurements for any instrument.

16 June: the correlation and regression analysis of the limonene oxidation experiment on 16 June already identified (varying) losses of $\mathrm{NO}_{3}$ inside different instruments and their inlets due to SOA. A corresponding box-and-whisker plot, however, gave no conclusive results because of the small dynamic range of the aerosol surface concentration and the limited SMPS data set.

18 June: a similar result to that on 11 June was obtained for the isoprene/ammonium sulphate seed aerosol experiment on 18 June. During the short time period of high $\mathrm{NO}_{3}$ mixing ratios, the aerosol surface concentration was relatively low (only about twice the level of the ambient air day) and changed only marginally $\left(0.3-0.4 \times 10^{8} \mathrm{~nm}^{2} \mathrm{~cm}^{-3}\right)$. Also the regression analysis did not show any evidence of a significant effect of aerosol.

\subsubsection{Ammonium sulphate aerosol experiment}

On 15 June ammonium sulphate aerosol was added twice to the chamber. The data analysis is presented as a boxand-whisker plot in Fig. 11. $\mathrm{NO}_{3}$ mixing ratios from FZJDOAS were offset relative to NOAA-CRDS by $+28 \mathrm{pptv}$ and highly variable, so no trend in FZJ-NOAA difference with aerosol surface area could be quantified. Also for UCCIBBCEAS and ULEIC-BBCRDS (reduced performance due to variable ingress of ambient air) no clear influence of the increasing aerosol concentration on the detection of $\mathrm{NO}_{3}$ could be inferred. UHD-CEDOAS showed a slight tendency to an increasing $\mathrm{NO}_{3}$ deficit at the highest aerosol concentrations, but a clear trend could not be identified. The most pronounced $\mathrm{NO}_{3}$ loss was found in the UAF-CRDS instrument. This instrument used one single filter per day. $\mathrm{NO}_{3}$ losses increased with increasing aerosol load on the filter. The loss of $\mathrm{NO}_{3}$ is illustrated in the box-and-whisker plots in Fig. 11 and in the regression plot of Fig. 8 (grey circles, slope 0.86). Fuchs et al. (2012) reported similar observations for the measurements of $\mathrm{N}_{2} \mathrm{O}_{5}$ in the presence of ammonium sulphate aerosol during NO3Comp. They showed that $\mathrm{N}_{2} \mathrm{O}_{5}$ mixing ratios recorded by UAF-CRDS were generally much smaller than those by NOAA-CRDS and concluded that an unaccounted-for $\mathrm{NO}_{3}$ loss in the inlet of the UAF-CRDS instrument might have been the reason. This hypothesis is consistent with the $\mathrm{NO}_{3}$ measurements. 

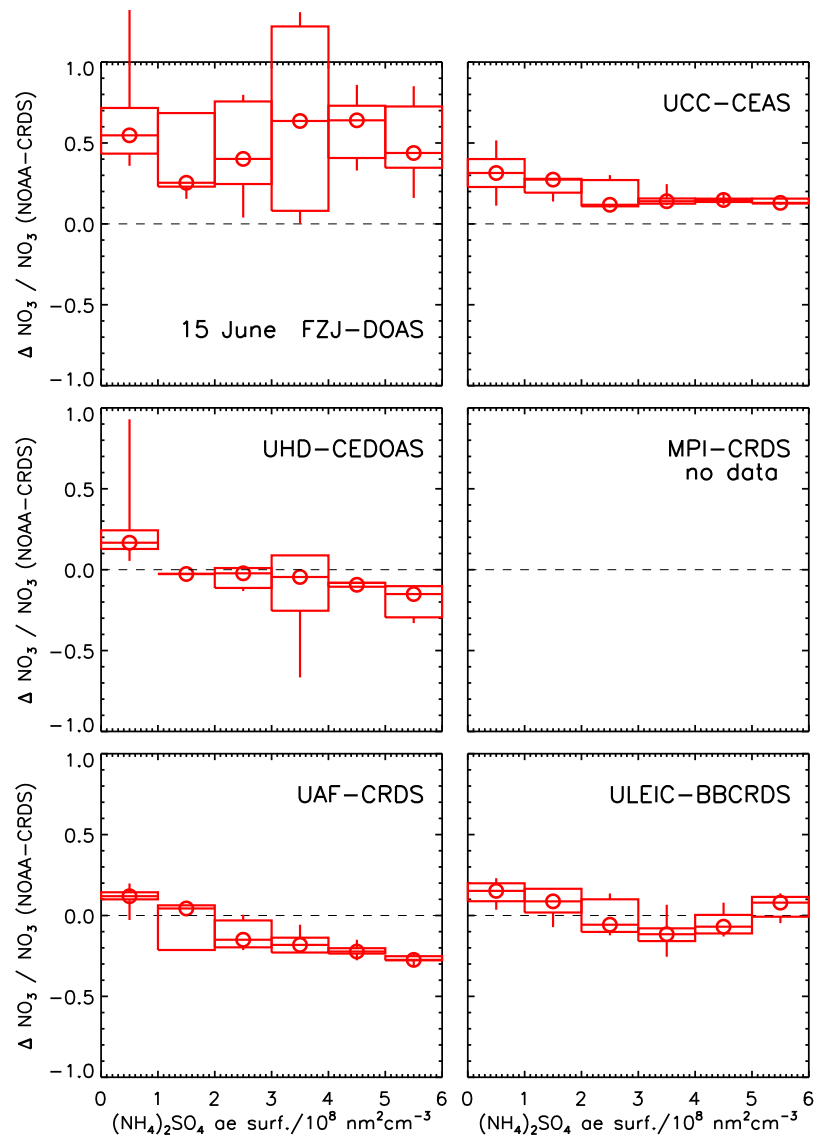

Fig. 11. Box-and-whisker plot of the relative difference of $\mathrm{NO}_{3}$ measurements between various instruments and the reference NOAA-CRDS as function of the surface of ammonium sulphate aerosol during the "inorganic aerosol" experiment on 15 June. Dots are medians, boxes give the first and third quartile and whiskers denote the 10th and 90th percentiles.

\subsubsection{Secondary organic aerosol experiments}

As shown in Sect. 3.3.3 several instruments clearly detected lower $\mathrm{NO}_{3}$ mixing ratios than the NOAA-CRDS instrument after secondary organic aerosol was formed in the reaction of $\beta$-pinene with $\mathrm{NO}_{3}$ in dry air on 20 June (cf. Figs. 8 and 6 - blue circles). The box-and-whisker plots in Fig. 12 present the difference of $\mathrm{NO}_{3}$ mixing ratios relative to NOAA-CRDS as a function of the measured dry SOA surface concentration. Note that in contrast to the experiment on 15 June the aerosol concentration was highest in the beginning of the experiment and decreased towards the end, so that the integrated "aerosol exposure" increases from right to left in Fig. 12. As discussed in Sect. 3.3.3 the DOAS-based techniques FZJ-DOAS and UHD-CEDOAS were mostly unaffected by aerosol. For the remaining instruments (using no or just a single filter per day) a clear trend to lower $\mathrm{NO}_{3}$ mixing ratios relative to NOAA was evident, which is consistent with the hypothesis that $\mathrm{NO}_{3}$ is partially removed from sample air as it is drawn

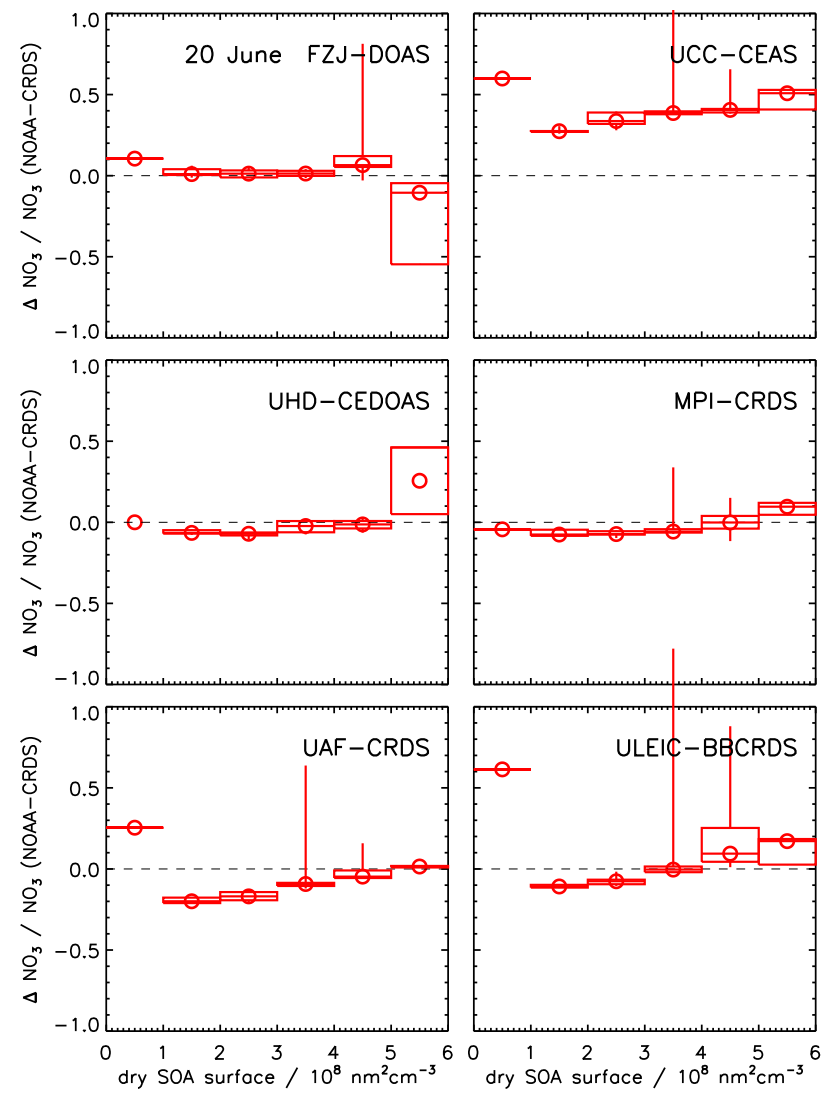

Fig. 12. Box-and-whisker plot of the relative difference of $\mathrm{NO}_{3}$ measurements between various instruments and the reference NOAA-CRDS as function of the surface of dry secondary organic aerosol (SOA) during the " $\beta$-pinene oxidation" experiment on 20 June. Dots are medians, boxes give the first and third quartile and whiskers denote the 10th and 90th percentiles.

through the inlet and filters which are covered with reactive organic aerosol. Fry et al. (2009) investigated the chemistry and the SOA yield for this chamber experiment using a gasphase kinetics/aerosol partitioning model. They found an unexplained high yield of $6 \mathrm{ppbv}$ of $\mathrm{HNO}_{3}$ at the end of the dry $\beta$-pinene experiment which they attributed to heterogeneous reaction of $\mathrm{NO}_{3}$ on organic aerosol surfaces, abstracting $\mathrm{H}$ from an alkane. This type of reaction could also be responsible for the partial loss of $\mathrm{NO}_{3}$ in the inlet systems of the instruments. In this context we note that Tang et al. (2010) have shown that filter losses of $\mathrm{NO}_{3}$ and $\mathrm{N}_{2} \mathrm{O}_{5}$ can be very variable, with contamination by ambient-aerosol-containing organic compounds strongly favouring $\mathrm{NO}_{3}$ loss.

A corresponding box-and-whisker analysis could not be performed for the experiment on 21 June which repeated the measurements of the previous day at high relative humidity. Shortly after the maximum aerosol surface concentration was reached, a technical issue caused the SMPS to stop measuring, leaving too few data per bin for a convincing analysis. Fry et al. (2009) showed that both experiments 
did not significantly differ in terms of reaction mechanism and aerosol yields. However, due to the five-fold higher wall losses of $\mathrm{NO}_{3}$ (and $\mathrm{N}_{2} \mathrm{O}_{5}$ ) at $60 \% \mathrm{RH}$ (Fry et al., 2009) but comparable $\mathrm{NO}_{3}$ production rates for both experiments, the $\mathrm{NO}_{3}$ (and $\mathrm{N}_{2} \mathrm{O}_{5}$ ) mixing ratios were significantly lower on 21 June. Consequently the maximum of the aerosol surface concentration was reached about 45 min later than the dry experiment, and also the formation of $\mathrm{HNO}_{3}$ was limited to only 2.5 ppbv. However, the temporal profiles of the $\mathrm{NO}_{3}$ mixing ratios on both days were very similar, showing increasing differences of $\mathrm{NO}_{3}$ between the instruments towards the end of the measurements (Sect. 3.3.3 and Fig. 4).

So far, it is not understood why the UCC-IBBCEAS instrument, which detected $\mathrm{NO}_{3}$ in situ in the chamber, showed behaviour on 20 June identical to that of the instruments using inlet lines and aerosol filters. Contrary to UCCIBBCEAS, both other in situ techniques, FZJ-DOAS and UHD-CEDOAS, were unaffected by aerosol as can be seen in the corresponding panels in Fig. 6 (blue circles). Their $\mathrm{NO}_{3}$ data scatter uniformly around the regression lines. It is unlikely that the observed effects resulted from a feature of the NOAA-CRDS reference instrument. Filters were exchanged frequently at short time intervals during the aerosol experiments. The fact that the temporal profiles of the $\mathrm{NO}_{3}$ mixing ratios did not show any discontinuities between filter changes was convincingly verified. This is in contrast to the MPI-CRDS instrument which changed the filter rarely and therefore is more vulnerable to losses of $\mathrm{NO}_{3}$. An example of $\mathrm{NO}_{3}$ losses on the surface of a filter is shown in the temporal profile of the $\mathrm{NO}_{3}$ mixing ratios on 20 June (solid violet diamonds in Fig. 4). At 13:30 UTC, close to the maximum of the $\mathrm{NO}_{3}$ mixing ratio, the aerosol filter of the MPI-CRDS instrument was exchanged. After restarting the measurements the difference in the $\mathrm{NO}_{3}$ mixing ratio relative to NOAA-CRDS was considerably smaller than before the filter change.

\section{Summary and conclusions}

Instruments developed for the detection of tropospheric $\mathrm{NO}_{3}$ radicals were compared during the "NO3Comp" campaign. Simultaneous measurements of $\mathrm{NO}_{3}$ radical mixing ratios were conducted by seven instruments under well controlled experimental conditions at the atmosphere simulation chamber SAPHIR in Jülich. All $\mathrm{NO}_{3}$ instruments assembled at the chamber were based on absorption spectroscopy. Four instruments made use of the principle of cavity ring-down spectroscopy, two utilised cavity-enhanced absorption spectroscopy, and one applied "classical" differential optical absorption spectroscopy. The latter three instruments detected $\mathrm{NO}_{3}$ in situ in open-path configuration inside the chamber, while the CRDS instruments extracted air from the wellmixed chamber volume. On twelve days in June 2007 chamber studies were performed under a wide variety of chemical conditions. The experiments were designed to compare the instruments under variable concentrations of $\mathrm{NO}_{3}, \mathrm{~N}_{2} \mathrm{O}_{5}$, $\mathrm{NO}_{2}$, and water vapour, in the presence of inorganic aerosol injected into the chamber or during complex experiments investigating the oxidation of terpenes with $\mathrm{NO}_{3}$ accompanied by formation of secondary organic aerosol, but also for mixing ratio conditions representative of ambient atmosphere.

Zero air measurements in the clean chamber were used to study the precision of the $\mathrm{NO}_{3}$ detection. The overall precision of the IBBCEAS and the CRDS instruments varied within 0.5 and 2 pptv; that of the CEDOAS and the DOAS instrument was 5 pptv and 9 pptv, respectively. The instrumental "zero" was also very well defined. The maximum deviation was $\pm 0.2 \mathrm{pptv}$ for the IBBCEAS and the CRDS instruments and +3 pptv and +2 pptv for the CEDOAS and the DOAS instrument, respectively. The sensitivity of the cavityassisted techniques was very high and permitted the detection of $\mathrm{NO}_{3}$ radicals with the precision stated above with a time resolution of $1 \mathrm{~s}$ (NOAA-CRDS and UAF-CRDS), $5 \mathrm{~s}$ (UCC-CEAS), $10 \mathrm{~s}$ (MPI-CRDS), $1 \mathrm{~min}$ (ULEIC-BBCRDS and FZJ-DOAS), and 5 min (UHD-CEDOAS).

Overall, in situ instruments (FZJ-DOAS, UCC-IBBCEAS, and UHD-CEDOAS) are in very good agreement with instruments sampling air from the chamber volume. The $\mathrm{NO}_{3}$ data of all instruments are very well linearly correlated with the NOAA-CRDS instrument, which was selected as the common reference to compare the instruments. The median of the coefficient of determination, $r^{2}$, for all experiment days (60 correlations) is $r^{2}=0.981$ (1./3. quartile: 0.949/0.994; $\mathrm{min} / \max : 0.540 / 0.999$, cf. Table 4). The linear regression analysis of the corresponding data set yielded very small intercepts (median: 1.1 pptv; Q1/Q3: -1.1/2.6 pptv; $\min / \max :-14.1 / 22.2 \mathrm{pptv}$ ) and the slopes of the regression lines were close to unity (median: 1.01; Q1/Q3: 0.92/1.10; $\mathrm{min} / \max : 0.72 / 1.36$ ). In any case the deviation of the individual regression slopes from unity was within the combined accuracies of the instrument pairs compared. The variety of $\mathrm{NO}_{3}$ instruments, their exceptionally high precision and accuracy, the large dynamic range of the $\mathrm{NO}_{3}$ measurements, and the comprehensive set of $\mathrm{NO}_{3}$ data acquired under the well controlled homogeneous measurement conditions in the atmosphere simulation chamber allowed the performance of a rigorous statistical data analysis which would not have been possible under less-controlled conditions as, e.g., encountered in field campaigns.

No hint of a cross interference of $\mathrm{NO}_{2}$ was found for the instruments. The effect of non-Lambert-Beer behaviour of water vapour absorption lines on the accuracy of the $\mathrm{NO}_{3}$ detection by broadband CEAS and DOAS was found to be small and well accounted for in the data products supplied by the instrument operators.

The loss of $\mathrm{NO}_{3}$ in the air sampling inlet systems of the instruments which sampled air from the chamber had to be accurately measured. Correction factors under very different chemical conditions were experimentally determined by the participants during NO3Comp and applied for their 
respective data retrieval. The very good correspondence between the time-dependent $\mathrm{NO}_{3}$ mixing ratios measured by all instruments for all aerosol-free experiments indicated that the inlet losses were generally quantified reliably. For experiments with aerosol loading on the inlet systems, however, a marked difference in the loss of $\mathrm{NO}_{3}$ was noted between instruments using no or just a single aerosol filter per day, and the NOAA-CRDS reference instrument in which the filter was replaced regularly. Differences between $\mathrm{NO}_{3}$ data were detectable in experiments with added inorganic aerosol or SOA formed during the experiment. The discrepancies increased with time, pointing to accumulating losses due to high aerosol loadings. No difference was found for losses of $\mathrm{NO}_{3}$ on inorganic or organic aerosol particles. Instruments using DOAS-type analysis showed no significant effect of aerosol on the detection of $\mathrm{NO}_{3}$.

The NO3Comp campaign demonstrated the high quality, reliability, and robustness of performance of current state-ofthe-art instrumentation for $\mathrm{NO}_{3}$ detection. It was shown that the most significant influence on the performance of instruments was generally caused by the presence of aerosol. Consequently instruments deployed to field measurements concerning $\mathrm{NO}_{3}$ (and $\mathrm{N}_{2} \mathrm{O}_{5}$ ) need to filter the sample air from aerosol particles by Teflon filters close to the head of the sampling line.

The filters should be exchanged frequently; however, there is no general recommendation for the maximum filter "age" because the filter "lifetime" may vary with the aerosol composition and the aerosol mass load in ambient air. The inlet and filter losses are specific for each instrument and hence need to be characterised rigorously and individually for the individual instruments under the different operating conditions in the field.

The $\mathrm{NO}_{3}$ transmission efficiency due to losses on the filter, in the inlet system, and inside the cavity have to be precisely determined for each instrument. Generally losses to the walls can be minimized by reduction of the residence time of the sample air in the instrument. Fuchs et al. (2008) used sampling lines with $6.4 \mathrm{~mm}$ i.d. and reduced the pressure to $350 \mathrm{hPa}$ to establish a residence time of $100 \mathrm{~ms}$ between the filter and the centre of the detection cavity. The resulting wall losses of $\mathrm{NO}_{3}$ were $3 \pm 1 \%$. Together with $\mathrm{NO}_{3}$ loss on the filter, an overall $\mathrm{NO}_{3}$ transmission of $92 \pm 2 \%$ was achieved.

Due to the strong temperature dependence of the $\mathrm{N}_{2} \mathrm{O}_{5}$ equilibrium constant (Reaction R5), the difference between the temperature of the ambient air and the (usually higher) temperature inside the $\mathrm{NO}_{3}$ detection cell should be minimised in order to avoid decomposition to $\mathrm{NO}_{3}$ especially when the $\mathrm{N}_{2} \mathrm{O}_{5} / \mathrm{NO}_{3}$ ratio is large.

The informal NO3Comp intercomparison stimulated the exchange of ideas and methodologies for tropospheric $\mathrm{NO}_{3}$ and $\mathrm{N}_{2} \mathrm{O}_{5}$ detection and was very helpful for the further development of these instruments. Their employment on different platforms in the field is ongoing.

\section{Supplementary material related to this article is available online at: http://www.atmos-meas-tech.net/6/ 1111/2013/amt-6-1111-2013-supplement.pdf.}

Acknowledgements. The authors thank Robert Wegener for measurement of butanal concentrations shown in Fig. 3. The NO3Comp campaign was supported by the European-Community-funded Network of Excellence ACCENT - Atmospheric Composition Change: the European Network (Grant GOCE-CT-2004-505337) and the FP-6 programme Support for Research Infrastructures: Integrated Infrastructure Initiative: EUROCHAMP (Grant RII3CT-2004-505968). Authors associated with the University of Alaska Fairbanks were supported by the National Science Foundation (Grants CHE- 0094038 and ATM-0624448), as well as by the United States Department of Energy (Grant DE-FG0203ER83695). The UCC team acknowledges support from the Irish Environmental Protection Agency (Project: TRACES 2005-ETMS-28-M3). The University of Leicester authors acknowledge support from the Natural Environment Research Council via a $\mathrm{PhD}$ studentship for Alex Shillings and a grant (NER/T/S/2002/00036) to develop the BBCRDS instrument.

The service charges for this open access publication have been covered by a Research Centre of the Helmholtz Association.

Edited by: D. Heard

\section{References}

Aldener, M., Brown, S. S., Stark, H., Williams, E. J., Lerner, B. M., Kuster, W. C., Goldan, P. D., Quinn, P. K., Bates, T. S., Fehsenfeld, F. C., and Ravishankara, A. R.: Reactivity and loss mechanisms of $\mathrm{NO}_{3}$ and $\mathrm{N}_{2} \mathrm{O}_{5}$ in a polluted marine environment: results from in situ measurements during New England Air Quality Study 2002, J. Geophys. Res., 111, D23s73, doi:10.1029/2006jd007252, 2006.

Aliwell, S. R. and Jones, R. L.: Measurement of atmospheric $\mathrm{NO}_{3}$. 1. Improved removal of water vapour absorption features in the analysis for $\mathrm{NO}_{3}$, Geophys. Res. Lett., 23, 2585-2588, 1996.

Allan, B. J., McFiggans, G., Plane, J. M. C., Coe, H., and McFadyen, G. G.: The nitrate radical in the remote marine boundary layer, J. Geophys. Res., 105, 24191-24204, 2000.

Ayers, J. D., Apodaca, R. L., Simpson, W. R., and Baer, D. S.: Offaxis cavity ringdown spectroscopy: application to atmospheric nitrate radical detection, Appl. Optics, 44, 7239-7242, 2005.

Ball, S. M. and Jones, R. L.: Broad-band cavity ring-down spectroscopy, Chem. Rev., 103, 5239-5262, 2003.

Ball, S. M. and Jones, A. E.: Broadband cavity ring-down spectroscopy, chap. 3, in: Cavity Ring-Down Spectroscopy: Techniques and Applications, edited by: Berden, G. and Engeln, R., John Wiley \& Sons Ltd, Chichester, UK, 57-88, 2009.

Bitter, M., Ball, S. M., Povey, I. M., and Jones, R. L.: A broadband cavity ringdown spectrometer for in-situ measurements of atmospheric trace gases, Atmos. Chem. Phys., 5, 2547-2560, doi:10.5194/acp-5-2547-2005, 2005.

Bossmeyer, J., Brauers, T., Richter, C., Rohrer, F., Wegener, R., and Wahner, A.: Simulation chamber studies on the $\mathrm{NO}_{3}$ chemistry 
of atmospheric aldehydes, Geophys. Res. Lett., 33, L18810, doi:10.1029/2006g1026778, 2006.

Brauers, T., Bossmeyer, J., Dorn, H.-P., Schlosser, E., Tillmann, R., Wegener, R., and Wahner, A.: Investigation of the formaldehyde differential absorption cross section at high and low spectral resolution in the simulation chamber SAPHIR, Atmos. Chem. Phys., 7, 3579-3586, doi:10.5194/acp-7-3579-2007, 2007.

Brown, S. S.: Absorption spectroscopy in high-finesse cavities for atmospheric studies, Chem. Rev., 103, 5219-5238, doi:10.1021/cr020645c, 2003.

Brown, S. S. and Stutz, J.: Nighttime radical observations and chemistry, Chem. Soc. Rev., 41, 6405-6447, doi:10.1039/c2cs35181a, 2012.

Brown, S. S., Stark, H., Ciciora, S. J., and Ravishankara, A. R.: Insitu measurement of atmospheric $\mathrm{NO}_{3}$ and $\mathrm{N}_{2} \mathrm{O}_{5}$ via cavity ringdown spectroscopy, Geophys. Res. Lett., 28, 3227-3230, 2001.

Brown, S. S., Stark, H., Ciciora, S. J., McLaughlin, R. J., and Ravishankara, A. R.: Simultaneous in situ detection of atmospheric $\mathrm{NO}_{3}$ and $\mathrm{N}_{2} \mathrm{O}_{5}$ via cavity ring-down spectroscopy, Rev. Sci. Instrum., 73, 3291-3301, doi:10.1063/1.1499214, 2002a.

Brown, S. S., Stark, H., and Ravishankara, A. R.: Cavity ringdown spectroscopy for atmospheric trace gas detection: application to the nitrate radical $\left(\mathrm{NO}_{3}\right)$, Appl. Phys. B, 75, 173-182, doi:10.1007/s00340-002-0980-y, 2002b.

Brown, S. S., Stark, H., Ryerson, T. B., Williams, E. J., Nicks, D. K., Trainer, M., Fehsenfeld, F. C., and Ravishankara, A. R.: Nitrogen oxides in the nocturnal boundary layer: Simultaneous in situ measurements of $\mathrm{NO}_{3}, \mathrm{~N}_{2} \mathrm{O}_{5}, \mathrm{NO}_{2}, \mathrm{NO}$, and $\mathrm{O}_{3}$, J. Geophys. Res., 108, 4299, doi:10.1029/2002jd002917, 2003.

Brown, S. S., Dibb, J. E., Stark, H., Aldener, M., Vozella, M., Whitlow, S., Williams, E. J., Lerner, B. M., Jakoubek, R., Middlebrook, A. M., DeGouw, J. A., Warneke, C., Goldan, P. D., Kuster, W. C., Angevine, W. M., Sueper, D. T., Quinn, P. K., Bates, T. S., Meagher, J. F., Fehsenfeld, F. C., and Ravishankara, A. R.: Nighttime removal of $\mathrm{NO}_{\mathrm{x}}$ in the summer marine boundary layer, Geophys. Res. Lett., 31, L07108, doi:10.1029/2004g1019412, 2004.

Brown, S. S., Osthoff, H. D., Stark, H., Dubé, W. P., Ryerson, T. B., Warneke, C., de Gouw, J. A., Wollny, A. G., Parrish, D. D., Fehsenfeld, F. C., and Ravishankara, A. R.: Aircraft observations of daytime $\mathrm{NO}_{3}$ and $\mathrm{N}_{2} \mathrm{O}_{5}$ and their implications for tropospheric chemistry, J. Photoch. Photobio. A, 176, 270-278, doi:10.1016/j.jphotochem.2005.10.004, 2005.

Brown, S. S., Neuman, J. A., Ryerson, T. B., Trainer, M., Dubé, W. P., Holloway, J. S., Warneke, C., de Gouw, J. A., Donnelly, S. G., Atlas, E., Matthew, B., Middlebrook, A. M., Peltier, R., Weber, R. J., Stohl, A., Meagher, J. F., Fehsenfeld, F. C., and Ravishankara, A. R.: Nocturnal odd-oxygen budget and its implications for ozone loss in the lower troposphere, Geophys. Res. Lett., 33, L08801, doi:10.1029/2006GL025900, 2006.

Brown, S. S., Dubé, W. P., Osthoff, H. D., Wolfe, D. E., Angevine, W. M., and Ravishankara, A. R.: High resolution vertical distributions of $\mathrm{NO}_{3}$ and $\mathrm{N}_{2} \mathrm{O}_{5}$ through the nocturnal boundary layer, Atmos. Chem. Phys., 7, 139-149, doi:10.5194/acp-7139-2007, 2007.

Canagaratna, M. R., Jayne, J. T., Jimenez, J. L., Allan, J. D., Alfarra, M. R., Zhang, Q., Onasch, T. B., Drewnick, F., Coe, H., Middlebrook, A., Delia, A., Williams, L. R., Trimborn, A. M., Northway, M. J., DeCarlo, P. F., Kolb, C. E., Davidovits, P., and Worsnop, D. R.: Chemical and microphysical characterization of ambient aerosols with the aerodyne aerosol mass spectrometer, Mass Spectrom. Rev., 26, 185-222, doi:10.1002/Mas.20115, 2007.

Chang, W. L., Bhave, P. V., Brown, S. S., Riemer, N., Stutz, J., and Dabdub, D.: Heterogeneous atmospheric chemistry, ambient measurements, and model calculations of $\mathrm{N}_{2} \mathrm{O}_{5}$ : a review, Aerosol Sci. Tech., 45, 665-695, doi:10.1080/02786826.2010.551672, 2011.

Doussin, J.-F., Dominique, R., and Patrick, C.: Multiple-pass cell for very-long-path infrared spectrometry, Appl. Optics, 38, 4145-4150, doi:10.1364/AO.38.004145, 1999.

Dubé, W. P., Brown, S. S., Osthoff, H. D., Nunley, M. R., Ciciora, S. J., Paris, M. W., McLaughlin, R. J., and Ravishankara, A. R.: Aircraft instrument for simultaneous, in situ measurement of $\mathrm{NO}_{3}$ and $\mathrm{N}_{2} \mathrm{O}_{5}$ via pulsed cavity ring-down spectroscopy, Rev. Sci. Instrum., 77, 034101, doi:10.1063/1.2176058, 2006.

Efron, B. and Tibshirani, R. J.: An Introduction to the Bootstrap, Chapman and Hall, New York, 1993.

Fiedler, S. E., Hese, A., and Ruth, A. A.: Incoherent broad-band cavity-enhanced absorption spectroscopy, Chem. Phys. Lett., 371, 284-294, doi:10.1016/j.cplett.2003.10.075, 2003.

Fiedler, S. E., Hese, A., and Ruth, A. A.: Incoherent broad-band cavity-enhanced absorption spectroscopy of liquids, Rev. Sci. Instrum., 76, 023107, doi:10.1063/1.1841872, 2005.

Fiedler, S. E., Hese, A., and Heitmann, U.: Influence of the cavity parameters on the output intensity in incoherent broadband cavity-enhanced absorption spectroscopy, Rev. Sci. Instrum., 78, 073104, doi:10.1063/1.2752608, 2007

Freedman, D. and Diaconis, P.: On the histogram as a density estimator: $\mathrm{L}_{2}$ theory, Probab. Theory Rel., 57, 453-476, doi:10.1007/bf01025868, 1981.

Fry, J. L., Kiendler-Scharr, A., Rollins, A. W., Wooldridge, P. J., Brown, S. S., Fuchs, H., Dubé, W., Mensah, A., dal Maso, M., Tillmann, R., Dorn, H.-P., Brauers, T., and Cohen, R. C.: Organic nitrate and secondary organic aerosol yield from $\mathrm{NO}_{3}$ oxidation of $\beta$-pinene evaluated using a gas-phase kinetics/aerosol partitioning model, Atmos. Chem. Phys., 9, 14311449, doi:10.5194/acp-9-1431-2009, 2009.

Fry, J. L., Kiendler-Scharr, A., Rollins, A. W., Brauers, T., Brown, S. S., Dorn, H.-P., Dubé, W. P., Fuchs, H., Mensah, A., Rohrer, F., Tillmann, R., Wahner, A., Wooldridge, P. J., and Cohen, R. C.: SOA from limonene: role of $\mathrm{NO}_{3}$ in its generation and degradation, Atmos. Chem. Phys., 11, 3879-3894, doi:10.5194/acp-11-3879-2011, 2011.

Fuchs, H., Dubé, W. P., Ciciora, S. J., and Brown, S. S.: Determination of inlet transmission and conversion efficiencies for in situ measurements of the nocturnal nitrogen oxides, $\mathrm{NO}_{3}, \mathrm{~N}_{2} \mathrm{O}_{5}$ and $\mathrm{NO}_{2}$, via pulsed cavity ring-down spectroscopy, Anal. Chem., 80, 6010-6017, doi:10.1021/ac8007253, 2008.

Fuchs, H., Ball, S. M., Bohn, B., Brauers, T., Cohen, R. C., Dorn, H.-P., Dubé, W. P., Fry, J. L., Häseler, R., Heitmann, U., Jones, R. L., Kleffmann, J., Mentel, T. F., Müsgen, P., Rohrer, F., Rollins, A. W., Ruth, A. A., Kiendler-Scharr, A., Schlosser, E., Shillings, A. J. L., Tillmann, R., Varma, R. M., Venables, D. S., Villena Tapia, G., Wahner, A., Wegener, R., Wooldridge, P. J., and Brown, S. S.: Intercomparison of measurements of $\mathrm{NO}_{2}$ concentrations in the atmosphere simulation chamber SAPHIR during the NO3Comp campaign, Atmos. Meas. Tech., 3, 21-37, doi:10.5194/amt-3-21-2010, 2010a. 
Fuchs, H., Brauers, T., Dorn, H.-P., Harder, H., Häseler, R., Hofzumahaus, A., Holland, F., Kanaya, Y., Kajii, Y., Kubistin, D., Lou, S., Martinez, M., Miyamoto, K., Nishida, S., Rudolf, M., Schlosser, E., Wahner, A., Yoshino, A., and Schurath, U.: Technical Note: Formal blind intercomparison of $\mathrm{HO}_{2}$ measurements in the atmosphere simulation chamber SAPHIR during the HOxComp campaign, Atmos. Chem. Phys., 10, 12233-12250, doi:10.5194/acp-10-12233-2010, 2010 b.

Fuchs, H., Simpson, W. R., Apodaca, R. L., Brauers, T., Cohen, R. C., Crowley, J. N., Dorn, H.-P., Dubé, W. P., Fry, J. L., Häseler, R., Kajii, Y., Kiendler-Scharr, A., Labazan, I., Matsumoto, J., Mentel, T. F., Nakashima, Y., Rohrer, F., Rollins, A. W., Schuster, G., Tillmann, R., Wahner, A., Wooldridge, P. J., and Brown, S. S.: Comparison of $\mathrm{N}_{2} \mathrm{O}_{5}$ mixing ratios during NO3Comp 2007 in SAPHIR, Atmos. Meas. Tech., 5, 2763-2777, doi:10.5194/amt-5-2763-2012, 2012.

Geyer, A., Alicke, B., Mihelcic, D., Stutz, J., and Platt, U.: Comparison of tropospheric $\mathrm{NO}_{3}$ radical measurements by differential optical absorption spectroscopy and matrix isolation electron spin resonance, J. Geophys. Res., 104, 26097-26105, 1999.

Geyer, A., Ackermann, R., Dubois, R., Lohrmann, B., Muller, T., and Platt, U.: Long-term observation of nitrate radicals in the continental boundary layer near Berlin, Atmos. Environ., 35, 3619-3631, doi:10.1016/S1352-2310(00)00549-5, 2001.

Geyer, A., Alicke, B., Ackermann, R., Martinez, M., Harder, H., Brune, W., di Carlo, P., Williams, E., Jobson, T., Hall, S., Shetter, R., and Stutz, J.: Direct observations of daytime $\mathrm{NO}_{3}$ : implications for urban boundary layer chemistry, J. Geophys. Res., 108, 4368, doi:10.1029/2002jd002967, 2003.

Gherman, T., Venables, D. S., Vaughan, S., Orphal, J., and Ruth, A. A.: Incoherent broadband cavity-enhanced absorption spectroscopy in the near-ultraviolet: application to $\mathrm{HONO}$ and $\mathrm{NO}_{2}$, Environ. Sci. Technol., 42, 890-895, doi:10.1021/es0716913, 2008.

Hausmann, M., Brandenburger, U., Brauers, T., and Dorn, H.-P.: Simple Monte Carlo methods to estimate the spectra evaluation error in differential-optical-absorption spectroscopy, Appl. Optics, 38, 462-475, doi:10.1364/AO.38.000462, 1999.

Kasyutich, V. L., Canosa-Mas, C. E., Pfrang, C., Vaughan, S., and Wayne, R. P.: Off-axis continuous-wave cavity-enhanced absorption spectroscopy of narrow-band and broadband absorbers using red diode lasers, Appl. Phys. B, 75, 755-761, 2002.

King, M. D., Dick, E. M., and Simpson, W. R.: A new method for the atmospheric detection of the nitrate radical $\left(\mathrm{NO}_{3}\right)$, Atmos. Environ., 34, 685-688, doi:10.1016/S1352-2310(99)00418-5, 2000.

Kraus, S. G.: DOASIS, A Framework Design for DOAS, Dissertation, Institut of Physics, University of Mannheim, Germany, 2006.

Langridge, J. M., Ball, S. M., Shillings, A. J. L., and Jones, R. L.: A broadband absorption spectrometer using light emitting diodes for ultrasensitive, in situ trace gas detection, Rev. Sci. Instrum., 79, 123110, doi:10.1063/1.3046282, 2008a.

Lindinger, W., Hansel, A., and Jordan, A.: On-line monitoring of volatile organic compounds at pptv levels by means of protontransfer-reaction mass spectrometry (PTR-MS) - medical applications, food control and environmental research, Int. J. Mass Spectrom., 173, 191-241, doi:10.1016/S0168-1176(97)00281-4, 1998.
Matsumoto, J., Kosugi, N., Imai, H., and Kajii, Y.: Development of a measurement system for nitrate radical and dinitrogen pentoxide using a thermal conversion/laser-induced fluorescence technique, Rev. Sci. Instrum., 76, 064101, doi:10.1063/1.1927098, 2005.

McLaren, R., Salmon, R. A., Liggio, J., Hayden, K. L., Anlauf, K. G., and Leaitch, W. R.: Nighttime chemistry at a rural site in the Lower Fraser Valley, Atmos. Environ., 38, 5837-5848, doi:10.1016/j.atmosenv.2004.03.074, 2004.

Meinen, J., Thieser, J., Platt, U., and Leisner, T.: Technical Note: Using a high finesse optical resonator to provide a long light path for differential optical absorption spectroscopy: CE-DOAS, Atmos. Chem. Phys., 10, 3901-3914, doi:10.5194/acp-10-39012010, 2010.

Mihelcic, D., Klemp, D., Musgen, P., Patz, H. W., and Volzthomas, A.: Simultaneous measurements of peroxy and nitrate radicals at Schauinsland, J. Atmos. Chem., 16, 313-335, doi:10.1007/BF01032628, 1993.

NIST/SEMATECH: e-Handbook of Statistical Methods, available at: http://www.itl.nist.gov/div898/handbook/, last access: 30 December, 2012.

Orphal, J., Fellows, C. E., and Flaud, P. M.: The visible absorption spectrum of $\mathrm{NO}_{3}$ measured by high-resolution Fourier transform spectroscopy, J. Geophys. Res., 108, D002489, doi:10.1029/2002JD002489, 2003.

Osthoff, H. D., Brown, S. S., Ryerson, T. B., Fortin, T. J., Lerner, B. M., Williams, E. J., Pettersson, A., Baynard, T., Dubé, W. P., Ciciora, S. J., and Ravishankara, A. R.: Measurement of atmospheric $\mathrm{NO}_{2}$ by pulsed cavity ring-down spectroscopy, J. Geophys. Res., 111, D12305, doi:10.1029/2005jd006942, 2006.

Osthoff, H. D., Pilling, M. J., Ravishankara, A. R., and Brown, S. S.: Temperature dependence of the $\mathrm{NO}_{3}$ absorption crosssection above $298 \mathrm{~K}$ and determination of the equilibrium constant for $\mathrm{NO}_{3}+\mathrm{NO}_{2} \leftrightarrow \mathrm{N}_{2} \mathrm{O}_{5}$ at atmospherically relevant conditions, Phys. Chem. Chem. Phys., 9, 5785-5793, doi:10.1039/B709193a, 2007.

Paul, J. B., Lapson, L., and Anderson, J. G.: Ultrasensitive absorption spectroscopy with a high-finesse optical cavity and off-axis alignment, Appl. Optics, 40, 4904-4910, 2001.

Platt, U. and Perner, D.: Direct measurements of atmospheric $\mathrm{CH}_{2} \mathrm{O}, \mathrm{HNO}_{2}, \mathrm{O}_{3}, \mathrm{NO}_{2}$, and $\mathrm{SO}_{2}$ by differential optical absorption in the near UV, J. Geophys. Res., 85, 7453-7458, 1980.

Platt, U. and Stutz, J.: Differential Optical Absorption Spectroscopy - Principles and Applications, Physics of Earth and Space Environments, Springer Verlag, Berlin, Heidelberg, 2008.

Platt, U., Perner, D., Winer, A. M., Harris, G. W., and Pitts, J. N.: Detection of $\mathrm{NO}_{3}$ in the polluted troposphere by differential optical-absorption, Geophys. Res. Lett., 7, 89-92, 1980.

Platt, U., Perner, D., Schroder, J., Kessler, C., and Toennissen, A.: The diurnal-variation of $\mathrm{NO}_{3}$, J. Geophys. Res., 86, 1965-1970, 1981.

Platt, U., Meinen, J., Pöhler, D., and Leisner, T.: Broadband Cavity Enhanced Differential Optical Absorption Spectroscopy (CEDOAS) - applicability and corrections, Atmos. Meas. Tech., 2, 713-723, doi:10.5194/amt-2-713-2009, 2009.

Press, W. H., Teukolsky, S. A., Vetterling, W. T., and Flannery, B. P.: Numerical recipies in C. The Art of Scientific Computing, 2nd Edn., Cambridge University Press, Cambridge, UK, 1992. 
Rohrer, F., Bohn, B., Brauers, T., Brüning, D., Johnen, F.-J., Wahner, A., and Kleffmann, J.: Characterisation of the photolytic HONO-source in the atmosphere simulation chamber SAPHIR, Atmos. Chem. Phys., 5, 2189-2201, doi:10.5194/acp-5-21892005, 2005.

Rollins, A. W., Kiendler-Scharr, A., Fry, J. L., Brauers, T., Brown, S. S., Dorn, H.-P., Dubé, W. P., Fuchs, H., Mensah, A., Mentel, T. F., Rohrer, F., Tillmann, R., Wegener, R., Wooldridge, P. J., and Cohen, R. C.: Isoprene oxidation by nitrate radical: alkyl nitrate and secondary organic aerosol yields, Atmos. Chem. Phys., 9, 6685-6703, doi:10.5194/acp-9-6685-2009, 2009.

Sander, S. P., Abbat, J., Barker, R., Burkholder, J. B., Friedl, R. R., Golden, D. M., Huie, R. E., Kolb, C. E., Kurylo, M. J., Moortgat, G. K., Orkin, V. L., and Wine, P.: Chemical Kinetics and Photochemical Data for Use in Atmospheric Studies, Evaluation Number 17, JPL Publication 10-6, Jet Propulsion Laboratory, Pasadena, 2011.

Schlosser, E., Bohn, B., Brauers, T., Dorn, H.-P., Fuchs, H., Häseler, R., Hofzumahaus, A., Holland, F., Rohrer, F., Rupp, L., Siese, M., Tillmann, R., and Wahner, A.: Intercomparison of two hydroxyl radical measurement techniques at the Atmosphere Simulation Chamber SAPHIR, J. Atmos. Chem., 56, 187-205, doi:10.1007/s10874-006-9049-3, 2007.

Schlosser, E., Brauers, T., Dorn, H.-P., Fuchs, H., Häseler, R., Hofzumahaus, A., Holland, F., Wahner, A., Kanaya, Y., Kajii, Y., Miyamoto, K., Nishida, S., Watanabe, K., Yoshino, A., Kubistin, D., Martinez, M., Rudolf, M., Harder, H., Berresheim, H., Elste, T., Plass-Dülmer, C., Stange, G., and Schurath, U.: Technical Note: Formal blind intercomparison of $\mathrm{OH}$ measurements: results from the international campaign HOxComp, Atmos. Chem. Phys., 9, 7923-7948, doi:10.5194/acp-9-7923-2009, 2009.

Schuster, G., Labazan, I., and Crowley, J. N.: A cavity ring down/cavity enhanced absorption device for measurement of ambient $\mathrm{NO}_{3}$ and $\mathrm{N}_{2} \mathrm{O}_{5}$, Atmos. Meas. Tech., 2, 1-13, doi:10.5194/amt-2-1-2009, 2009.

Shillings, A. J. L., Ball, S. M., Barber, M. J., Tennyson, J., and Jones, R. L.: An upper limit for water dimer absorption in the $750 \mathrm{~nm}$ spectral region and a revised water line list, Atmos. Chem. Phys., 11, 4273-4287, doi:10.5194/acp-11-4273-2011, 2011.

Simpson, W. R.: Continuous wave cavity ring-down spectroscopy applied to in situ detection of dinitrogen pentoxide $\left(\mathrm{N}_{2} \mathrm{O}_{5}\right)$, Rev. Sci. Instrum., 74, 3442-3452, 2003.

Sommariva, R., Pilling, M. J., Bloss, W. J., Heard, D. E., Lee, J. D., Fleming, Z. L., Monks, P. S., Plane, J. M. C., Saiz-Lopez, A., Ball, S. M., Bitter, M., Jones, R. L., Brough, N., Penkett, S. A., Hopkins, J. R., Lewis, A. C., and Read, K. A.: Night-time radical chemistry during the NAMBLEX campaign, Atmos. Chem. Phys., 7, 587-598, doi:10.5194/acp-7-587-2007, 2007.

Stutz, J., Alicke, B., Ackermann, R., Geyer, A., White, A., and Williams, E.: Vertical profiles of $\mathrm{NO}_{3}, \mathrm{~N}_{2} \mathrm{O}_{5}, \mathrm{O}_{3}$, and $\mathrm{NO}_{\mathrm{x}}$ in the nocturnal boundary layer: 1 . Observations during the Texas Air Quality Study 2000, J. Geophys. Res., 109, D12306, doi:10.1029/2003jd004209, 2004.

Tang, M. J., Thieser, J., Schuster, G., and Crowley, J. N.: Uptake of $\mathrm{NO}_{3}$ and $\mathrm{N}_{2} \mathrm{O}_{5}$ to Saharan dust, ambient urban aerosol and soot: a relative rate study, Atmos. Chem. Phys., 10, 2965-2974, doi:10.5194/acp-10-2965-2010, 2010.
Triki, M., Cermak, P., Mejean, G., and Romanini, D.: Cavityenhanced absorption spectroscopy with a red LED source for $\mathrm{NO}_{\mathrm{x}}$ trace analysis, Appl. Phys. B, 91, 195-201, doi:10.1007/s00340-008-2958-x, 2008.

Troutman, B. M. and Williams, G. P.: Fitting Straight Lines in the Earth Sciences, Vol. 1, in: Use and Abuse of Statistical Methods in Earth Sciences, edited by: Size, W. B., Oxford University Press, Oxford, 107-128, 1987.

Varma, R. M., Venables, D. S., Ruth, A. A., Heitmann, U., Schlosser, E., and Dixneuf, S.: Long optical cavities for openpath monitoring of atmospheric trace gases and aerosol extinction, Appl. Optics, 48, B159-B171, doi:10.1364/AO.48.00B159, 2009.

Varma, R. M., Ball, S. M., Brauers, T., Dorn, H.-P., Heitmann, U., Jones, R. L., Meinen, J., Platt, U., Pöhler, D., Ruth, A. A., Shillings, J. E., Thieser, J., Wahner, A., and Venables, D. S.: Secondary organic aerosol extinction: an intercomparison of three broadband optical cavity spectrometers, Atmos. Meas. Tech., in preparation, 2013.

Venables, D. S., Gherman, T., Orphal, J., Wenger, J. C., and Ruth, A. A.: High sensitivity in situ monitoring of $\mathrm{NO}_{3}$ in an atmospheric simulation chamber using incoherent broadband cavityenhanced absorption spectroscopy, Environ. Sci. Technol., 40, 6758-6763, doi:10.1021/Es061076j, 2006.

Vrekoussis, M., Kanakidou, M., Mihalopoulos, N., Crutzen, P. J., Lelieveld, J., Perner, D., Berresheim, H., and Baboukas, E.: Role of the $\mathrm{NO}_{3}$ radicals in oxidation processes in the eastern Mediterranean troposphere during the MINOS campaign, Atmos. Chem. Phys., 4, 169-182, doi:10.5194/acp-4-169-2004, 2004.

Vrekoussis, M., Mihalopoulos, N., Gerasopoulos, E., Kanakidou, M., Crutzen, P. J., and Lelieveld, J.: Two-years of $\mathrm{NO}_{3}$ radical observations in the boundary layer over the Eastern Mediterranean, Atmos. Chem. Phys., 7, 315-327, doi:10.5194/acp-7315-2007, 2007.

Wängberg, I., Barnes, I., and Becker, K. H.: Product and mechanistic study of the reaction of $\mathrm{NO}_{3}$ radicals with alpha-pinene, Environ. Sci. Technol., 31, 2130-2135, 1997.

Wayne, R. P., Barnes, I., Biggs, P., Burrows, J. P., Canosamas, C. E., Hjorth, J., Lebras, G., Moortgat, G. K., Perner, D., Poulet, G., Restelli, G., and Sidebottom, H.: The nitrate radical - physics, chemistry, and the atmosphere, Atmos. Environ., 25, 1-203, 1991.

Wegener, R., Brauers, T., Koppmann, R., Rodriguez Bares, S., Rohrer, F., Tillmann, R., Wahner, A., Hansel, A., and Wisthaler, A.: Simulation chamber investigation of the reactions of ozone with short-chained alkenes, J. Geophys. Res., 112, 1-17, doi:10.1029/2006JD007531, 2007.

Wood, E. C., Wooldridge, P. J., Freese, J. H., Albrecht, T., and Cohen, R. C.: Prototype for in situ detection of atmospheric $\mathrm{NO}_{3}$ and $\mathrm{N}_{2} \mathrm{O}_{5}$ via laser-induced fluorescence, Environ. Sci. Technol., 37, 5732-5738, doi:10.1021/es034507w, 2003.

Yokelson, R. J., Burkholder, J. B., Fox, R. W., Talukdar, R. K., and Ravishankara, A. R.: Temperature-dependence of the $\mathrm{NO}_{3}$ absorption-spectrum, J. Phys. Chem., 98, 13144-13150, doi:10.1021/j100101a009, 1994. 